\title{
Synthesis of $\beta$-Peptides for the \\ Organization as Helix Bundles in Lipid Membranes
}

\section{Dissertation}

\author{
for the award of the degree \\ "Doctor rerum naturalium“ (Dr.rer.nat.) \\ of the Georg-August-Universität Göttingen \\ within the doctoral program chemistry \\ of the Georg-August-University School of Science (GAUSS)
}

\author{
submitted by \\ Martin Kloos \\ from Einbeck, Germany
}

Göttingen, 2021 



\section{Thesis Committee}

Prof. Dr. Ulf Diederichsen

Prof. Dr. Claudia Steinem
Institute of Organic and Biomolecular Chemistry, Georg-August Universität Göttingen Institute of Organic and Biomolecular Chemistry, Georg-August Universität Göttingen

\section{Members of the Examination Board}

Reviewer:

Prof. Dr. Claudia Steinem Institute of Organic and Biomolecular Chemistry, Georg-August Universität Göttingen

Second Reviewer:

Prof. Dr. Kai Tittmann

Dept. of Molecular Enzymology, Georg-August Universität Göttingen

\section{Further Members of the Examination Board}

Prof. Dr. Ulf Diederichsen

Prof. Dr. Jörg Enderlein

Dr. Michael John

Dr. Holm Frauendorf
Institute of Organic and Biomolecular Chemistry, Georg-August Universität Göttingen

III. Physical Institute,

Georg-August Universität Göttingen

Institute of Organic and Biomolecular Chemistry, Georg-August Universität Göttingen Institute of Organic and Biomolecular Chemistry, Georg-August Universität Göttingen 
The work which is presented in this thesis was carried out under the guidance of Prof. Dr. Ulf Diederichsen at the Institute of Organic and Biomolecular Chemistry of the GeorgAugust-University Göttingen between November 2017 and August 2021.

This work was supported by the collaborative research center 803 (SFB 803, Functionality controlled by organization in and between membranes) from the Deutsche Forschungsgemeinschaft. 


\section{Publications}

Parts of this thesis have been published in scientific journals:

M. Kloos, A. Sharma, J. Enderlein, U. Diederichsen, J. Pept. Sci. 2021, e3355,

DOI: 10.1002/psc.3355.

\section{Declaration of Authorship}

Hereby, I declare that this doctoral thesis with the title "Synthesis of $\beta$-Peptides for the Organization as Helix Bundles in Lipid Membranes" is written all by myself with no other sources and aids than the mentioned.

Göttingen, August 23, 2021

Martin Kloos 





\section{Contents}

1 Introduction ....................................................................................................... 1

2 Fundamentals of $\beta$-Amino Acids and $\beta$-Peptides ......................................................... 5

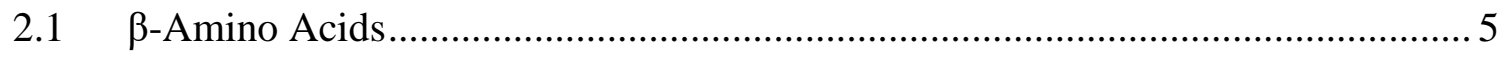

$2.2 \quad$ -

2.3 Artificial Transmembrane $\beta$-Peptides ………………………………………..... 11

3 Synthesis of Transmembrane $\beta$-Peptides for the Organization in Lipid

Bilayers ............................................................................................................................................. 13

3.1 Self-Assembly of Cyanuric Acid and Melamine ………........................................ 13

3.2 Design and Synthesis of Transmembrane $\beta$-Peptides ........................................... 18

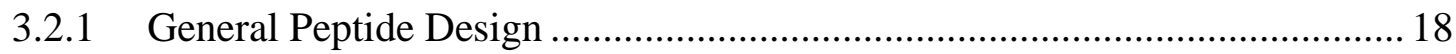

3.2.2 Synthesis of Artificial $\beta^{3}$-D-Amino Acids ..................................................... 21

3.2.3 Synthesis and Labeling of Artificial $\beta$-Peptides ............................................. 24

3.3 Proton Translocation by Membrane-Incorporated Transmembrane $\beta$-Peptides... 29

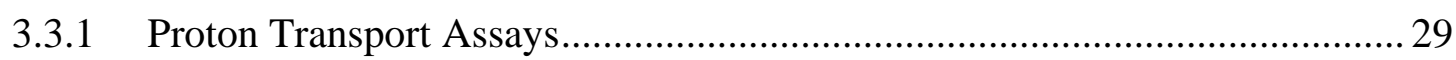

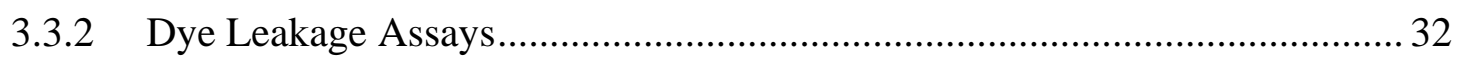

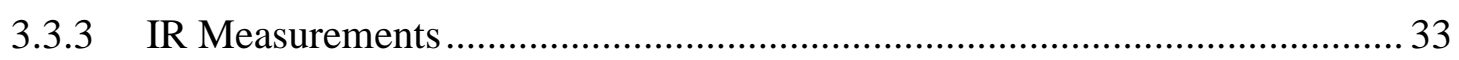

3.4 FRET-based Aggregation Studies of Transmembrane $\beta$-Peptides ........................ 34

3.5 Conductance of Lipid Bilayers with Incorporated Transmembrane $\beta$-Peptides... 37

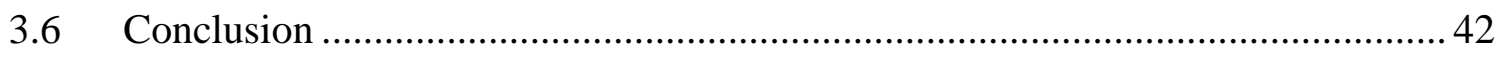




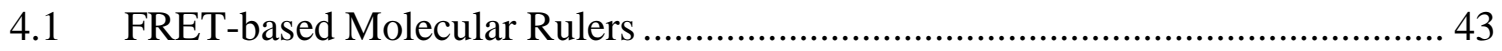

4.2 Graphene-based Metal-Induced Energy Transfer............................................. 46

4.3 Design and Synthesis of Atto643-labeled Transmembrane $\beta$-Peptides................ 49

4.4 grapheneMIET Measurements of Atto643-labeled Transmembrane $\beta$-Peptides.. 53

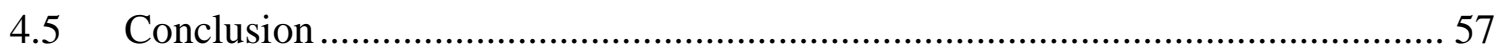

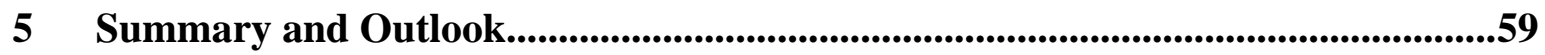

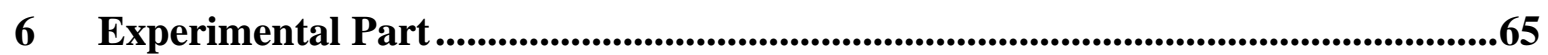

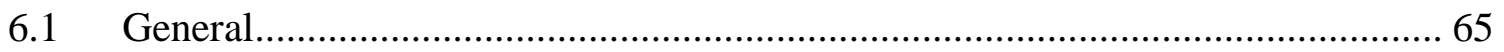

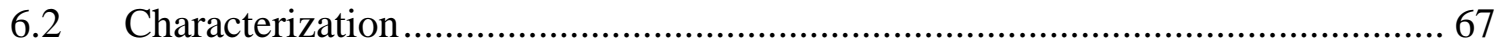

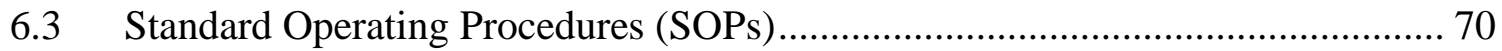

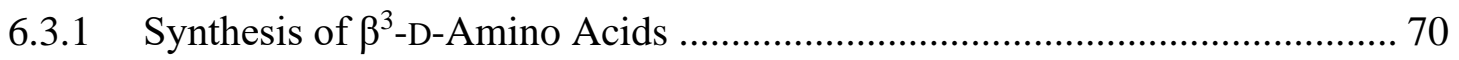

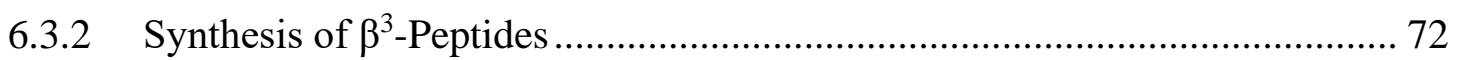

6.3.3 Preparation of Large Unilamellar Vesicles (LUVs) .................................... 75

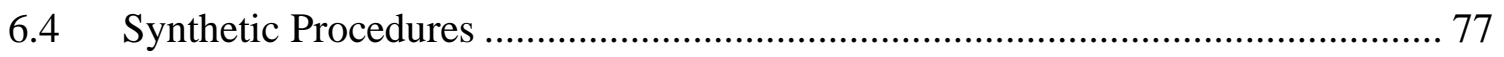

6.4.1 Synthesis of Cyanuric Acid and Melamine modified $\beta^{3}$-Amino Acids ......... 77

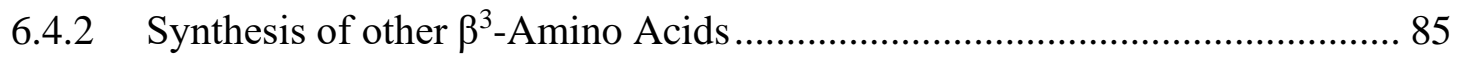

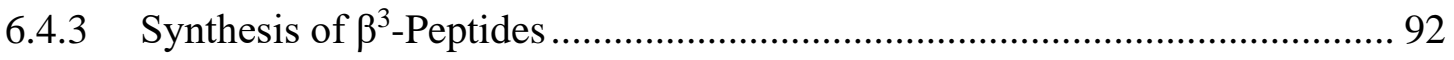

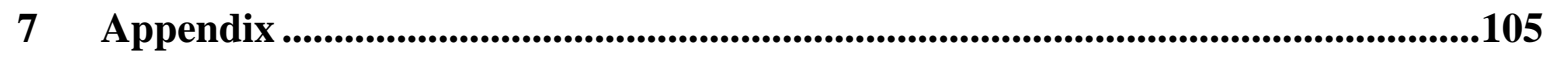

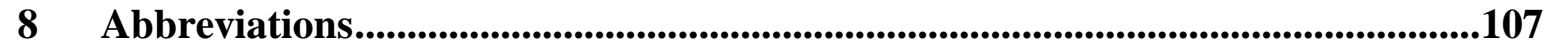

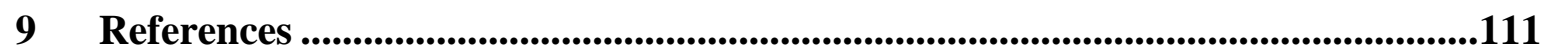

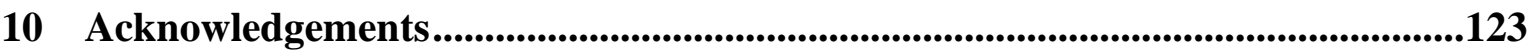




\section{Introduction}

Membrane proteins are omnipresent in biological systems, being estimated to make up 20-30\% of genome encoded proteins. ${ }^{[1]}$ Functions of those immensely important macromolecules range from ion transport over signal transduction to catalysis and many more. ${ }^{[2,3]}$ One particularly relevant species of those structures are transmembrane proteins, spanning through lipid bilayers and thus anchoring the proteins in the membrane environment. Research in this interesting field of protein chemistry has especially generated great relevance since the current pandemic with the SARS-CoV-2 genome also encoding transmembrane proteins which are linked to the process of infection. ${ }^{[4]}$ Another prominent example in the field of transmembrane proteins is bacteriorhodopsin, which consists of seven $\alpha$-helical transmembrane units, being able to transport protons across lipid membranes. ${ }^{[5]}$ In general, analysis of such proteins proved to be challenging since their acquisition can be limited by low expression rates or complex, multi-step synthetic routes. ${ }^{[6]}$ Therefore, the need for simplified model systems arises in order to gain more accessible insights in those biological processes.

A great and commonly used class of peptidomimetics are $\beta$-peptides, consisting of $\beta$-amino acids. Due to their additional methylene unit in the amino acid backbone, $\beta$-peptide helices are much more versatile compared to their $\alpha$-analogues while still forming similar helices like the 12 - or the 14-helix. ${ }^{[7]}$ Furthermore, the peptides are immune to natural proteolysis and form substantially more stable helices. Generating well-known and characterized helices with a minimal amount of six amino acids in aqueous media, $\beta$-peptides are perfectly suitable for the use as model systems to mimic natural $\alpha$-peptides. ${ }^{[8]}$

In the DIEDERICHSEN group, preliminary studies dealt with secondary structure regulation of transmembrane $\beta$-peptides by substitution of single amino acids with cyclic amino acids. ${ }^{[9]}$ In addition, transmembrane 14-helices were characterized in lipid bilayers and aggregation 
studies were performed with incorporated glutamine moieties. ${ }^{[10,11]}$ Thereby, a transmembrane model system was established which is suitable for further aggregation studies in lipid membranes. $^{[12]}$

Other studies on deca- $\beta^{3}$-peptides with incorporated cyanuric acid (CA) and melamine (M) building blocks lead to the self-assembly of helix bundles in the aqueous phase, consisting of six peptides according to the CA.M lattice. ${ }^{[13]}$ Well-studied CA·M interactions were utilized to create supramolecular rosette structures, bearing a cavity of $4 \AA$ in the middle of this hexagon. Multiple layers of pure $\mathrm{CA} \cdot \mathrm{M}$ aggregates were also shown to create channels by self-assembly. ${ }^{[14]}$

In the first part of this work, $\mathrm{CA} \cdot \mathrm{M}$ building blocks were synthesized and incorporated into an elongated transmembrane model system. The peptides were designed in a way that the aggregation takes place in the outer-membrane environment, similar to previous studies on molecular recognition by nucleobase pairing. ${ }^{[15]}$ Potential aggregation and channel formation by these peptides and the transmembrane model system itself were examined with various assays. FÖRSTER resonance energy transfer (FRET) efficiency measurements of the pure transmembrane domain, similar to STOLLBERG (née ROST), were performed by the introduction of two fluorophores. Proton transport assays to determine the channel function of peptides were performed by D. RUPPELT from the STEINEM group. Furthermore, membrane conductivity measurements with incorporated peptides were executed in collaboration with A. MAZNICHENKO from the POHL group.

The second part of this thesis deals with the development of a novel transmembrane $\beta$-peptide molecular ruler. In general, molecular rulers reveal inter- and intramolecular distances on the nanometer or even ångström scale. For example, this can be determined by X-ray studies, spectroscopical methods like nuclear magnetic resonance (NMR) and electron paramagnetic resonance (EPR) or by fluorescence techniques. ${ }^{[16-19]}$

Especially, the near-membrane environment is an important location to study since present ion concentrations are linked to vital processes like membrane fusion. ${ }^{[20]} \beta$-Peptidic transmembrane 14-helices promote themselves for the application as molecular rulers due to their intrinsic stability and rigidity. Literature-known and well-characterized dimensions of these helices lead to the possibility of defined spatial positioning of probes at the peptide side chain in different distances in regard to the membrane.

Here, two transmembrane $\beta$-peptides were synthesized as a proof of concept for the use as molecular rulers. Differing in length, both peptides were $N$-terminally labeled with Atto643 
and incorporated into lipid bilayers. Graphene-based metal-induced energy transfer (grapheneMIET) measurements were performed by A. SHARMA from the ENDERLEIN group, calculating the axial heights of the fluorophores with respect to the substrate surface. This technique enables determination of ångström distances, utilizing the energy transfer from the Atto643 dye to a single sheet of graphene. The use of these transmembrane peptides enables a novel approach to molecular rulers, being synthetically available with medium effort and being easily modifiable with probes like proton, calcium or other ion sensors. With this, ion concentrations can be determined in dependency on the distance to the lipid membrane. 



\section{Fundamentals of $\beta$-Amino Acids and $\beta$-Peptides}

Since both topics of this work are dealing with the synthesis and application of $\beta^{3}$-peptides, the following chapter will give a general overview of the concept of $\beta^{3}$-D-amino acids and especially their properties when it comes to the formation of peptides. In addition, preliminary work on the aggregation and orientation of those peptides is presented in the context of incorporation into lipid membranes as well as temperature dependent aggregation studies.

\section{$2.1 \beta$-Amino Acids}

The interest in understanding biological processes into detail has substantially risen over the last century, peaking even more since the current pandemic crisis. ${ }^{[21,22]}$ In order to obtain full insight into specific functions of proteins or biological systems in general, large protein complexes, inter- and intramolecular interactions, differing membrane compositions, surroundings and a lot more variables have to be considered and evaluated. The problem that one is facing while dealing with these systems is that they are too complex to be understood in detail without breaking down the system in much simpler parts. ${ }^{[23]}$ In addition, when working with proteins or peptides, the expression of those is often not easy and synthetic approaches are limited to the number of amino acids in the sequence. ${ }^{[24]}$ Therefore, artificial model systems come in handy, which are simplifying biological processes and making them more accessible to be understood step by step. ${ }^{[25]}$ 
One of the more prominent as well as already widely examined model systems are $\beta$-peptides, consisting of $\beta$-amino acids and similarly to $\alpha$-peptides, they are capable of forming a variety of helices and other secondary structures. ${ }^{[26-31]}$ Promising properties are being less prone to proteolysis and forming stable secondary structures with only six amino acids with modulatable helices depending on the sequence..$^{[9,32-34]}$

$\beta$-Amino acids differ from their $\alpha$-analogues in an additional methylene unit in the backbone which is located between the carboxylic and the amino function of the respective amino acid (Figure 1). ${ }^{[35]}$ Depending on the location of the residue, different isomers are possible, ranging from monosubstituted $\beta^{2}$ - and $\beta^{3}$-amino acids to disubstituted $\beta^{2,2}-, \beta^{2,3}$ - or $\beta^{3,3}$-amino acids.<smiles>[R]C(N)C(=O)O</smiles>

$\alpha$-amino acid<smiles>[R]C(CN)C(=O)O</smiles>

$\beta^{2}$-amino acid<smiles>[R]C(N)CC(=O)O</smiles>

$\beta^{3}$-amino acid<smiles>[R]C(N)C([R])C(=O)O</smiles>

$\beta^{2,3}$-amino acid

Figure 1: General structure of $\beta$-amino acids compared to an $\alpha$-analogue. Starting to count at the carboxylic carbon atom, $\beta^{2}$-amino acids are substituted at position $\mathrm{C}$-2, whereas $\beta^{3}$-amino acids are substituted at position C-3. Disubstitution of amino acids leads for example to $\beta^{2,3}$-amino acids.

$\beta$-Amino acids are rarely found in nature. However, they were extracted from several prokaryotic and eukaryotic species. For example, $\beta^{3}$-lysine can only be found in some bacteria, whereas $\beta^{3}$-phenylalanine is present in bacteria as well as in certain plants and fungi. ${ }^{[36]}$ On the other hand, derivatives of $\beta$-alanine can be found in pantothenic acid (vitamin $B_{5}$ ). ${ }^{[37]}$ Synthetically, $\beta^{3}$-amino acids, which are used in this work, are accessible via the ARNDTEISTERT-homologation (Scheme 1). ${ }^{[38,39]}$

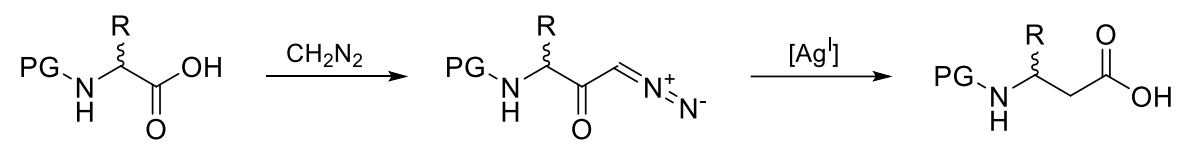

Scheme 1: Schematic synthesis of a $\beta^{3}$-amino acid with the ARNDT-EISTERT-homologation. The N-protected (PG) $\alpha$-analogue is converted into a diazo ketone with the use of diazomethane, followed by a silver(I) catalyzed WOLFF-rearrangement. 
Thereby, the respective $N$-protected $\alpha$-analogue is treated with diazomethane in order to convert it into a diazo ketone. In a WOLFF-rearrangement, the diazo ketone is then further modified, resulting in the final $\beta^{3}$-amino acid. ${ }^{[40]}$ Following this general procedure, $\beta^{3}$-amino acids can be synthesized based on their commercially available $\alpha$-analogues with relatively low effort and sufficient yields. However, it has to be mentioned that there is also a variety of other synthetic procedures to obtain these kind of amino acids. ${ }^{[37,41-43]}$ In contrast, $\beta^{2}$ amino acids are significantly more challenging to obtain due to the new stereogenic center, which has to be generated. Former strategies focused on auxiliary-based syntheses, followed by just recent developments in the synthesis of polar side chain containing $\beta^{2}$-amino acids via a collective synthesis. ${ }^{[44,45]}$

\section{$2.2 \beta$-Peptides}

Due to the backbone elongation in $\beta$-amino acids and thus the additional $C$ - $C$ bond, new rotation possibilities arise. Thereby, torsional angles $\omega, \varphi, \theta$ and $\psi$ (Figure 2) can be defined according to BALARAM and used to predict and modulate secondary structure formation. ${ }^{[27,46]}$

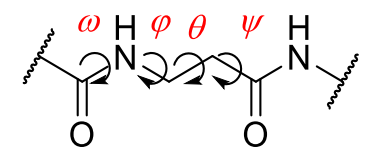

Figure 2: Notation of the rotational angles according to BALARAM. ${ }^{[27,46]}$

Counterintuitively, it was shown that the higher amount of freely rotatable bonds in $\beta$-amino acids leads to more stable and more rigid peptide helices compared to their $\alpha$-analogues, already forming helices with six amino acids instead of 15-20 in the aqueous phase. ${ }^{[30,31,33]}$ Regarding the angle $\theta$ which describes the rotation between $C-2$ and $C-3$, there is evidence that a trans conformation favors sheet-like structures (Figure 3). ${ }^{[47,48]}$ Also, CHENG et al. stated that a gauche conformation is required to form helical structures. ${ }^{[27]}$ Different substitutions of the $\beta$-amino acids lead to different secondary structures which was already well examined experimentally as well as theoretically. ${ }^{[49-53]}$ When positions $C-2$ or $C-3$ are substituted with hydrophobic residues, a gauche conformation is favored, even more with both 
positions being substituted. ${ }^{[54]}$ Furthermore, cyclic amino acids like trans-2-aminocyclohexanecarboxylic acid (ACHC) or trans-2-aminocyclopentanecarboxylic acid (ACPC) enforce a gauche conformation due to their geometric constraints. ${ }^{[55-57]}$

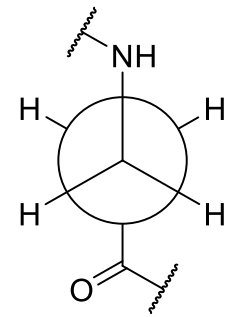

trans

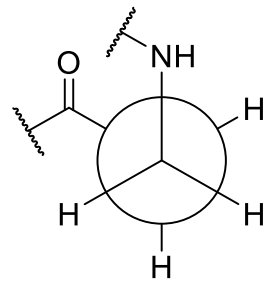

gauche

Figure 3: The NEWMAN projection of $\beta$-alanine shows two possible rotamers for the rotation between $C$ - 2 and $C-3$. Gauche conformations support helix formation, whereas trans conformation enforces sheet-like structures. ${ }^{[27]}$

One of the most prominent secondary structure elements of the $\beta$-peptides is the so-called 14-helix (Figure 4). In these helices, hydrogen bonds are formed between amide protons at position $i$ and carbonyl oxygen atoms at position $i+2$. Counting all atoms among this intramolecular interaction, a 14-membered ring can be described, leading to the notation of a 14helix. Across the field of $\beta$-peptide literature, nomenclature is not always consistent, therefore a variety of notations for the helices can be found. For example, $\mathrm{L}_{+2}, 2 \mathrm{~L}, 14$-helix, 3 1- $^{-}$ helix and 314 -helix all describe the same secondary structure. ${ }^{[33,58]}$<smiles>CCCC(CC)(CC)NC(=O)NC(C)C</smiles>

8-helix<smiles>CC(C)NCCC(=O)NCC1CC2CCC(C1)O2</smiles>

10-helix<smiles>CCC1(CC(=O)NCCC(=O)NC(C)C)CCOC1</smiles>

12-helix

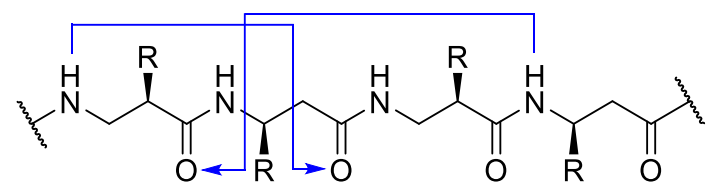

10/12 helix<smiles>CC(C)NCCC(=O)NCCC(=O)NCCCNC(=O)C(C)C</smiles>

14-helix

Figure 4: Selection of $\beta$-peptide helices and their nomenclature. The respective number indicates the amount of atoms in between hydrogen bonds after helix formation. ${ }^{[27]}$ 
First analyses of $\beta$-peptides were performed via fiber diffraction and infrared (IR) measurements, leading to the discovery of helical structures. ${ }^{[59,60]}$ A deeper insight was gained with NMR and X-ray studies while enforcing a 14-helix by the use of ACHC. Thereby, it was shown that these helices are formed in organic solvents as well as in solid state. ${ }^{[55,61,62]}$ The 14-helix is perfectly suitable for the role of a model system for $\alpha$-helices while being more rigid and having three amino acids per turn, resulting in every residue at position $i+3$ being stacked above the residue at position $i$ (Figure 5). ${ }^{[33,63]}$ Utilizing this fact, the 14-helix can be described with three flanks and modified in a way that intramolecular interactions (e.g. $\pi$-stacking or electrostatic interactions) between specific residues can be enforced.

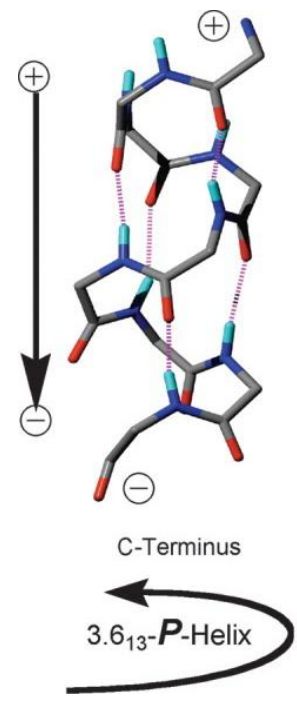

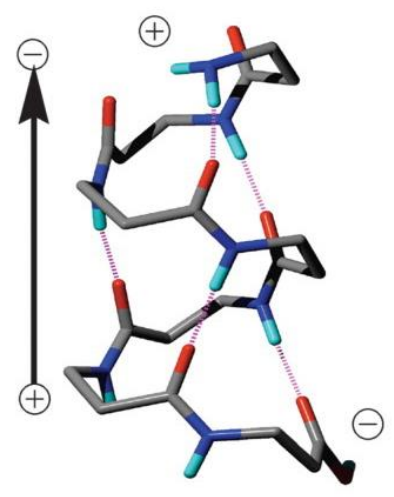

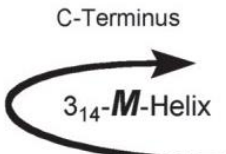

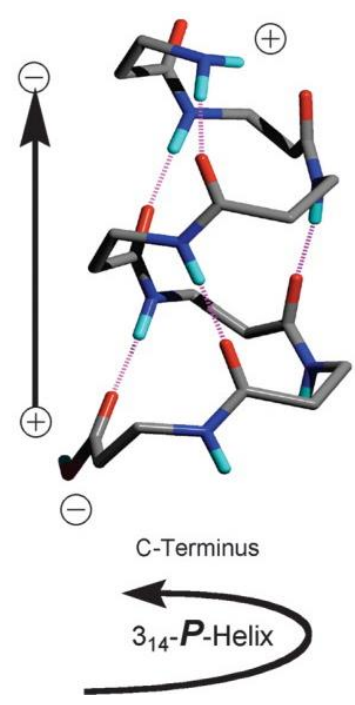

Figure 5: Structural differences between $\alpha$-helices (3.613-helix) and 14-helices ( $3_{14}$-helix). Handedness of the 14-helices can be modulated by the use of $\mathrm{D} / \mathrm{L} \beta$-amino acids. ${ }^{[64]}$

In addition to the different torsional angles in $\alpha$ - and 14-helices, the helices also differ in their dimensional properties. The inner radius of a 14-helix $(2.7 \AA)$ is wider compared to the $\alpha$-analogue (2.2 $\AA$ ). Also, there are more residues per turn in $\alpha$-helices (3.6 vs. 3.0 in 14 helices) with the rise per residue being smaller (1.5 $\AA$ vs. $1.56 \AA$ in 14 -helices). ${ }^{[65,66]}$

In order to work with 14-helices, one has to understand how stabilization of the helical structure can be ensured in the desired medium. In organic solvents, $\alpha$-helices are formed with 10-12 amino acids, whereas the 14-helix in general only needs six $\beta$-amino acids to establish a stable helix. ${ }^{[33,54,63]}$ The GELLMAN group even presented a $\beta$-peptide consisting only of four ACHC moieties which adapted a 14-helix in solid state. ${ }^{[8]} \mathrm{WU}$ et al. proposed that the astonishing ability to form a helix with just as few as four amino acids in organic solvents might arise from electrostatic interactions between nitrogen and carbon atoms in the amide 
bond. ${ }^{[51,67,68]}$

However, this exceptional property is limited to organic solvents whereas in aqueous media, 14-helices are significantly less stable. ${ }^{[27,61]}$ It was shown that hexa- $\beta$-peptides only form helices in water with a sufficient amount of cyclic amino acids like ACHC. ${ }^{[61]}$ Exchanging these highly 14-helix promoting amino acids with non-cyclic derivatives showed low tendency towards helix formation. A possible explanation was delivered by taking side chain interactions into account. In $\alpha$-helices, positions $i$ and $i+4$ have a distance of roughly $6.3 \AA$ with an angle of $40^{\circ}$ between them. However, in 14-helices positions $i$ and $i+3$ are closer with $5 \AA$ and almost parallel. Therefore, it was proposed that side chain interactions are playing an important role in the formation of 14-helices. In aqueous media, these interactions are minimized due to the present water which is competing with these electrostatical interactions. Similar behavior is observed for $\beta$-sheet structures in $\alpha$-peptides. ${ }^{[69-71]}$

CHENG and DEGRADO as well as ARVIDSSON et al. developed modified 14-helix using $\beta$ peptides which were stabilized by electrostatic interactions in the amino acid side chains. ${ }^{[72,73]} 14-$ Helix flanks (positions $i$ and $i+3$ respectively) were equipped with alternating $\beta$-glutamine and $\beta$-lysine or $\beta$-ornithine derivatives so that electrostatic interactions could occur upon helix formation.

In contrast to these findings, PAHLKE recently analyzed a sequence of alternating $\beta^{3}$-D-valine and $\beta^{3}$-D-lysine moieties in a nonapeptide. ${ }^{[74]}$ Thereby, 14-helix formation was clearly shown via circular dichroism (CD) spectroscopy (Figure 6), indicating that at a certain length, 14helices are able to form in aqueous media. Based on these measurements, the 14-helices are no longer bound to organic solvents or membrane surroundings but can also be generated in water.

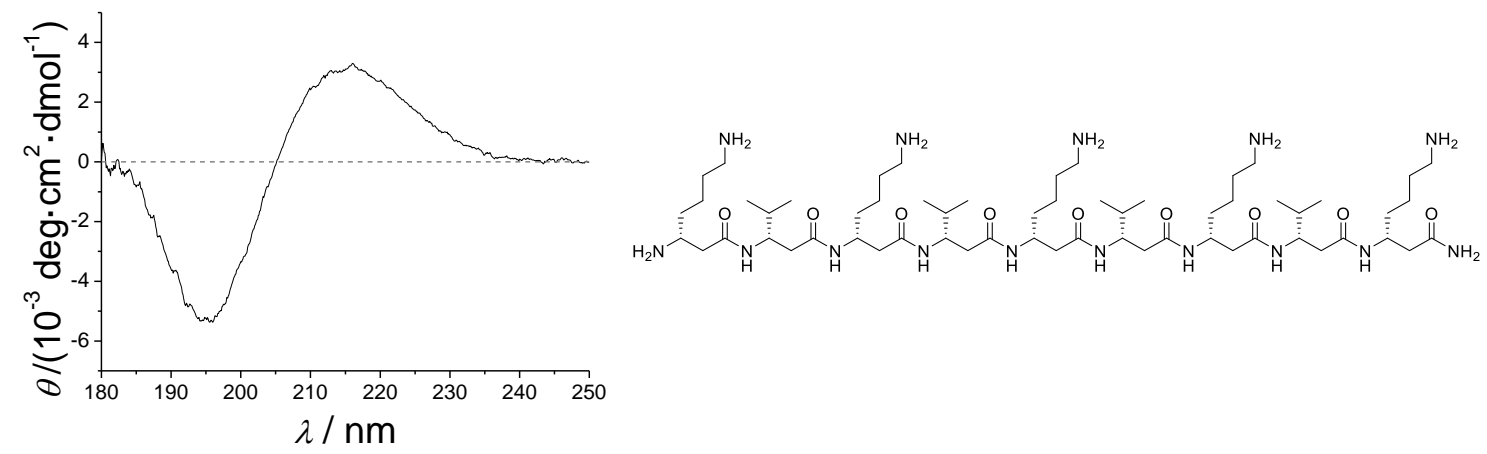

Figure 6: $C D$ spectrum of an alternating sequence of a nonapeptide with $\beta^{3}$-D-lysine and $\beta^{3}$-D-valine. In general, minima around $195 \mathrm{~nm}$ and maxima around $215 \mathrm{~nm}$ indacte a clear right-handed 14-helix formation. ${ }^{[27,74]}$ 


\subsection{Artificial Transmembrane $\beta$-Peptides}

It is estimated that $30 \%$ of all natural proteins are membrane proteins and therefore interact with biological membranes to accomplish various functions like signal transduction, enzyme activity, transport of ions and other vital processes. ${ }^{[75-79]}$ Since the demanding environment of proteins is crucial for their function, the analysis of those highly complex structures can be quite difficult. ${ }^{[75]}$

Breaking down these systems to a minimized level of complexity was for example achieved by KILLIAN by introducing transmembrane model systems like WALP. ${ }^{[80,81]}$ For this purpose, alternating sequences of leucine and alanine in different lengths were synthesized and flanked by two tryptophans respectively. ${ }^{[82]}$ Membrane insertion and especially the influence of hydrophobic lengths of the peptides on hydrophobic mismatches of the membrane were shown (Figure 7). A hydrophobic peptide core that is longer than the hydrophobic thickness of a membrane leads to a positive hydrophobic mismatch and vice versa. ${ }^{[83]}$ The biological membrane can adapt to this length differences in different ways. On the one hand, the membrane can stretch, shrink or even form a non-bilayer phase. On the other hand, the peptide or protein itself can form aggregates or tilt in order to slightly change its hydrophobic length. Another model system, KALP, showed the same results with the difference of having lysine residues in the sequence instead of tryptophans. ${ }^{[84-87]}$

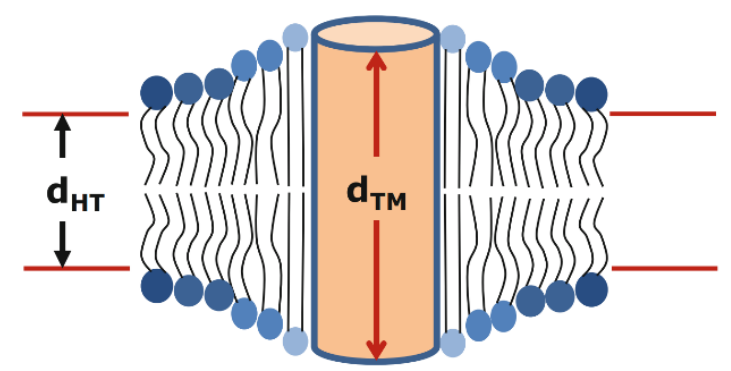

Figure 7: Schematic view on a positive mismatch. Since the transmembrane domain length $\left(\mathrm{d}_{\mathrm{TM}}\right)$ is longer than the membrane bilayer hydrophobic thickness $\left(\mathrm{d}_{\mathrm{HT}}\right)$, the membrane can adapt by stretching. ${ }^{[88]}$

Based on this knowledge and the advantages of $\beta$-peptides, especially in the shape of 14helices, the DIEDERICHSEN group specialized on the synthesis, characterization and organization of such KALP- and WALP-inspired transmembrane peptides. ${ }^{[12,74,89,90]}$ 
PAHLKE synthesized a variety of different transmembrane $\beta$-peptides with high $\beta^{3}$-D-leucine, $\beta^{3}$-D-isoleucine or $\beta^{3}$-D-valine contents to obtain 12 - and 14-helices. It was shown that the introduction of ACHC, similar to the findings of GELLMAN, DEGRADO and SEEBACH, converts 12 -helices to 14 -helices, making $\beta$-peptides a desirable class of transmembrane model systems due to their modulatable structure. ${ }^{[9,74]}$ The integrity of the peptides was proven via tryptophan's intrinsic fluorescence properties. It is known that tryptophan has an absorption maximum under $330 \mathrm{~nm}$ in hydrophobic environments, whereas the maximum shifts to over $330 \mathrm{~nm}$ in hydrophilic environments due to an electron density shift in the indole moiety. ${ }^{[11-94]}$ Transmembrane $\beta$-peptides were equipped with a $\beta^{3}$-tryptophan residue either in the middle of the sequence or $N$-terminally. The occurring shifts of the $\beta^{3}$-tryptophan absorption gave evidence about the successful incorporation of the synthesized peptides into lipid membranes. ${ }^{[74]}$

Furthermore, similar $\beta$-peptides were equipped with a novel diiodo-compound to locally increase the electron density in defined positions. X-ray diffraction measurements revealed the position of these compounds, being successfully incorporated into the lipid membrane. Since the peptide was designed with a longer hydrophobic part compared to the membrane (Figure 8), a positive mismatch was observed, resulting in tilting of the peptides by $16^{\circ} \cdot{ }^{[10,12]}$

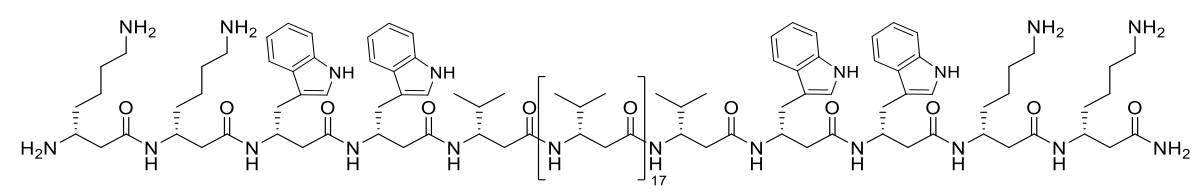

Figure 8: Transmembrane model system developed by STOLLBERG with a hydrophobic core of 19 consecutive $\beta^{3}$-D-valines, flanked by two $\beta^{3}$ - D-tryptophans and two $\beta^{3}$ - D-lysines. ${ }^{[12]}$

Based on this new standard model system, $\beta^{3}$-glutamine amino acids were incorporated into the sequence in order to analyze the non-covalent aggregation of those peptides in lipid membranes. Measuring and evaluating the FRET efficiency, trimeric aggregation states could be found when incorporating two or three $\beta^{3}$-glutamine moieties at $25^{\circ} \mathrm{C} .^{[11]}$ Temperature-dependent fluorescence spectroscopy measurements revealed that the stability of associated 14-helices is highly dependent on the number of incorporated $\beta^{3}$-glutamines. 


\section{Synthesis of Transmembrane $\beta$-Pep- tides for the Organization in Lipid}

Bilayers

Since protein aggregation is key to many vital processes, scientists have been extensively investigating this biochemical phenomenon in the last decades. In this chapter, the aggregation behavior of artificial transmembrane $\beta$-peptide model systems is examined based on non-covalent hydrogen bonding induced by cyanuric acid (CA) and melamine (M) recognition units. Design, synthesis and labeling strategies are presented as well as the surprising comparison to the pure transmembrane domain. Further analyses included fluorescencebased proton transport assays in collaboration with D. RUPPELT, membrane conductivity measurements in cooperation with A. MAZNICHENKO and FRET efficiency measurements.

\subsection{Self-Assembly of Cyanuric Acid and Melamine}

Organization and aggregation of oligomeric biomolecules such as peptides and proteins play a crucial role in their functionality and stability. ${ }^{[55,96]}$ Depending on the environment of such proteins, different folding states and assembly properties can be realized. Being highly complex, this area of research proved to be fundamental for understanding the mechanistics of protein function. ${ }^{[97,98]}$

Contrary to classic organic chemistry, these interactions happen on a reversible, non-covalent level which makes protein folding and aggregation a versatile and complicated process 
to study. Since hydrogen bond interactions are generally weaker than covalent bonds by tenfold, aggregation products are less stable. However, the formation of aggregation structures is reversible, leading to decomposition of non-favorable conformations. ${ }^{[99-101]}$ Examples for these interactions are found in base pairing or the hemoprotein Nitrophorin 4 which even changes its conformation in dependency on the $\mathrm{pH}$ value. ${ }^{[102,103]}$

Also, barbiturates, that are of biological and pharmaceutical relevance, show strong affinity to build up hydrogen bonds, resulting in supramolecular frameworks. ${ }^{[99,104,105]}$ Another quite similar, yet interesting hydrogen bond network can be found in the so-called CA·M lattice. First investigated by WHITESIDES et al., various possibilities of aggregation modes were found. ${ }^{[106,107]}$ Utilizing the $C-3$ symmetry of cyanuric acid (CA) and melamine (M), the $\mathrm{CA} \cdot \mathrm{M}$ network is built from multiple hydrogen bonds per building block (Figure 9).

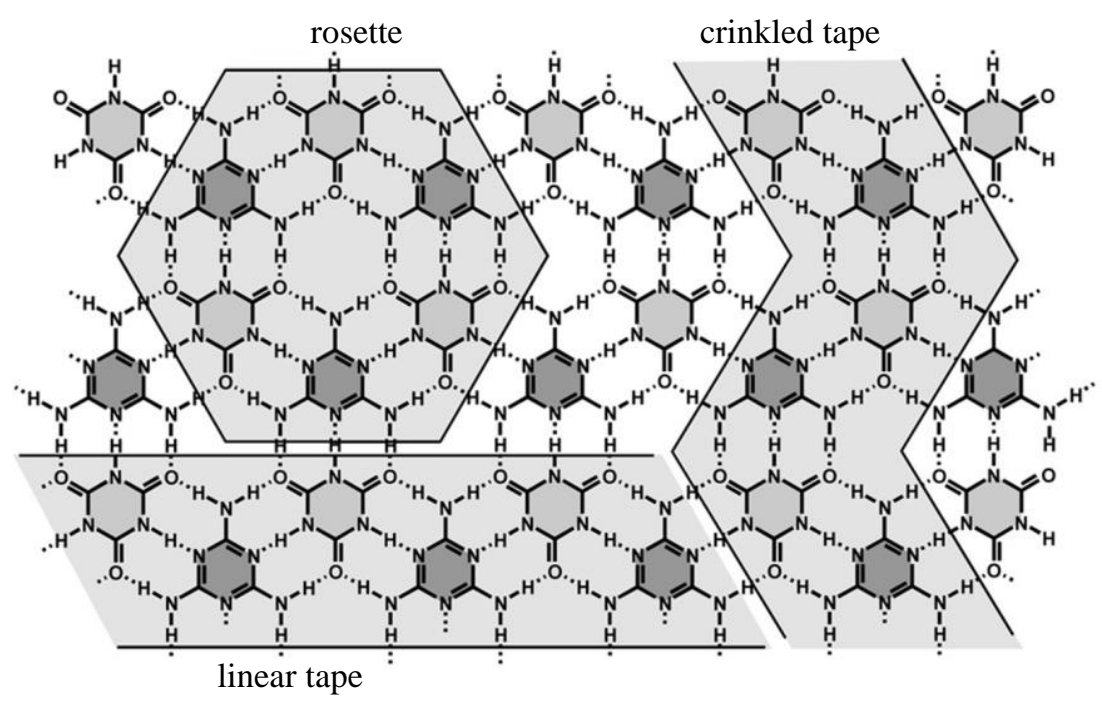

Figure 9: Equimolar mixtures of cyanuric acid and melamine are able to build up supramolecular structures. Here, a two dimensional network of the CA.M lattice is shown with three present shapes, which can be defined: the hexameric rosette, the infinite crinkled tape and the infinite linear tape. ${ }^{[99]}$

Thereby, three different macromolecular patterns were defined. The rosette motif consists of three melamine and three cyanuric acid moieties, aligned in an alternating fashion. With only six monomers, already 18 hydrogen bonds are formed, leading to a remarkably stable structure. Furthermore, the infinite, non-cyclic structures of the linear and the crinkled tape can be found in the CA·M lattice. ${ }^{[99]}$ However, especially hexameric assemblies like the rosette are a well-known pattern in nature as it is for example found in apicomplexan adenosine triphosphate (ATP) synthase or in amyloid- $\beta$ oligomers which may contribute to Alzheimer's disease. ${ }^{[108,109]}$ 
In terms of the CA-M assemblies, WHITESIDES proposed two approaches to ensure the formation of rosette structures (Figure 10). First, he named the concept of covalent preorganization. There, a $C-3$ symmetric spacer is used to link three melamine units covalently, bringing three of six units already in close proximity to each other. Insertion of the cyanuric acid building blocks then leads to a facilitated rosette formation. ${ }^{[110]}$ Second, he proposed the use of sterically demanding substituents in order to block defined sides of the melamine units. Thus, only specific areas are accessible for hydrogen bonding and aggregation. ${ }^{[107,111,112]}$ Due to low solubility in organic solvents, X-ray measurements of single rosettes proved to be difficult. ${ }^{[14]}$ Also, solutions of cyanuric and melamine in alcohol or water did not lead to sufficient crystallization. ${ }^{[106,107,113]}$

a)

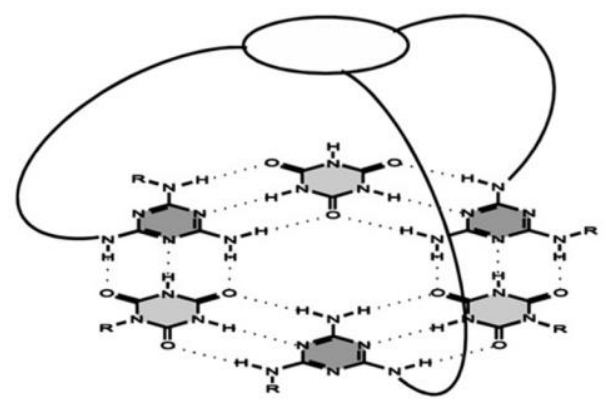

b)

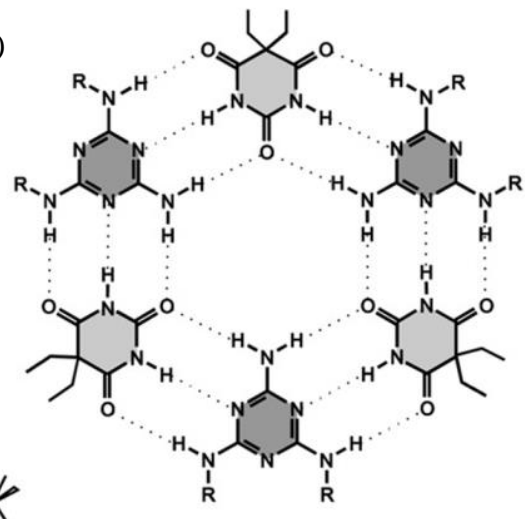

Figure 10: WHITESIDE's two proposed approaches to ensure rosette formation of an equimolar mixture of cyanuric acid and melamine. a) The concept of covalent preorganization: three melamine units are linked with a $C-3$ symmetric spacer in order to bring them in close proximity to facilitate insertion of cyanuric acid. b) The concept of peripheral crowding: Bulky substituents $\mathrm{R}$ are supposed to prevent other hydrogen bonding than the ones for rosette formation. ${ }^{[99]}$

However, RANGANATHAN et al. obtained CA·M rosette crystals by crystallization under hydrothermal conditions, revealing the dimensions of such rosettes (Figure 11 a). Furthermore, stacking of individual layers of rosettes was observed which build up a macromolecular channel structure (Figure $11 \mathrm{~b}$ ). The cavity which is formed in the middle of the CA·M rosette was observed to have a diameter of roughly $4 \AA^{[14]}$

More recent studies from МотLOCH et al. utilized similar rosette structures to synthesize self-assembling hybrid cages. ${ }^{[114]}$ During these experiments, barbiturate-pyridine (BA) was coordinated by palladium(II) or platinum(II) before adding it to modified melamine units in 
chloroform. Cage formation was monitored and characterized by ${ }^{1} \mathrm{H}-\mathrm{NMR}$, nuclear OVERHAUSER enhancement spectroscopy (NOESY) and diffusion ordered spectroscopy (DOSY), revealing the hydrodynamic radii of formed cages (Figure 12).

a)

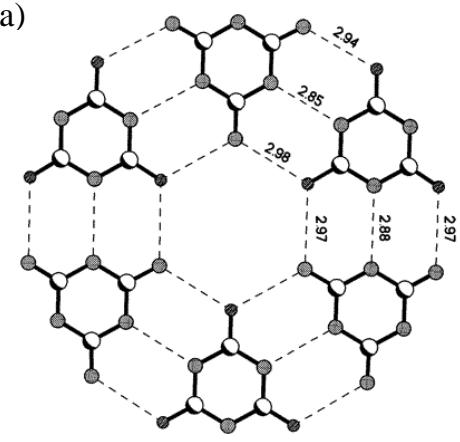

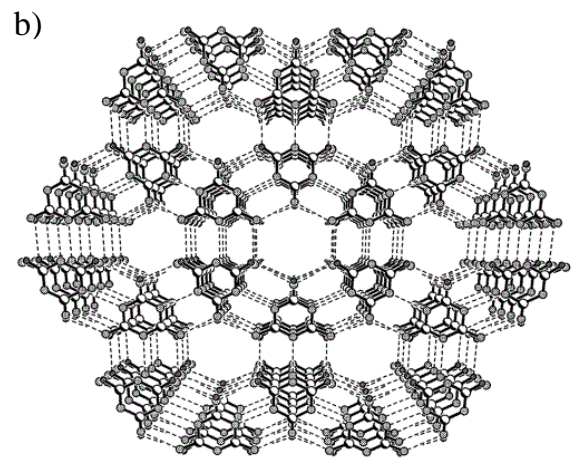

b)

Figure 11: a) Rosette dimensions obtained with hydrothermal condition crystallization and subsequent X-ray measurements. b) Three dimensional channel formation by stacking individual layers of rosettes. ${ }^{[14]}$

Successful self-assembly could also be achieved by adding all single components in a onepot reaction. Furthermore, dual controllable disassembly could be shown by either introducing strong ligands which form more stable complexes with the metal ion or by adding a cyanurate moiety which forms more stable rosettes without the possibility of coordinating the metal.

a)

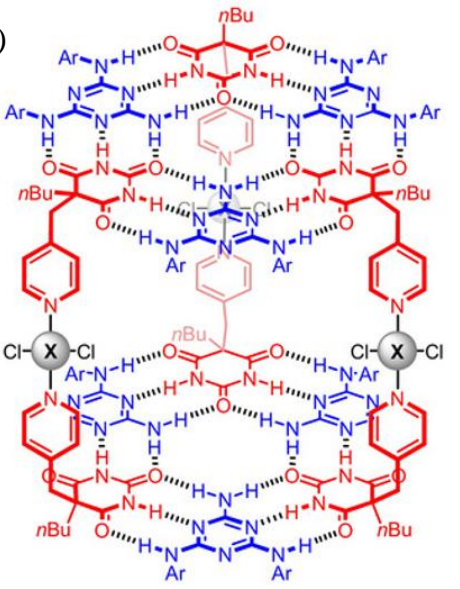

b)

c)

d)

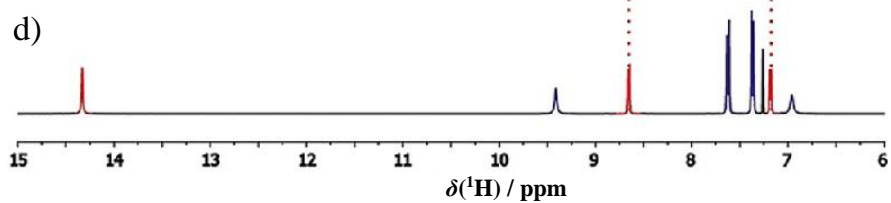

Figure 12: a) Structure of the rosette inspired hybrid cage by MOTLOCH et al. X depicts the used metal, in this case $\mathrm{Pd}(\mathrm{II})$ or $\mathrm{Pt}(\mathrm{II})$. Occurring cage formation was monitored via ${ }^{1} \mathrm{H}-\mathrm{NMR}$. The characteristic rosette peak (barbiturate N-H) at approx. 14 ppm gives evidence of formed cages. Usage of Pd(II) (b), Pt(II) (c) and onepot self-assembly (d) was observed to successfully allow the formation of cages. Barbiturate related structures and peaks are marked in red, whereas melamine related details are encoded in blue. ${ }^{[14]}$ 
Regarding the attachment of these $\mathrm{CA} \cdot \mathrm{M}$ building blocks to biomolecules, especially in the context of this thesis, recent research was done by KABATAS GLOWACKI from the DIEDERICHSEN group. ${ }^{[13]}$ There, two $\beta^{3}$-peptides were synthesized which contained three units of cyanuric acid and melamine, respectively (Figure 13). Adopting a 14-helix, they were designed in a way that the recognition units were stacked on top of each other upon helix formation, following positions $i$ and $i+3$ (also see chapter 2.2). Analysis and characterization of formed rosette structures was observed via dynamic light scattering (DLS) measurements and ESI-HRMS. In DLS, hydrodynamic sizes of 2.3-3.1 nm were found for peptidic rosette aggregates, whereas monomeric peptides showed sizes of less than $1 \mathrm{~nm}$.

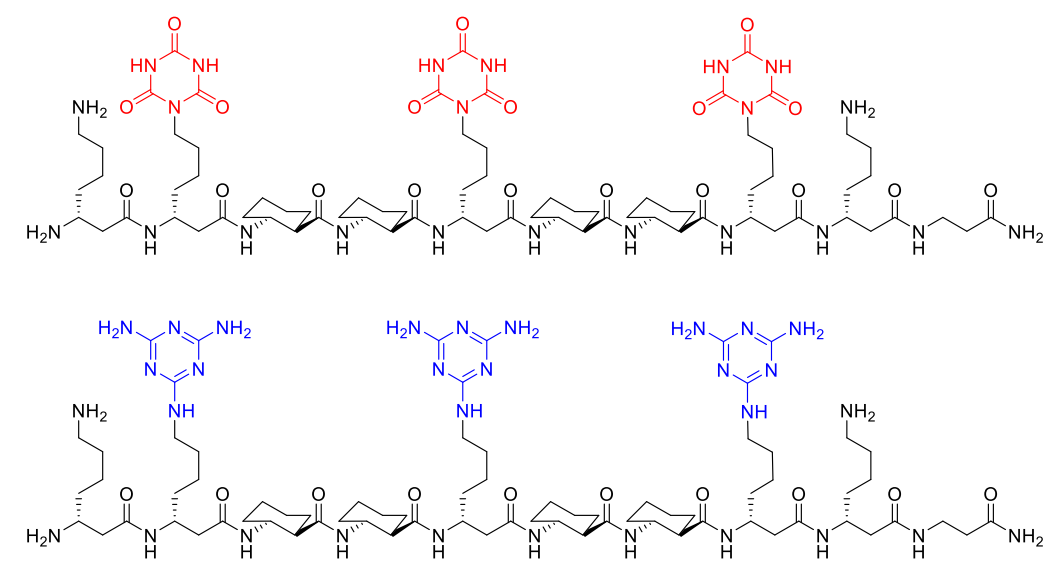

Figure 13: Deca- $\beta^{3}$-peptides which were synthesized by KABATAS GLOWACKI for the organization as hexameric helix bundles in solution. Cyanuric acid related structures are marked in red, melamine structures in blue. ${ }^{[13]}$

On the one hand, these results were perfectly aligned with theoretical estimations. On the other hand, further ESI measurements were carried out, finding evidence of threefold cyanuric acid and melamine adducts as expected in CA·M rosettes (Figure 14). With these results, hexameric rosette formation according to the CA·M lattice was confirmed to be adopted by 14-helices, leading to new possible approaches in the field of aggregation of $\beta^{3}$-peptides. In this work, the rosette shaped helix bundle will be taken to the transmembrane level in order to create artificial self-assemblies within lipid membranes. 

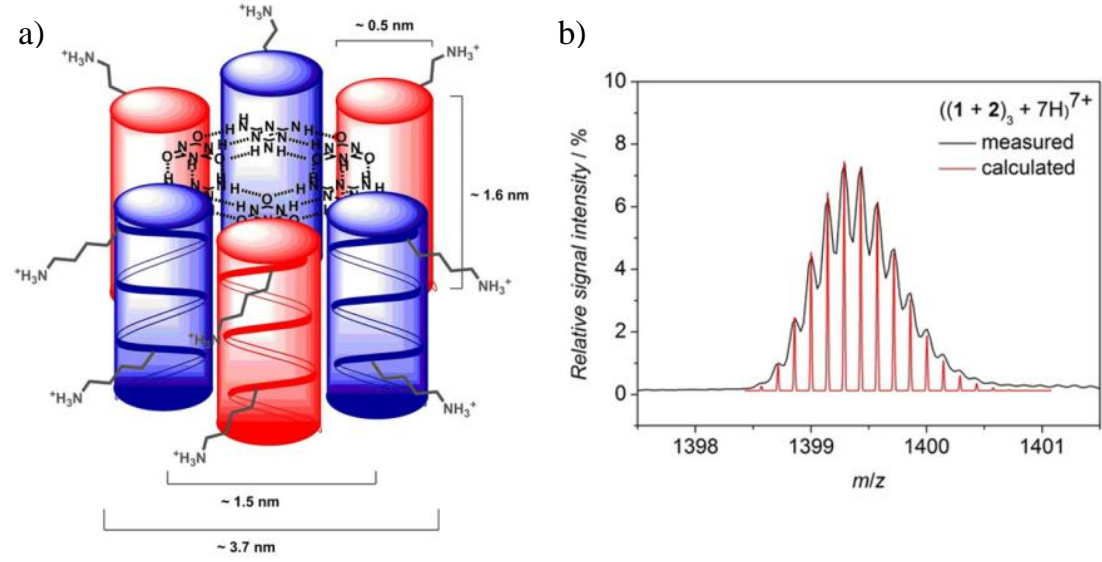

Figure 14: a) Schematic view on the formed helix bundle according to the CA $\cdot M$ lattice by introduction of cyanuric acid and melamine into $\beta^{3}$-peptides. Cyanuric acid related structures are marked in red, melamine structures in blue b) Mass spectrum of the formed rosette structure in sevenfold charge. Measured and calculated spectra are in perfect agreement, strongly supporting the assumption of aggregation. ${ }^{[13]}$

\subsection{Design and Synthesis of Transmembrane $\beta$-Peptides}

\subsubsection{General Peptide Design}

In order to maintain comparability with previous work on transmembrane $\beta$-peptides from the DIEDERICHSEN group, this work is based on D-amino acids, which, in case of 14-helices, adapt a right-handed helix. Based on the results of PAHLKE and KABATAS GLOWACKI, $\beta^{3}$ peptides are able to form 14-helices in aqueous media without cyclic amino acids and can be aggregated by the use of cyanuric acid and melamine according to the CA-M lattice. ${ }^{[13,74]}$ Combining these findings with preliminary results on artificial transmembrane $\beta$-peptides, possibilities arise of assembling elongated transmembrane 14-helices which penetrate the membrane-water interface of lipid bilayers. ${ }^{[10,11]}$ Similar work was done by PAHLKE in terms of near-membrane proton and calcium sensors based on the elongation of the standard transmembrane $\beta$-peptide model system with alternating sequences of $\beta^{3}$-D-valine and $\beta^{3}$-Dlysine. ${ }^{[74]}$ Since self-assembly of the pure transmembrane domain was excluded by STOLLBERG via FRET efficiency measurements, cyanuric acid and melamine were chosen as building blocks in order to enforce helix bundle formation out of transmembrane 14-helices. $^{[11,12]}$ 
The transmembrane section of these peptides was adopted from STOLLBERG and consists of $19 \beta^{3}$-D-valine units which are flanked by two $\beta^{3}$-D-tryptophans and two $\beta^{3}$-D-lysines with an additional $C$-terminal $\beta^{3}$-D-lysine for fluorophore modification (Figure 15). The strongly 14-helix promoting $\beta^{3}$-D-valine units build up the hydrophobic core of the peptide which spans through the hydrophobic part of the membrane. ${ }^{[12,115,116]}$ In addition, terminal flanking tryptophans are known to anchor peptides to the membrane-water interface, whereas lysine moieties enhance the solubility and therefore the handling of those compounds significantly. ${ }^{[117,118]}$ Since KABATAS GLOWACKI presented aggregation of 14-helices in aqueous solution, the WALP- and KALP-inspired transmembrane model systems were elongated and modified with cyanuric acid and melamine to achieve aggregation by hydrogen bond formation in the water phase. Comparably, SCHNEGGENBURGER et al. developed nucleobase modified gramicidin A derivatives which assembled themselves by outer-membrane hydrogen bonds. ${ }^{[15]}$

The self-assembly according to the $\mathrm{CA} \cdot \mathrm{M}$ lattice relies on two hydrogen bond forming, aromatic building blocks. In general, aromatic side chains are known to interact with lipid membranes, being able to affect membrane stability and properties. ${ }^{[119]}$ Therefore, a three amino acid linker was introduced to the $N$-terminus of the transmembrane unit in order to prevent interactions between cyanuric acid or melamine units and the lipid membrane. Consisting of $\beta^{3}$-D-valine, $\beta^{3}$-D-lysine and $\beta^{3}$-D-valine, the linker also promotes 14-helix formation, which is particularly important due to its positioning within the membrane-water interface. Then, cyanuric acid or melamine, respectively, were introduced by using a modified $\beta^{3}$-D-lysine moiety, enabling the potential of aggregation without breaking helix symmetry. According to 14-helix specific stacking positions of $i$ and $i+3$, two $\beta^{3}$-D-amino acids were incorporated, followed by another cyanuric acid or melamine building block (Figure 15). In this work, the peptides were designed in a way that the rosette layers are shifted by one position (Figure 16). Thereby, two aromatic residues are stacked on top of each other upon helix formation. Formed rosettes can be stabilized by hydrogen bonding as well as $\pi$-stacking of the aromatic building blocks. Based on this design, rosette formation of 14-helices in lipid membranes can be facilitated. The formation of artificial channel structures which can be formed due to the cavity, created within the rosette (Figure 16), was examined in subsequent assays. Also, $C$-terminal addition of an orthogonally protected $\beta^{3}$-D-lysine motif enables the possibility of labeling the peptides. For initial analysis and proof of concept, 5(6)-carboxytetramethylrhodamine (TAMRA) and 7-nitrobenzofurazan (NBD) can be incorporated into the peptides. 


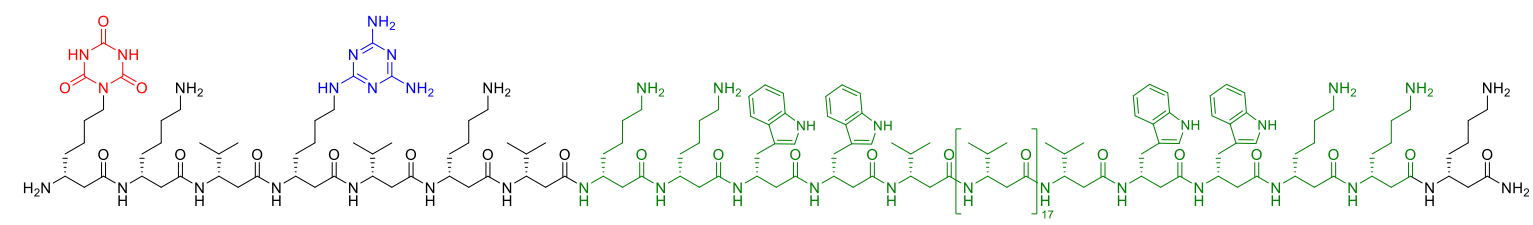

1

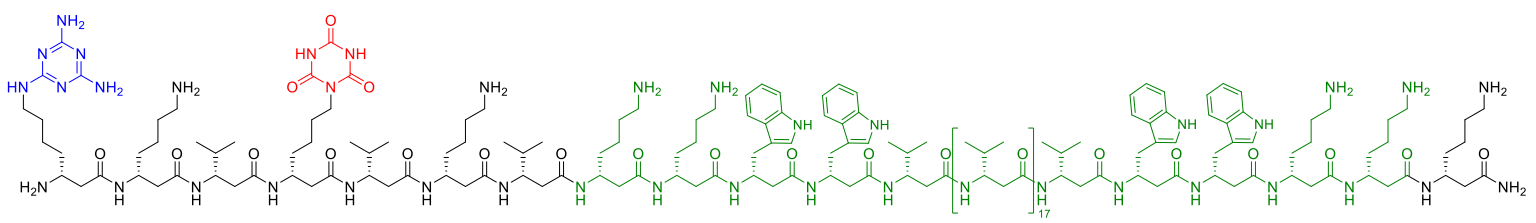

2

Figure 15: Chemical structure of cyanuric acid and melamine modified $\beta$-peptide transmembrane model systems. The $C$-terminal $\beta^{3}$-D-lysine can be used to modify the peptides with a fluorophore, followed by the standard transmembrane system (green) and a short, three amino acid linker. A building block at position $i$ with the next one being at position $i+3$ leads to stacking upon 14-helix formation. Cyanuric acid related structures are marked in red, melamine structures in blue.

Carrying out FRET measurements, the proximity of both peptides can be determined in the lipid membrane to observe aggregation in the first place. However, determination of aggregation states requires more advanced spectroscopical techniques like FCS.

a)

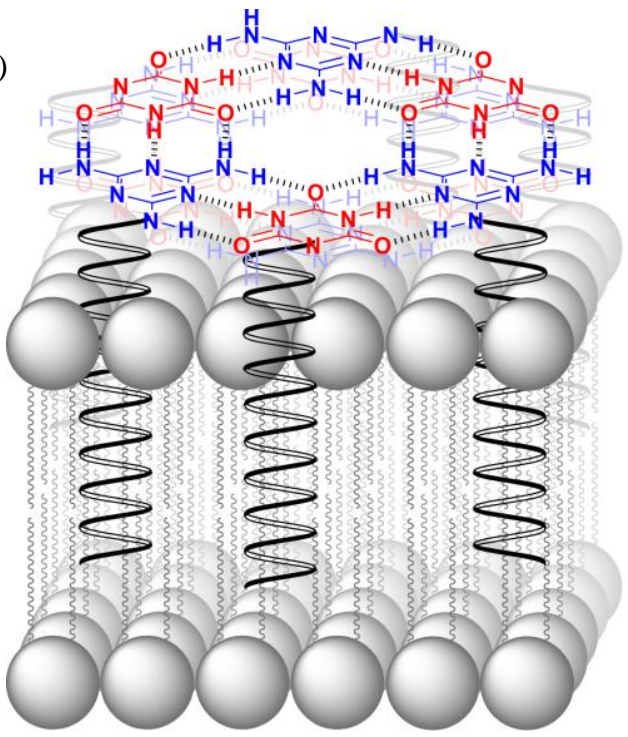

b)

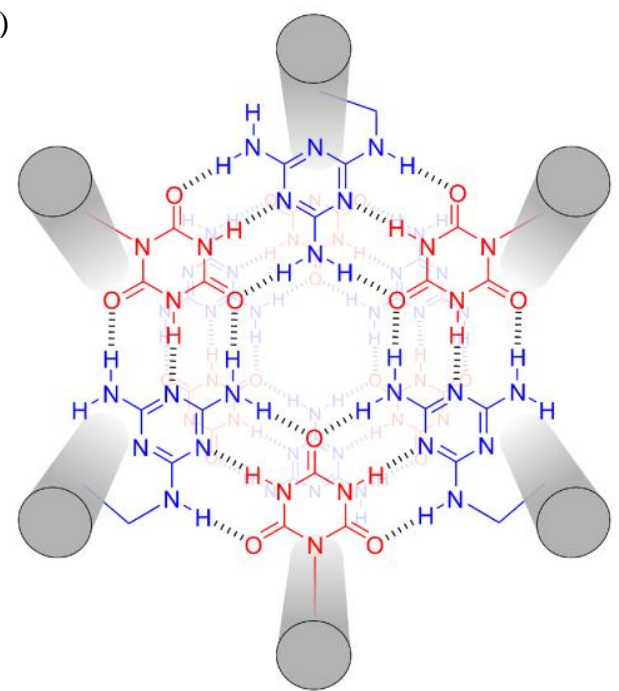

Figure 16: a) Schematic side view on the peptide alignment in a hexameric shape in the lipid membrane with two $\mathrm{CA} \cdot \mathrm{M}$ rosettes. b) Top view on stacking $\mathrm{CA} \cdot \mathrm{M}$ rosette-induced peptide aggregation, leading to a cavity within the helices. For a more comprehensive view, the transmembrane domain tilt of $16^{\circ}$ is not considered in both figures. 


\subsubsection{Synthesis of Artificial $\beta^{3}$-D-Amino Acids}

Since $\beta$-peptides and most of the $\beta$-amino acids do not appear in nature, synthesis of $\beta^{3}$-Damino acids was achieved from their commercially available $\alpha$-analogues. Conversion into $\beta^{3}$-D-amino acids was performed by the already established ARNDT-EISTERT-homologation (Scheme 2). ${ }^{[39]}$ Hereby, the side chain and $N$-terminally protected amino acids were activated with triethylamine (1.10 eq) and isobutyl chloroformate $(1.10 \mathrm{eq})$, followed by addition of diazomethane (2.00 eq). After nucleophilic substitution, a diazo ketone is formed as an intermediate in quantitative yield which was used without further purification. In a consecutive step, the diazo ketone was directly transferred to the respective $\beta^{3}$-amino acid with silver benzoate $(0.10 \mathrm{eq})$ and water in a WOLFF-rearrangement. Thereby, two literature-known methods were used. For the synthesis of Fmoc- $\beta^{3}-\mathrm{D}-\mathrm{Val}-\mathrm{OH}$, the diazo ketone was dissolved in a mixture of 1,4-dioxane and water $(2: 1, v / v)$ and after addition of silver benzoate, the mixture was irradiated with $460 \mathrm{~W}$ for $1 \mathrm{~min}$ in a domestic microwave oven (method B, see SOP4). For all other $\beta^{3}$-D-amino acids, the respective diazo ketone was dissolved in a mixture of THF and water $(9: 1, v / v)$, followed by the addition of silver benzoate and sonication for $2 \mathrm{~h}$ under the exclusion of light (method A, see SOP3). In both cases, final purification was achieved by precipitation in cold diethyl ether.

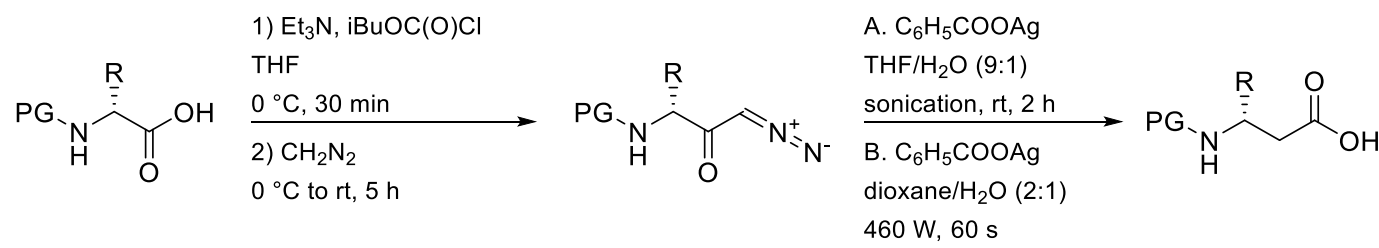

Scheme 2: Synthetic route to obtain $N$-terminally protected $\beta^{3}$-D-amino acids. Respective $\alpha$-analogues were activated by triethylamine and isobutyl chloroformate to achieve backbone methylation by diazomethane. Resulting diazo ketones were then transferred to final $\beta^{3}$-D-amino acids by either using method A via sonication or using method B in a domestic microwave oven. ${ }^{[39]}$

Utilizing the ARNDT-EISTERT-homologation, various amino acids could be synthesized in sufficient yields (Table 1). Ranging from $64 \%$ to $93 \%$, the resulting $\beta^{3}$-D-amino acids were then further modified or used in solid-phase peptide synthesis (SPPS). 
Table 1: Respective yields of synthesized $N$-terminally protected $\beta^{3}$-D-amino acids, resulting from the ARNDTEISTERT-homologation.

\begin{tabular}{lc} 
& Yield / \% \\
\hline Fmoc- $\beta^{3}$-D-Val-OH (3) & 77 \\
pNZ- $\beta^{3}$-D-Val-OH (4) & 64 \\
Fmoc- $\beta^{3}$-D-Trp(Boc)-OH (5) & 89 \\
\hline Fmoc- $\beta^{3}$-D-Lys(Boc)-OH (6) & 79 \\
\hline Fmoc- $\beta^{3}$-D-Lys(Mtt)-OH (7) & 78 \\
\hline Boc- $\beta^{3}$-D-Lys(Boc)-OH (8) & 92 \\
\hline Boc- $\beta^{3}$-D-Lys(Cbz)-OH (9) & 93 \\
\hline
\end{tabular}

In order to incorporate cyanuric acid and melamine into $\beta$-peptides, the $\mathrm{CA} \cdot \mathrm{M}$ building blocks were attached to 14-helix promoting $\beta^{3}$-D-amino acids. As already mentioned, this was achieved by modifying a $\beta^{3}$-D-lysine moiety. For this purpose, a synthetic route based on Kabatas GlOwaCKI was adapted. ${ }^{[13]}$ The starting material, Boc-D-Lys(Cbz)-OH (10), remains stable under basic conditions. However, final substitution of the Boc-protecting group with a Fmoc-protecting group had to be executed in order to use building blocks in SPPS. First, the respective $\beta^{3}$-D-amino acid 9 was synthesized via the ARNDT-EISTERT-homologation with a yield of $93 \%$. Subsequent palladium-catalyzed deprotection of the Cbzprotected side chain was carried out by applying high pressures of hydrogen gas with $94 \%$ yield. Thus, the resulting compound 11 was obtained with an overall yield of $86 \%$ and was used as a key intermediate for both building blocks (Scheme 3).
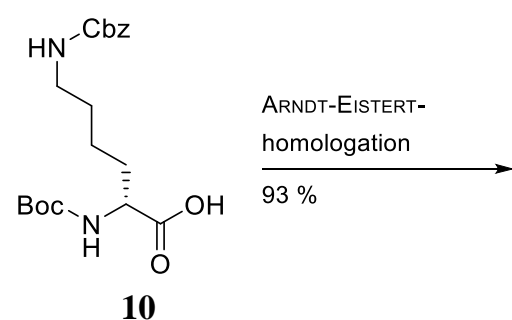

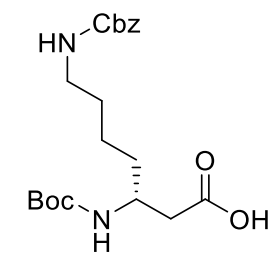

9

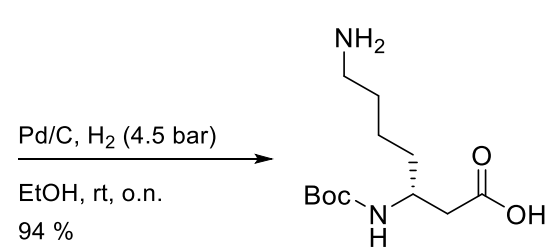

11

Scheme 3: Synthetic route to obtain key intermediate 11. First, the starting material $\mathbf{1 0}$ was converted to the respective $\beta^{3}$-D-amino acid, followed by Cbz-deprotection via Pd-catalyzed hydrogenation.

For the synthesis of the melamine functionalized building block, the now unprotected intermediate 11 was converted to 12 via nucleophilic aromatic substitution by the use of $\mathrm{NaOH}$ (2.00 eq) and 2,4-diamino-6-chlorotriazine (1.20 eq) with a yield of $35 \%$ (Scheme 4). Final 
Boc-deprotection with excess of TFA and Fmoc-protection with $\mathrm{NaHCO}_{3}$ (1.50 eq) and Fmoc-OSu (1.50 eq) resulted in the final building block, Fmoc- $\beta^{3}$-D-Lys(M)-OH (13), with a yield of $58 \%$ over two steps.

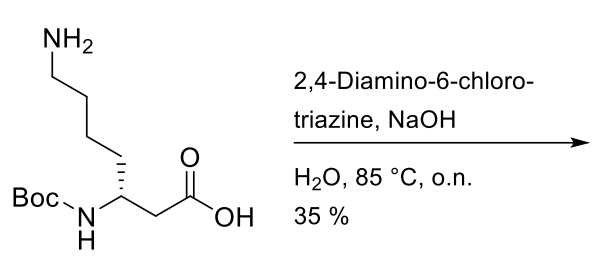

11

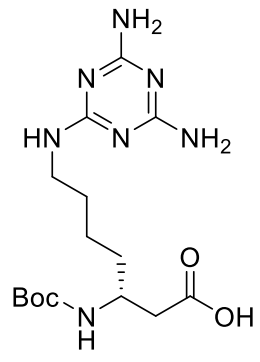

12

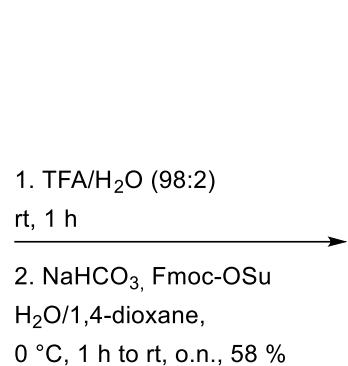

$0{ }^{\circ} \mathrm{C}, 1 \mathrm{~h}$ to rt, o.n., $58 \%$

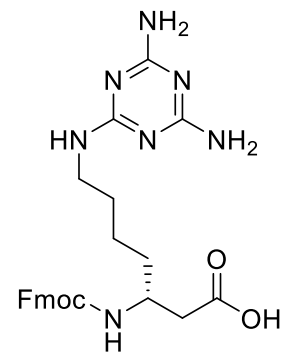

13

Scheme 4: Synthetic route to obtain the melamine functionalized building block 13. The unprotected $\beta^{3}$-Damino acid 11 was treated with 2,4-diamino-6-chlorotriazine and $\mathrm{NaOH}$ to obtain the Boc-protected building block 12, followed by final deprotection and Fmoc-protection.

The cyanuric acid modified building block was also synthesized by starting from key intermediate 11 (Scheme 5). First, the side chain amine was converted to a hydroxyl group in a nucleophilic substitution by treatment with sodium nitroprusside (1.53 eq) and sodium hydroxide $(3.08 \mathrm{eq}$ ) with a yield of $50 \%$. It has to be mentioned that higher yields are very unlikely for this reaction since the substitution reaction has to compete with the elimination, which also occurs under these conditions. The resulting, hydroxyl functionalized $\beta^{3}$-D-amino acid 14 was further modified in an APPEL reaction under usage of tetrabromomethane (1.45 eq) and polymer-bound triphenylphosphine (2.10 eq). Yielding compound 15 with $60 \%$, final side chain conversion was achieved with a yield of $24 \%$ by using cyanuric acid (5.00 eq) and DBU (1.00 eq). Ultimately, the Boc-protected building block 16 was converted to the final Fmoc- $\beta^{3}$-D-Lys(CA)-OH (17) with a yield of $77 \%$. After adjusting KABATAS GLOWACKI's synthetic route, further syntheses of these building blocks were executed and kindly provided by B. WORBS. 
<smiles>NCCCC[C@H](CC(=O)O)NC(=O)OCc1ccccc1</smiles>

11

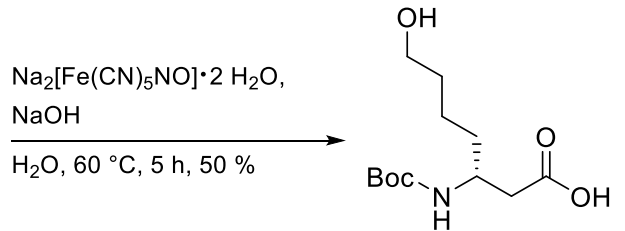

14

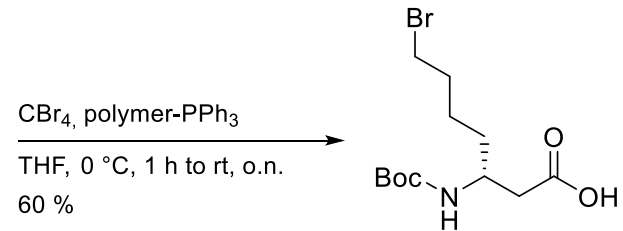

15

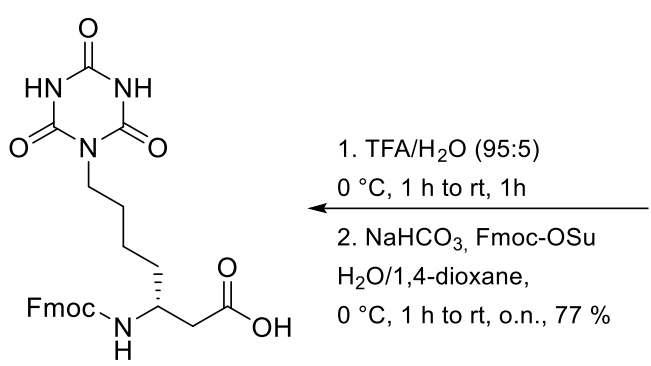

17

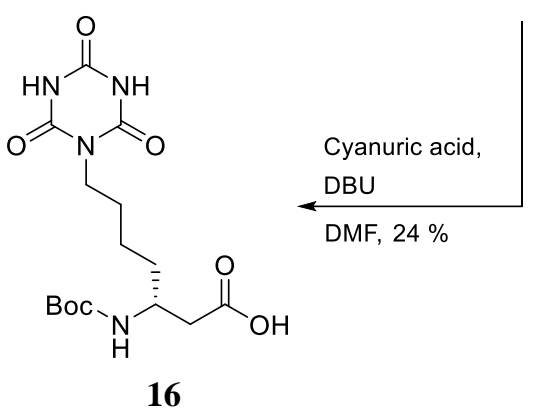

Scheme 5: Synthetic route for the cyanuric acid functionalized building block 17. First, the side chain amine of key intermediate $\mathbf{1 1}$ was transformed into a hydroxyl group, followed by conversion to the bromo compound 15. Then, nucleophilic substitution takes place, resulting in the Boc-protected building block 16. Similar to the melamine functionalized building block, changing the protection group to Fmoc results in the final building block 17.

\subsubsection{Synthesis and Labeling of Artificial $\beta$-Peptides}

Having all necessary $\beta^{3}$-D-amino acids at hand, peptide synthesis was achieved by manual microwave-assisted solid-phase peptide synthesis (SPPS) according to the standard Fmocprotocol. First developed by MERRIFIELD, this method allows a progressive elongation of amino acid chains with ease (Scheme 6). ${ }^{[120,121]}$ Based on a polymeric resin, amino acids can be attached stepwise while impurities and side products, which are not bound to the solid phase, can be separated by simple washing of the resin with organic solvent. For all peptides in this work, a low loaded NovaPEG rink amide resin with an occupancy of 170-200 $\mu \mathrm{mol} / \mathrm{g}$ was used. After initial swelling in DMF for $2 \mathrm{~h}$, the first amino acid was coupled. In general, $\beta^{3}$-D-amino acid activation was achieved by using HATU (5.00 eq) and HOAt (5.00 eq) in DMF, followed by addition of DIPEA (10.0 eq) in NMP. Non-converted $N$-termini of the growing peptide chain were acetylated after every coupled amino acid with a mixture of $\mathrm{Ac}_{2} \mathrm{O}$ and NMP $(1: 4, v / v)$ in order to keep aborted sequences short, which facilitates later on purification procedures. Fmoc-deprotection was carried out by using DBU, piperidine and NMP $(1: 20: 79, v / v / v)$ in two steps. For every amino acid, double coupling was performed which is especially important for the later stages of peptide synthesis (ten amino acids and 
more), since the coupling efficiency significantly decreases with longer sequences. ${ }^{[122]} \mathrm{Be}-$ tween every step of SPPS, multiple washing steps with $\mathrm{MeOH}$ and DMF were performed. Final cleavage of the peptide from the resin was achieved by using a cleavage cocktail, consisting of TFA, TIS and ultra-pure water (95:2.5:2.5, $v / v / v)$. In the case of automated SPPS, another coupling step with DIC (10.0 eq), Oxyma (5.00 eq) and DIPEA (0.50 eq) was added. Further experimental details can be found in chapter 6, SOP5 and SOP7.

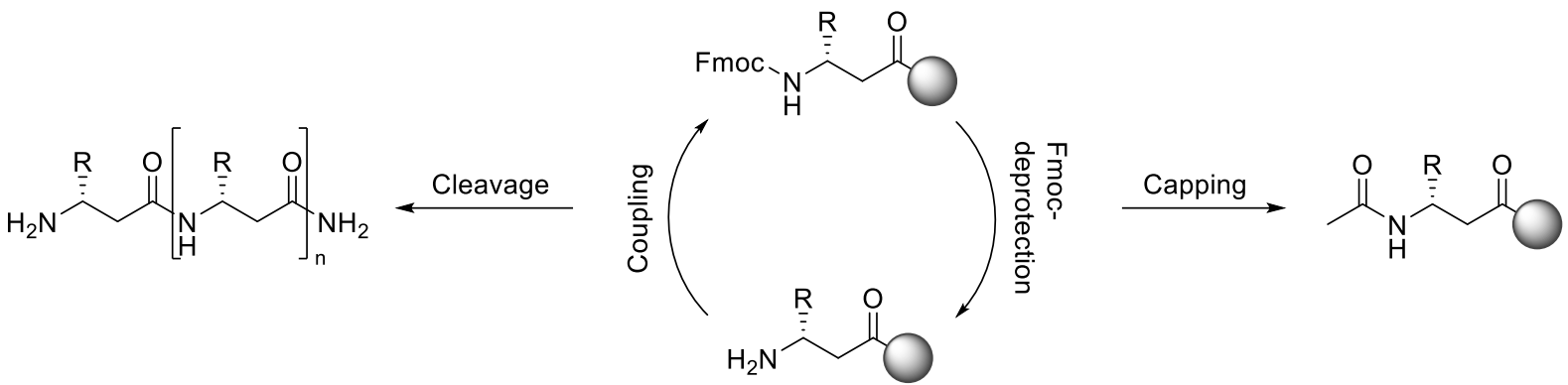

Scheme 6: Schematic procedure of solid-phase peptide synthesis. Fmoc-protected amino acids, which are bound to the resin (grey sphere), can be deprotected by the use of DBU, piperidine and NMP, resulting in an unprotected $N$-terminus. At this stage, amino acid coupling can take place by activation with HATU, HOAt and DIPEA. After amino acid coupling, non-reacted $N$-termini are acetylated with $\mathrm{Ac}_{2} \mathrm{O}$ in a capping step to prevent further side reactions. Once the final sequence is achieved, cleavage from the resin with TFA, TIS and water leads to the crude peptide.

For the synthesis of $\mathbf{1}$ and $\mathbf{2}$, eight different amino acids were used. As necessary in SPPS, an orthogonal protecting group strategy was utilized by using $N$-terminally Fmoc-protected amino acids. Since deprotection of Fmoc can be carried out under basic conditions, respective side chains were protected with Boc protection groups, which can be cleaved under acidic conditions. For the initial, $C$-terminal $\beta^{3}$-D-lysine moiety another side chain protecting group had to be chosen in order to deprotect and modify it selectively after coupling of the sequence. In this case, the Mtt-protection group was utilized, which is cleaved in slightly acidic conditions while maintaining orthogonality of the used protecting groups. Thereby, it can be selectively deprotected by using low amounts of acid, whereas Boc-protecting groups remain attached. According to this strategy, Fmoc- $\beta^{3}-\mathrm{D}-\mathrm{Lys}(\mathrm{Mtt})-\mathrm{OH}$, Fmoc- $\beta^{3}-\mathrm{D}-$ Lys(Boc)-OH, Fmoc- $\beta^{3}$-D-Trp(Boc)-OH, Fmoc- $\beta^{3}$-D-Val-OH, Boc- $\beta^{3}$-D-Lys(CA)-OH, Boc- $\beta^{3}$-D-Lys(M)-OH, Fmoc- $\beta^{3}$-D-Lys(CA)-OH and Fmoc- $\beta^{3}$-D-Lys(M)-OH were used to obtain both peptides. Since it is literature-known that deprotection of the Mtt-protecting group can also lead to Fmoc-deprotection, Boc-protected building blocks 12 and $\mathbf{1 6}$ were 
used for final $N$-terminal coupling instead. ${ }^{[123]}$ As already mentioned, initial analyses of aggregation were planned to be executed by utilizing FRET measurements. Therefore, two fluorophores had to be attached to the sequence after deprotection of the $C$-terminal lysine moiety. Mtt-deprotection was carried out by using a mixture of TFA, DCM and MeOH $(1: 98: 1, v / v / v)$ overnight (also see SOP8).

To attach TAMRA, the dye (5.00 eq), DIC (10.0 eq) and Oxyma (5.00 eq) were added in DMF to the resin, followed by microwave-assisted heating to $65^{\circ} \mathrm{C}$ for $1 \mathrm{~h}$ and excessive washing (Figure 17). However, in multiple attempts only traces of product could be observed and isolated after cleavage. Alternative reaction conditions like the use of PyBop and DIPEA or PyAOP and HOAt did not lead to product formation.

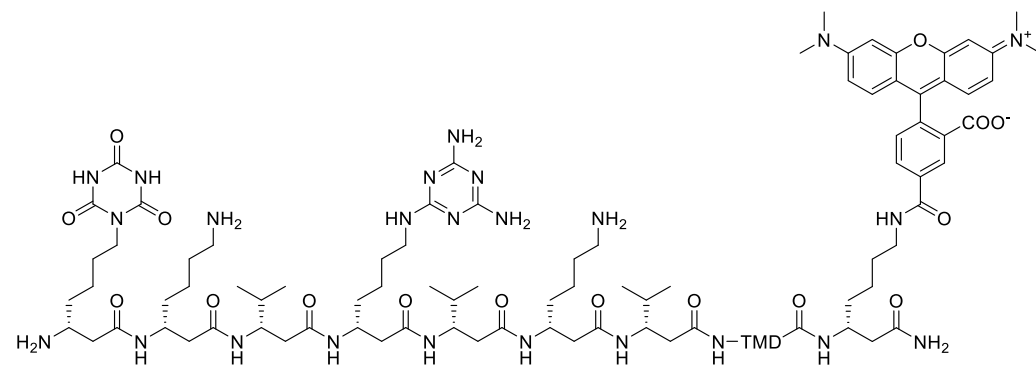

18

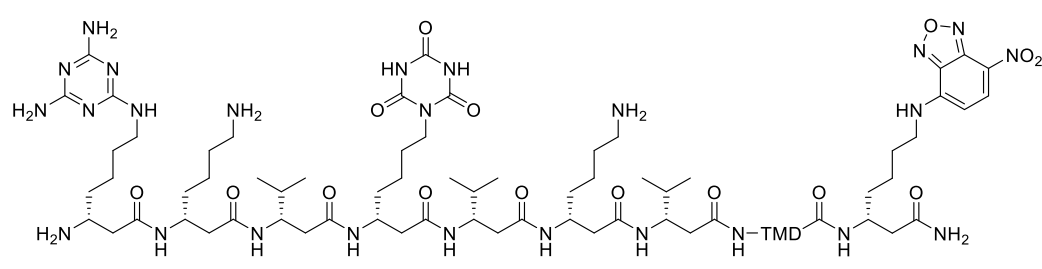

19

Figure 17: Structures of $C$-terminally labeled $C A \cdot M \beta$-peptides. TAMRA-labeling was only achieved in traces, whereas NBD-labeling did not show conversion at all. TMD represents the transmembrane domain sequence.

For the NBD labeled peptide, neither the use of NBD-Cl nor NBD-F were successful. Here, one can assume that NBD labeling is in general more challenging since a nucleophilic substitution takes place instead of amide bond formation as in the case of TAMRA labeling. Afterwards, test labeling without any $\mathrm{CA} \cdot \mathrm{M}$ building blocks was performed in order to examine their influence on labeling reactions. Indeed, when labeling the transmembrane only, successful conversion was observed. This leads to the assumption that labeling of the peptides interferes with the aromatic building blocks. According to this, the labeling strategy was changed to first labeling the transmembrane, followed by subsequent elongation with 
the building blocks. In order to achieve this strategy, a different temporary, $N$-terminal protection group than Fmoc had to be used. Since the Fmoc-protecting group is also cleaved upon Mtt-deprotection, $p$-nitrobenzyloxycarbonyl (pNZ) was used instead. pNZ is another carbamate group which is cleaved in reducing conditions. ${ }^{[124]}$ In order to incorporate this protecting group, a pNZ- $\beta^{3}$-D-valine moiety was synthesized and added to the sequence (Scheme 7). Upon Mtt-deprotection, labeling with NBD was successful with the use of NBD-F (5.00 eq) and DIPEA (20.0 eq) in DMF. Subsequent pNZ-deprotection was achieved by adding $6 \mathrm{M} \mathrm{SnCl}_{2}$ and $1.6 \mathrm{mM} \mathrm{HCl} /$ dioxane in $\mathrm{DMF}$.

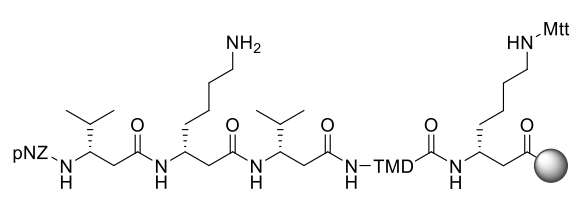

1) Mtt-deprotection 2) NBD-labeling 3) pNZ-deprotection 4) Cleavage

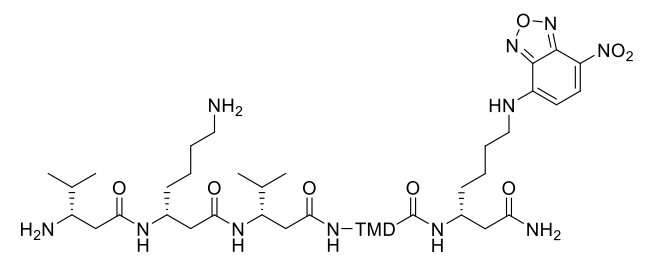

20

Scheme 7: Labeling of the pNZ-protected transmembrane domain. First, the Mtt-protecting group was cleaved, followed by NBD-labeling with NBD-F. pNZ deprotection lead to the free $N$-terminus, which was then further modified in SPPS. TMD represents the transmembrane domain.

After thorough washing, the labeled and deprotected peptide $\mathbf{2 0}$ could be observed after test cleavage. However, further coupling of the CA·M building blocks to the already labeled transmembrane domain was not successful.

After not being able to pair $C$-terminal labeling with the building blocks, the Mtt-protected lysine moiety was attached to the $N$-terminus instead. On the one hand, labeling directly in proximity to the building blocks can enhance the interactions between the building blocks and the dye even more. On the other hand, locating the reaction site further away from the resin can also significantly increase coupling efficiency, gaining spatial accessibility. However, these attempts were also not successful in terms of product formation.

Since FRET measurements would only show initial aggregation of the CA·M modified building blocks in the first place, further labeling strategies were not executed. Additional possibilities would have been the attachment of the dyes directly to lysine moieties, followed by use in SPPS or use even more reactive dye species, like the TAMRA-NHS ester. In the case of NBD, a carboxylic acid linker could be introduced to the aromatic ring in order to obtain labeling via amide bond formation. Instead, peptides $\mathbf{1}$ and $\mathbf{2}$ were resynthesized and used without any labeling for further measurements, directly aiming towards the potential 
channel formation of aggregates with different assays. In addition, the pure transmembrane domain 21 was synthesized for later on comparisons with the $\mathrm{CA} \cdot \mathrm{M}$ modified peptides (Figure 18).

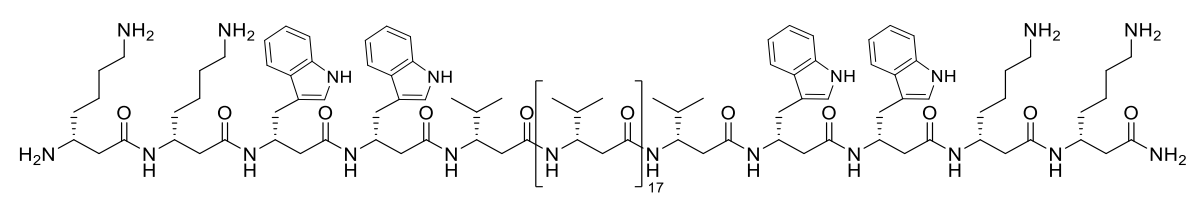

21

Figure 18: Chemical structure of the non-modified transmembrane domain 21, which was synthesized for the comparison with CA·M modified peptides.

For peptides 1, 2 and 21, successful synthesis was characterized by high resolution mass spectrometry (HR-MS) and CD spectroscopy (Figure 19). Both CA·M modified peptides as well as the transmembrane domain itself show a zero crossing at 195-200 nm, with minima at $190-195 \mathrm{~nm}$ and maxima at 203-210 $\mathrm{nm}$. According to literature, this clearly indicates $14-$ helix formation. ${ }^{[63,126,127]}$

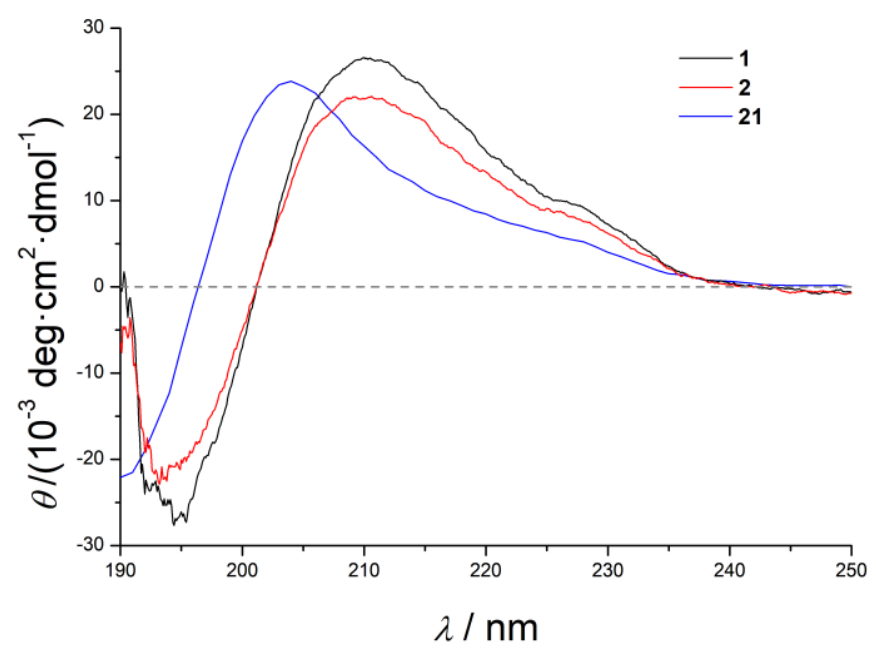

Figure 19: $\mathrm{CD}$ spectra of $\mathrm{CA} \cdot \mathrm{M}$ modified peptides $\mathbf{1}$ and $\mathbf{2}(20 \mu \mathrm{M})$ as well as the transmembrane domain 21 $(50 \mu \mathrm{M})$ in $\mathrm{MeOH}$ at $25^{\circ} \mathrm{C}$. All peptides show minima at $190-195 \mathrm{~nm}$ with a zero crossing at $195-200 \mathrm{~nm}$ and maxima at 203-210 $\mathrm{nm}$. All spectra were normalized according to GREENFIELD. ${ }^{[128]}$ 


\subsection{Proton Translocation by Membrane-Incorporated Transmembrane $\beta$-Peptides}

\subsubsection{Proton Transport Assays}

Due to the attachment of fluorophores to peptides $\mathbf{1}$ and $\mathbf{2}$ not being successful, analysis methods other than FRET had to be performed. Therefore, direct addressing of potential channel activity of the two peptides was considered. Since the cavity of $\mathrm{CA} \cdot \mathrm{M}$ rosettes is known to have a diameter of approximately $4 \AA$, these transmembrane peptides could enable transport or permeability of small ions across the membrane. ${ }^{[14]}$ Characterization and properties of biochemical channels can be determined, for example, by conductivity or fluorescence measurements. ${ }^{[129,130]}$

Just recently, SCHILLING et al. analyzed lugdunin, a thiazolidine peptide with antimicrobial activity. ${ }^{[131]}$ By execution of two different fluorescence assays, it was shown that membrane activity is present in the form of proton translocation. On the one hand, dye leakage assays revealed that membrane disruption or destabilization is not induced by lugdunin. On the other hand, proton translocation was reported in a proton gradient experiment, based on the use of a $\mathrm{pH}$ sensitive pyranine dye. In order to analyze membrane activity of CA·M modified peptides in terms of channel formation in lipid membranes, both experiments were executed with equimolar amounts of $\mathbf{1}$ and $\mathbf{2}$ as well as with the transmembrane domain $\mathbf{2 1}$ with different peptide to lipid (P/L) ratios. Both analyses were adapted and executed by D. RUPPELT from the STEINEM group.

For the proton transport assay, POPC vesicles, filled with 5 mM HEPES buffer at $\mathrm{pH} 7.4$, $100 \mathrm{mM} \mathrm{KCl}$ and $500 \mu \mathrm{M}$ pyranine, were prepared. Therefore, a stock solution of POPC in chloroform was transferred to a small test tube and dried under a nitrogen stream at $30{ }^{\circ} \mathrm{C}$. After further drying overnight under reduced pressure, the resulting lipid film was rehydrated with a pyranine-buffer solution and extruded 31 times to obtain vesicles with a size of roughly $200 \mathrm{~nm}$. Extravesicular dye which remained in the aqueous environment was removed via size exclusion chromatography, followed by determination of the residual lipid concentration with a phosphate test (for further experimental details see chapter 6.3.3). Then, the lipid solution was transferred to a quartz glass cuvette and diluted with fluorophore-free HEPES buffer with a pH different from 7.4 to obtain a total lipid concentration of $50 \mathrm{~mm}$. 
According to this setup, a $\mathrm{pH}$ gradient between the inside of the vesicles and the outer solution was obtained before adding the peptides. Thereby, either buffer with $\mathrm{pH} 6.4$ or 8.4 was used to dilute the vesicles, depending on whether proton influx or efflux should be monitored. For example, when using pH 6.4 in the outer-vesicle environment, the influx of protons into the vesicle can be observed after addition and incorporation of channel proteins (Figure 20). Protons can translocate into the vesicle, resulting in a decrease of the innervesicle $\mathrm{pH}$. Present pyranine reacts to this change of environment with a decreasing fluorescence intensity. ${ }^{[132]}$ In the case of dilution with $\mathrm{pH} 8.4$, an increase of fluorescence intensity can be seen, indicating proton efflux. In both measurements, pyranine excitation was performed at $458 \mathrm{~nm}$ with time-course recording of the emission intensity at $512 \mathrm{~nm} .{ }^{[131]}$

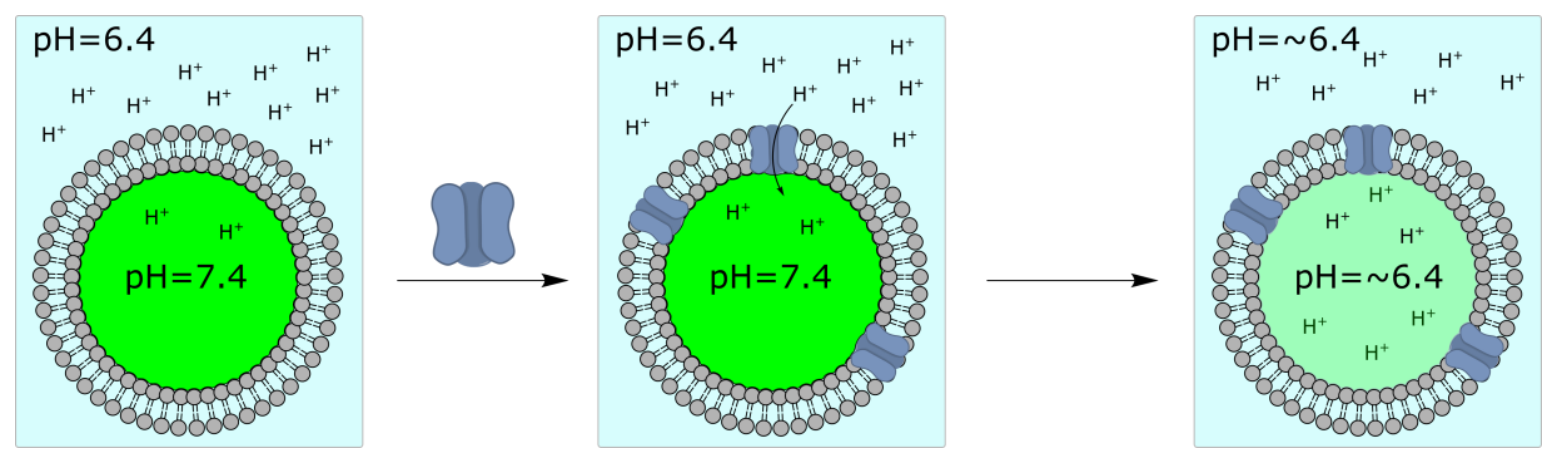

Figure 20: General view on proton transport assays. Vesicles with an inner $\mathrm{pH}$ of 7.4 are surrounded by HEPES buffer with $\mathrm{pH}$ 6.4. Upon addition in iPrOH or DMSO, channel peptides or proteins are incorporated into the membrane, leading to equilibration of the $\mathrm{pH}$ gradient. Resulting in a lower $\mathrm{pH}$ inside the vesicles, the pyranine emission intensity decreases.

For the measurements of peptides $\mathbf{1}$ and $\mathbf{2}$ and also the transmembrane domain $\mathbf{2 1}$, vesicles were diluted in the cuvette to a volume of $792 \mu \mathrm{L}$. Then, stock solutions of peptides in iPrOH or DMSO with different concentrations were added to the vesicles, resulting in different peptide to lipid ratios. Thereby, $8 \mu \mathrm{L}$ of peptide stock solution were used, keeping the organic solvent content at $1 \%$. As expected, proton influx in the case of an outer $\mathrm{pH}$ of 6.4 can be observed by decreasing intensity of the pyranine dye (Figure 21). Furthermore, an effect of different peptide to lipid ratios on the emission intensity was observed. The P/L ratio of 1:1000 shows a less significant intensity decrease compared to 1:500 and 1:100. For an outer $\mathrm{pH}$ of 8.4, proton efflux results in an increase of the observed emission intensity. However, concentration dependent trends are not as prominent. The curves of P/L ratios of 1:500 and 1:100 seem identical, meaning that the same amount of protons are translocated 
during this experiment. This could be explained by the fact that the peptides do not fully incorporate into the membrane. Incomplete incorporation would mean that the actual peptide concentration is not consistent and therefore no concentration dependent assumptions can be made. Also $p$-xylene-bis( $N$-pyridinium bromide) (DPX), a pyranine quenching agent, was added after the efflux of protons, leading to a slightly decreasing intensity (see appendix). This indicates that there is only a minor amount of pyranine present in the outer medium. Therefore, significant membrane disruption by the peptides and leakage of pyranine can be ruled out.

a)

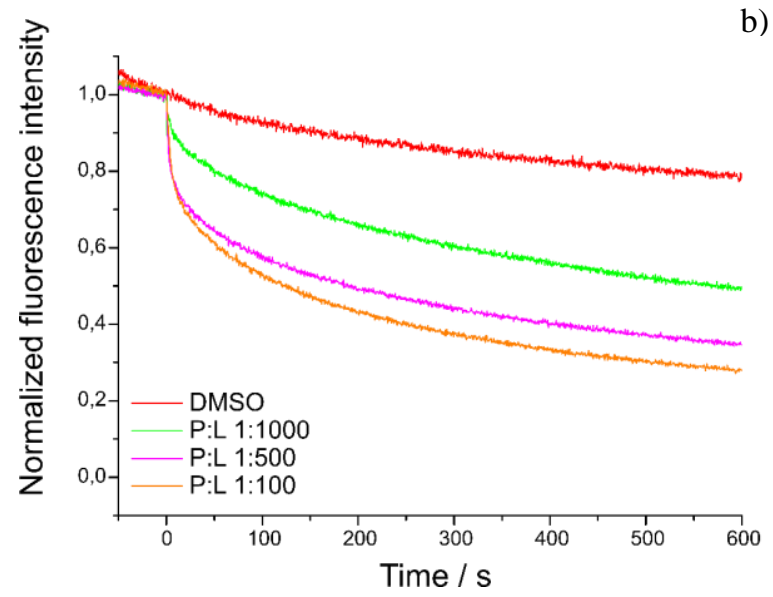

b)

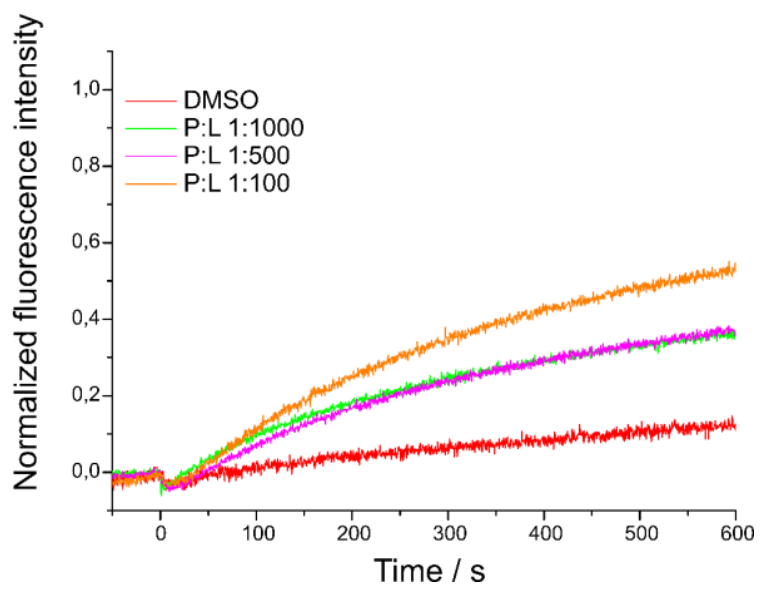

Figure 21: Proton transport assay results for CA·M modified peptides 1 and 2. a) Using an outer $\mathrm{pH}$ of 6.4 , protons rush into the vesicle upon peptide addition, leading to a decrease of intensity. b) An outer $\mathrm{pH}$ of 8.4, leads to a decrease of proton concentration in the vesicle, resulting in an increasing intensity.

In order to evaluate the influence of the $\mathrm{CA} \cdot \mathrm{M}$ building blocks on the proton assays, the results were compared with the pure transmembrane domain 21, applying the same assay with identical conditions. Surprisingly, the non-functionalized peptide shows the same tendency in terms of proton translocation (Figure 22). Proton influx as well as efflux was monitored with the proton transport assay. Also, the addition of DPX shows that no significant membrane destabilization takes place and that pyranine is not crossing the lipid membrane (see appendix). The results of both experiments suggest that the proton transport of synthesized $\beta$-peptides can be assigned to the transmembrane part of the 14-helix and is not induced by the CA·M aggregation. Therefore, further measurements focused on the analysis of the pure transmembrane peptide 21. Another observation after optimization of the transport assays was clear concentration dependency for P/L ratios in the range of 1:500 to 1:1000. 
a)

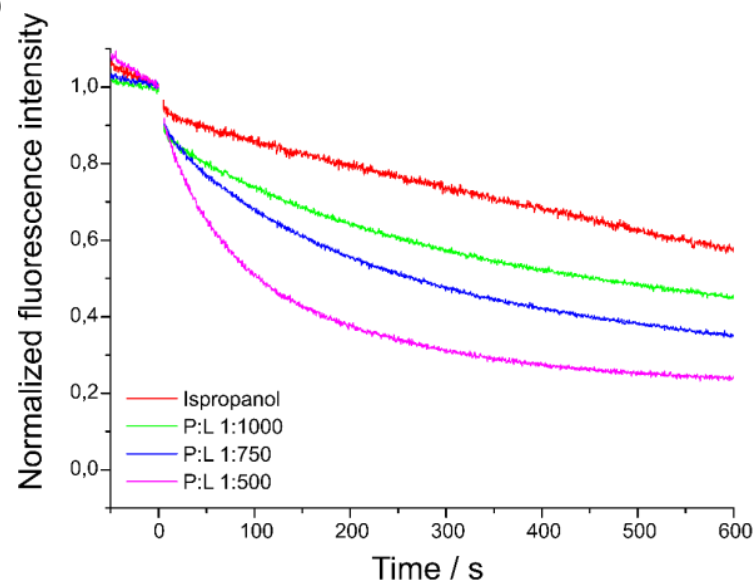

b)

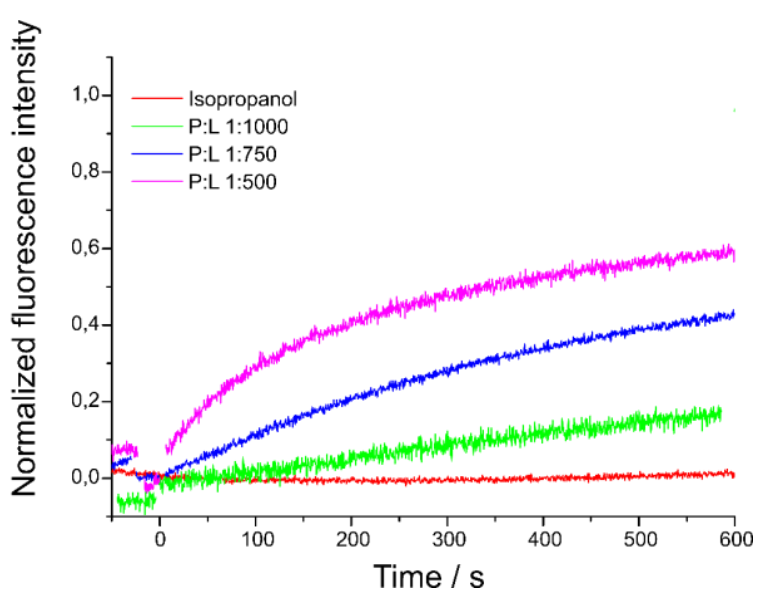

Figure 22: Optimized proton transport assay results for transmembrane domain 21. a) Using an acidified outermembrane solution, protons rush inside the vesicles, lowering the pyranine intensity. b) Applying more basic conditions, protons move from the vesicle to the outer environment, increasing the pyranine intensity.

\subsubsection{Dye Leakage Assays}

In order to further test the effect of the peptide addition on the membrane stability, a dye leakage assay was performed. Since carboxyfluorescein is self-quenching in higher concentrations, it can be used to determine the leakiness of lipid membrane vesicles. ${ }^{[131,133]}$ In addition, carboxyfluorescein is smaller than the pyranine dye. If the leakage of carboxyfluorescein is ruled out, leakage of pyranine is also not expected.

For this experiment, POPC vesicles were prepared, containing 20 mM HEPES and $100 \mathrm{mM}$ carboxyfluorescein instead of pyranine. As long as the dye remains inside the vesicle, the high concentration leads to a low observable fluorescence signal. Once carboxyfluorescein passes the membrane, dilution in buffer leads to a significantly increasing fluorescence signal. To guarantee that the occurring signal is only contributed by leaking dye, the prepared vesicles were purified via size exclusion chromatography, removing any excessive dye in the outer buffer solution. After determination of the remaining phosphate concentration, a total lipid concentration of $50 \mathrm{~mm}$ was used for the measurements.

Indeed, the initial assumption, that the membrane stays intact upon peptide addition, was confirmed, since the increase of carboxyfluorescein intensity for $\mathrm{P} / \mathrm{L}$ ratios from 1:500 to 1:1000 ranges from 1-3 \% (Figure 23). Only in the case of 1:100, a slightly more prominent 
leakage of $10 \%$ can be observed.

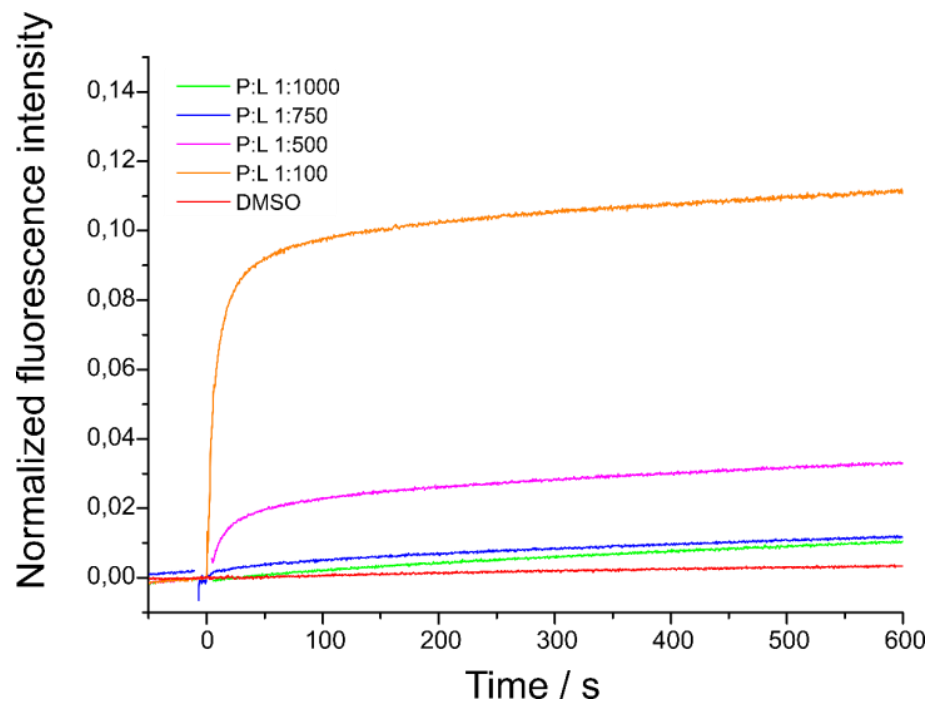

Figure 23: Dye leakage assay after addition of the transmembrane domain 21. P/L ratios ranging from 1:500 to $1: 1000$ show low amounts (1-3\%) of leaking dye, indicating that no significant membrane destabilization takes place. Even in the case of a P/L ratio of 1:100, only $10 \%$ of leakage can be observed.

\subsubsection{IR Measurements}

Since all preliminary work on transmembrane $\beta$-peptides was carried out by preparing lipid films with peptides, it remained to be shown that peptide addition to already formed vesicles leads to incorporation into the lipid membrane. ${ }^{[12,74]}$ For this purpose, attenuated total reflectance (ATR) measurements were performed by D. RUPPELT in order to prove that the results of the proton transport and dye leakage assays are caused by incorporated peptides. The so-called amide I vibration gives a signal ranging from $1600-1700 \mathrm{~cm}^{-1} .{ }^{[134]}$ Majorly contributed by $\mathrm{CO}$ stretching, this signal can be used to detect present proteins and peptides. Here, the transmembrane domain $\mathbf{2 1}$ was added to a suspension of POPC vesicles and incubated for $30 \mathrm{~min}$. Non-incorporated peptides were removed via size exclusion chromatography before spreading the vesicles on a germanium ATR-IR crystal. Thereby, multiple bilayers were obtained and examined (Figure 24). The POPC spectrum shows additional peaks in the amide I vibration range, the main peak being at roughly $1650 \mathrm{~cm}^{-1}$. According to KOZUCH, this region corresponds to either helical structures or to random coils. ${ }^{[135]}$ However, the high stability of 14-helices leads to the assumption of helical structures within the POPC bilayers. With this, successful incorporation of the transmembrane domain was shown. 

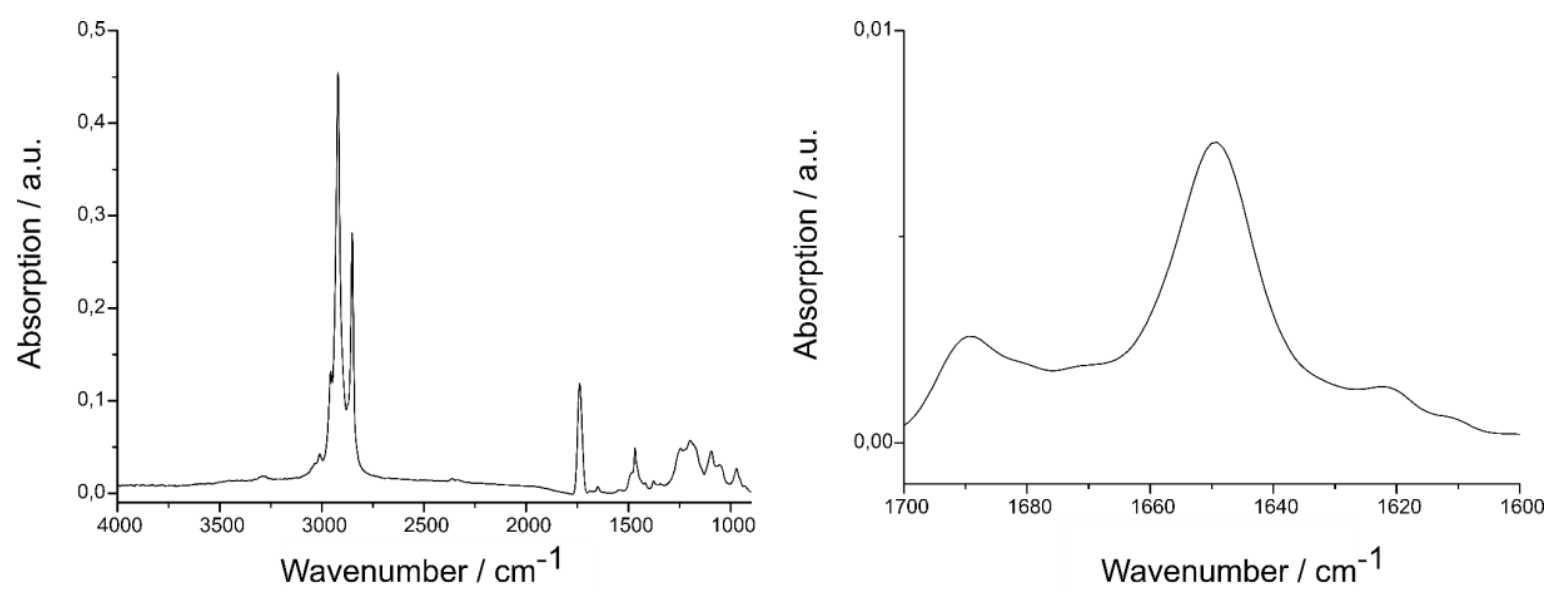

Figure 24: IR spectrum of the transmembrane domain after incorporation into POPC vesicles and spreading bilayers on an IR crystal. The signal at $1650 \mathrm{~cm}^{-1}$, which can be seen in the enhanced view, can be assigned to $\mathrm{CO}$ stretching of the amide I vibration, indicating incorporated peptides.

\subsection{FRET-based Aggregation Studies of Transmem- brane $\beta$-Peptides}

The results from the proton transport assay indicate that protons are passing the membrane upon peptide addition. Also transmembrane peptide incorporation was shown according to IR measurements. Since concentration dependency of the proton transport curves was observed, one can assume that this translocation relies on selective and reproducible interactions with potential channel structures being present. In order to examine the nature of these interactions, FRET measurements were utilized to determine the FRET efficiency of labeled transmembrane domains. With this assay, aggregation of the transmembrane peptides can be monitored. In previous work, STOLLBERG labeled these transmembrane domains with TAMRA and NBD for FRET efficiency measurements. There, no aggregation was found, since only a low amount of occurring FRET was observed. ${ }^{[12]}$ The peptides were designed in a way that their fluorophores face the same direction upon antiparallel organization of the transmembrane domain. In order to investigate if the orientation of the fluorophore has an influence on the self-assembly, the here used peptides were all labeled $N$-terminally. If antiparallel aggregation occurs, they would face opposite directions after incorporation into lipid bilayers. However, major differences in both approaches are not expected since antiparallel 
organization for $\beta$-peptides was only proven when nucleobases are present. ${ }^{[136,137]}$ In the case of the transmembrane model system, the peptides are almost symmetrical except for the attached fluorophore. Thus, there is no driving force for anisotropy with only the dipole moments of the peptides being able to contribute to a preferential orientation of organization.

For the execution for FRET measurements, three different transmembrane peptides had to be synthesized (Figure 25, for further details see section 6.4.3). Peptide 22 represents the TAMRA labeled transmembrane domain and peptide $\mathbf{2 3}$ the NBD labeled moiety, both contributing to the measurement as the respective FRET pair. The acetylated peptide $\mathbf{2 4}$ was needed in order to keep the total peptide concentration consistent throughout all experiments. For labeling of the $N$-terminal lysine moiety, Boc- $\beta^{3}$-D-Lys(Fmoc)-OH (25), which was kindly provided by N. HESSELBARTH, was used for selective deprotection at the labeling site.

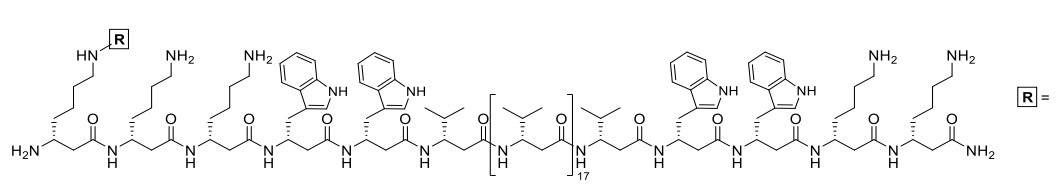

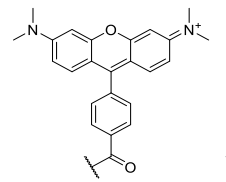

22

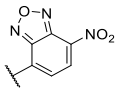

23

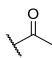

24

Figure 25: Modified transmembrane domain with an additional, $N$-terminal $\beta^{3}$-D-lysine moiety. Usage of Boc$\beta^{3}$-D-Lys(Fmoc)-OH leads to the possibility of orthogonal Fmoc deprotection and selective side-chain labeling.

FRET measurements were performed by keeping the total lipid concentration at $2.5 \mathrm{~mm}$ and using a P/L ratio of 1:500. From there, the mole fraction $\chi$ of the NBD labeled peptide was kept at 0.50 . The amount of TAMRA labeled peptide was varied from 0.00 to 0.50 in five steps. When necessary, the acetylated peptide was added to keep the total peptide concentration constant in all measurements. The NBD dye was excited at $464 \mathrm{~nm}$, recording the emission spectra from $500 \mathrm{~nm}$ to $650 \mathrm{~nm}$ (Figure 26). As expected, the NBD emission at $530 \mathrm{~nm}$ decreased when higher amounts of TAMRA labeled peptides were present. Successful FRET leads to the presence of a new TAMRA emission at around $570 \mathrm{~nm}$, increasing with every measurement. 
a)

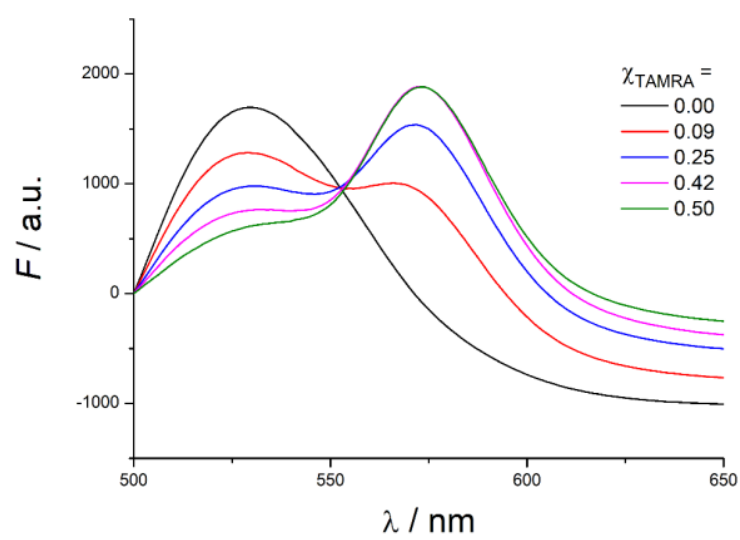

b)

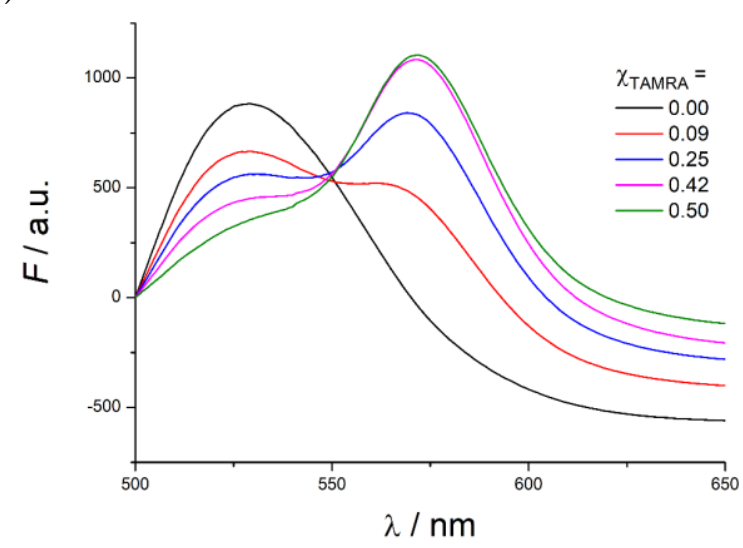

Figure 26: FRET curves for varying amounts of TAMRA labeled peptide at $25{ }^{\circ} \mathrm{C}$ (a) and $60{ }^{\circ} \mathrm{C}$ (b). The concentration of NBD-labeled peptide was kept at $\chi=0.50$ while adding the acetylated peptide to keep the total peptide concentration constant.

In order to distinguish between statistically occurring FRET and an aggregation-induced effect, the FRET efficiency was calculated. Therefore, the NBD emission at $530 \mathrm{~nm}$ for every respective measurement was divided by the emission at $530 \mathrm{~nm}$ with $\chi($ TAMRA $)=0.00$. According to this method, the aggregation state of glutamine modified transmembrane domains was determined by STOLLBERG (ROST) et. al. ${ }^{[1]}$ There, a FRET efficiency drop to $60 \%$ with same amounts of NBD and TAMRA labeled peptides $(\chi=0.50$ each $)$ indicated that only monomers are present. However in the experiments of this work, the FRET efficiency drops to roughly $36 \%$ for the same measurement (Figure 27). According to STOLLBERG, this value is in the range of a monomer-trimer equilibrium, indicating clear signs of transmembrane domain aggregation. ${ }^{[11,12]}$ In addition, almost the same behavior can be found for the measurement at $60{ }^{\circ} \mathrm{C}$. In line with the proton transport assays, peptidepeptide interaction was found which leads to the assumption that aggregation of these domains is likely. However, the different outcome in comparison to STOLLBERG's work is still unclear. Since the only difference was the $N$-terminal attachment of TAMRA, such major differences were not expected. An explanation could be that the orientation of the peptides plays a role for the aggregation of transmembrane $\beta$-peptides. If antiparallel aggregation was favorable, the sterical demand of the fluorophores could have an impact on the aggregation. In the setup of this work, the fluorophores would face different sides of the lipid membrane, inducing FRET while not being spatially constraint. In the case of STOLLBERG's work, the fluorophores would face the same direction if antiparallel aggregation takes place. 


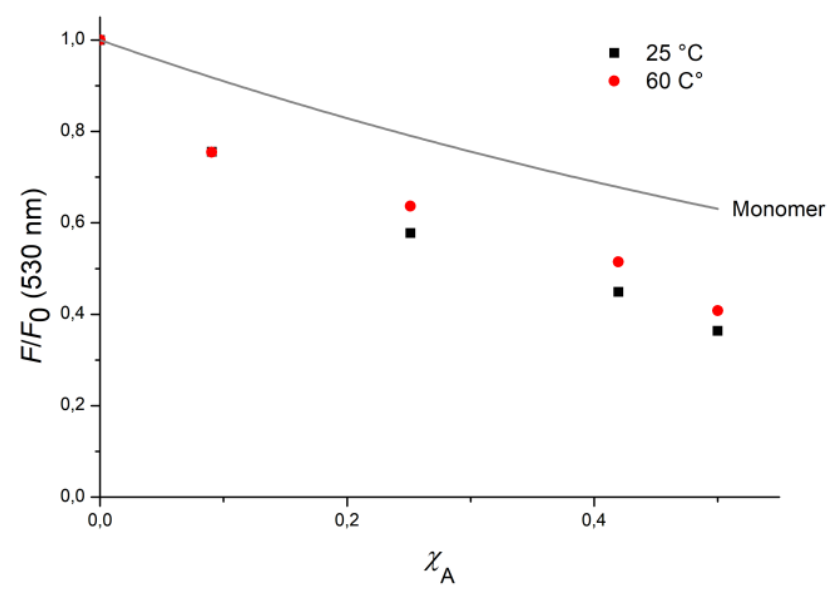

Figure 27: FRET efficiency data for the transmembrane domain at $25^{\circ} \mathrm{C}$ and $60{ }^{\circ} \mathrm{C}$. Data were acquired by dividing the NBD emission $F$ at $530 \mathrm{~nm}$ of respective FRET curves by the emission $F_{0}$ at $530 \mathrm{~nm}$ without any TAMRA peptide present. The grey line depicts the FRET efficiency with no aggregation of the peptides according to WOLBER et al. Statistical FRET efficiency data were kindly provided by STOLLBERG. ${ }^{[1,12]}$

There, sterical hindrance would be more influential. In order to reveal more information about the anisotropy of the transmembrane domain aggregation, one could replace NBD and TAMRA with a FRET-pair that has a lower FÖRSTER radius. Then, one would only observe FRET if the fluorophores face the same direction.

\subsection{Conductance of Lipid Bilayers with Incorporated Transmembrane $\beta$-Peptides}

The previous shown experiments indicate that the transmembrane $\beta$-peptides indeed form aggregates in lipid membranes, being capable of triggering proton translocation. In addition to these experiments, the influence of the transmembrane domain on the conductivity of lipid bilayers was analyzed in collaboration with A. MAZNICHENKO from the POHL group.

In various studies, the conductance of lipid membranes has been examined, especially with channel proteins being present. ${ }^{[129,139,140]}$ There, single opening events as well as the change in conductivity after establishing a charge gradient over the membrane can be analyzed in order to determine possible channel activities of peptides and proteins. ${ }^{[141]}$ In regard to this work, the transmembrane $\beta$-peptide 21 was also examined in terms of ion conductivity. A 
change of conductivity upon establishing a $\mathrm{pH}$ gradient across lipid membranes would indicate the presence of channel- or carrier-like aggregation of transmembrane $\beta$-peptides, confirming the previous results. Therefore, free-standing lipid bilayers were created on a small teflon septum $(120-180 \mu \mathrm{m})$ by the Mueller method. ${ }^{[142,143]}$ Buffers with $\mathrm{pH} 5.7$ or $\mathrm{pH} 5.2$ were used, depending on the measurement. Bilayer formation itself was confirmed by optical observation as well as capacitance measurements. Then, the transmembrane peptides were added in $\mathrm{iPrOH}$ to both sides of the bilayers and incubated for $40 \mathrm{~min}$ at $\mathrm{rt}$.

For low concentrations of the transmembrane domain $(25 \mathrm{nM})$, conductivity changes were measured and compared to a theoretical value, obtained by the NERNST potential (equation 3.1). ${ }^{[144]}$ The experimental NERNST potential for a $\mathrm{pH}$ gradient of 0.5 is equal to the shift of the reversal potential, since there is no gradient of other ions present. Thereby, currentvoltage properties were monitored with an applied voltage ramp signal from $-60 \mathrm{mV}$ to $+60 \mathrm{mV}$. In order to obtain an ion gradient across the membrane, $\beta$-alanine solution $(3 \mathrm{M})$ was added on one side of the membrane, resulting in $\mathrm{pH}$ values of 5.2 and 5.7, respectively.

$$
V=\frac{R T}{F} \cdot \ln \left(\frac{\left[\mathrm{H}^{+}\right]_{\text {outer }}}{\left[\mathrm{H}^{+}\right]_{\text {inner }}}\right)
$$

Using the universal gas constant $R$, a temperature of $295.15 \mathrm{~K}$, FARADAY's constant $F$ and transferring the $\mathrm{pH}$ values into proton concentrations according to $\left[\mathrm{H}^{+}\right]=10^{-\mathrm{pH}}$, the NERNST potential gives a value of $29.25 \mathrm{mV}$ for this setup. Measurements were carried out without a proton gradient at $\mathrm{pH} 5.2$ to obtain current-voltage curves, followed by the same measurement with an applied $\mathrm{pH}$ gradient of 0.5 on one side of the membrane. The shift in reversal potential can be found by determining the shift of the intersections with the X-axis. First measurements were carried out by using $50 \mathrm{~mm}$ potassium chloride buffer as well as $0.1 \mathrm{mM}$ MES (Figure 28). Comparison of the measurements with and without an applied $\mathrm{pH}$ gradient leads to a potential shift of $9.02 \mathrm{mV}$ instead of the expected $29.25 \mathrm{mV}$. On the one hand, this could be explained by the peptides not being able to conduct ions across the membrane to a sufficient extent. On the other hand, the translocation of other ions than protons would also lead to such a result, since it was not considered in the calculation of the NERNST potential. In order to examine the latter, the buffer was first changed to $50 \mathrm{~mm}$ potassium sulfate buffer, excluding the potential translocation of chloride ions (Figure 28). However, this experiment 
also leads to a similar potential shift of $13.66 \mathrm{mV}$, meaning that chloride ions are probably not conducted by the transmembrane peptides.

a)

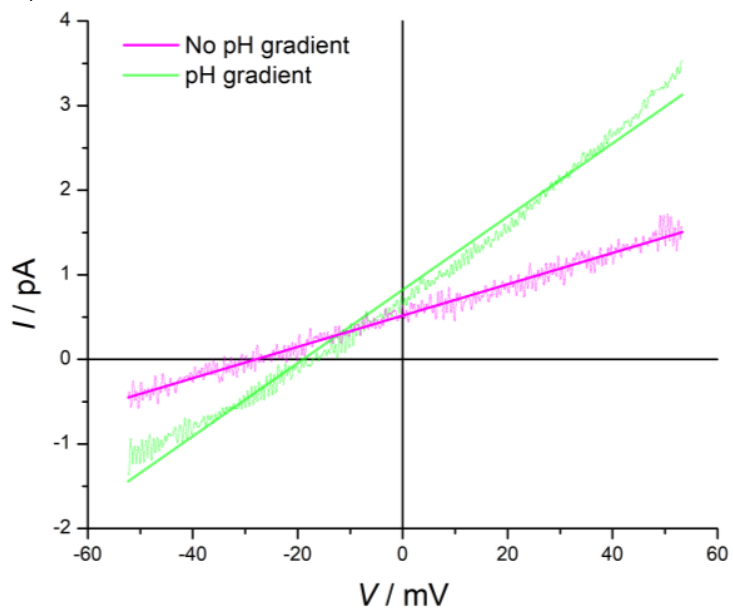

b)

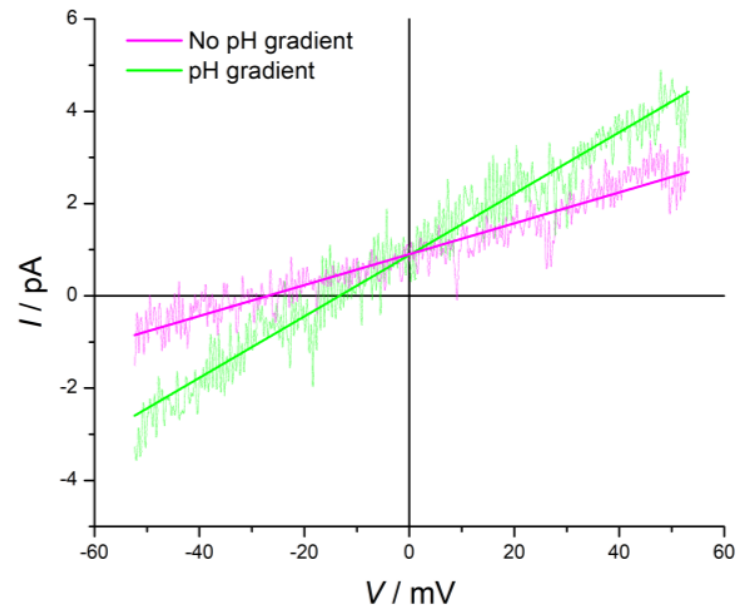

Figure 28: Current-voltage characteristics of lipid bilayers with incorporated transmembrane $\beta$-peptide 21 (25 nM) before applying a pH gradient. a) The use of $50 \mathrm{mM} \mathrm{KCl}$ buffer results in a potential shift of $9.02 \mathrm{mV}$. b) Changing the buffer to $50 \mathrm{mM}$ potassium sulfate buffer leads to a shift of the reversal potential of $13.66 \mathrm{mV}$.

Furthermore, $50 \mathrm{~mm}$ choline chloride buffer was used to analyze if potassium leads to different shifts in the potential. Indeed, for this measurement a potential shift of $28.44 \mathrm{mV}$ has been found which is in agreement with the expected value of $29.25 \mathrm{mV}$ (Figure 29). According to this result, one can assume that potassium ions contribute to the potential shift, therefore are also translocated by the used peptides. However, it has to be mentioned that the used concentration of potassium ions in the buffer $(50 \mathrm{mM})$ is much higher than the concentration of the protons $(\sim 2-6 \mu \mathrm{M})$, which could be leading to a much more prominent influence on the measurement. In terms of potassium transport, the translocation could be induced by the applied charge gradient due to the addition of $\beta$-alanine solution. Surprisingly, in the measurements with potassium containing buffer (Figure 28), the establishment of a pH gradient leads to an increased conductivity. This can be determined by the steeper slope of the current-voltage curve, since a more prominent change of current can be observed with the same change of voltage. 


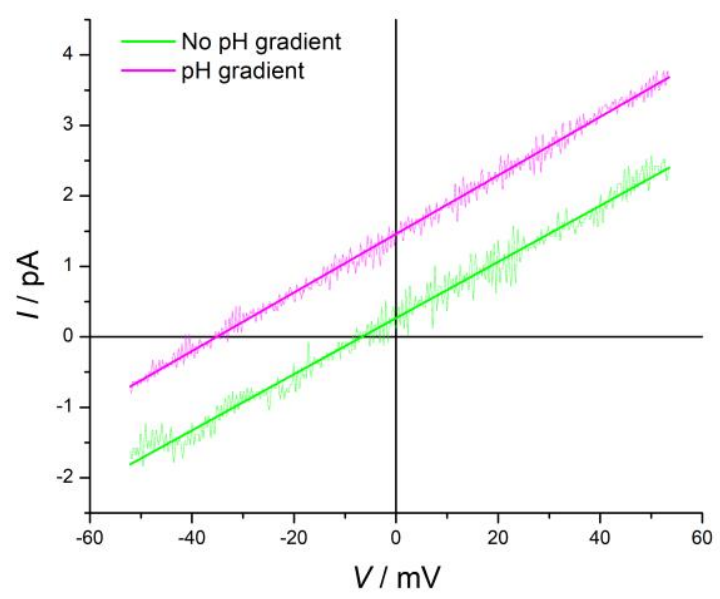

Figure 29: Current-voltage characteristics of lipid bilayers with incorporated transmembrane $\beta$-peptide 21 $(25 \mathrm{nM}$ ) before and after applying a $\mathrm{pH}$ gradient. The shift in reversal potential was found to be $28.44 \mathrm{mV}$.

In general, one would expect less conductivity for the measurements with a $\mathrm{pH}$ gradient. Assuming that the $\beta$-alanine and hydroxide ions are not able to cross the lipid membrane, there are less transportable protons present at $\mathrm{pH} 5.2$ and $\mathrm{pH} 5.7$ than at $\mathrm{pH} 5.2$ on both sides. However, this phenomenon cannot be observed with no potassium present (Figure 29). Since more translocation seems to take place with less transportable ions, the assumption can be made that there could be a competitive behavior between protons and potassium ions.

In general, the enhanced and channel-like conductivity with higher amounts of potassium ions in the solution could be possibly explained by electrostatic interactions between the carbonyl oxygen atoms of the peptides and the potassium itself, similar to KcsA, a potassium channel in Streptomyces lividans. ${ }^{[145]}$ There, stabilization of the aggregates can take place by potassium ions, leading to higher conductivities of the membrane.

In addition, measurements with application of a constant voltage of $150 \mathrm{mV}$ were carried out. Here, higher concentrations of potassium ions (1 $\mathrm{M} \mathrm{KCl}$ buffer) as well as peptides (100 nM) were used to observe the resulting current (Figure 30).

Here, clear channel activity can be seen in up to three opening stages. In comparison to the other conductivity measurements, the rate of ion conduction seems to be significantly higher, resulting in distinct channel opening events. However, the exact influence of potassium ions and mechanism of ion conduction are still under discussion, since no active transport is expected with the present sequence. Also, channel activity was tested for lower $\mathrm{pH}$ values. Here, no opening events could be observed. It has to be mentioned that no potassium was present in the low $\mathrm{pH}$ measurement, so the exact reason for the absence of channels is not 
clear. Subsequent experiments are currently executed by A. MAZNICHENKO. Further examination whether ion translocation occurs with similar ions like sodium or magnesium is still in progress.

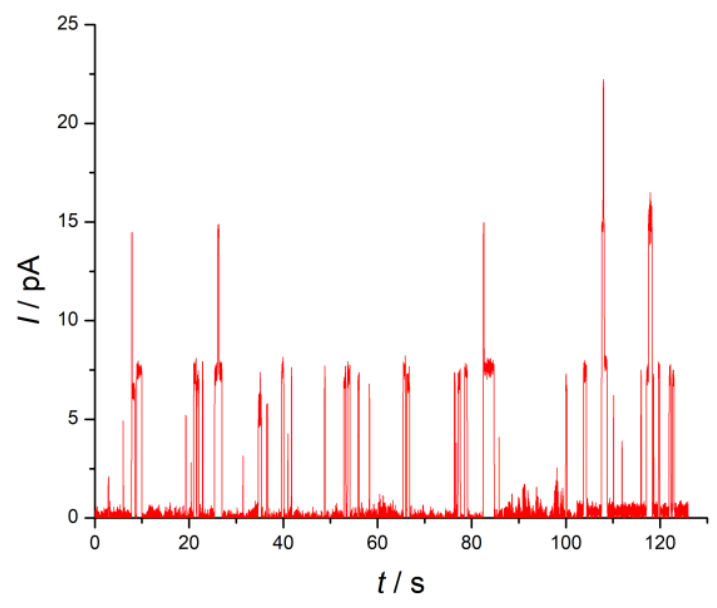

Figure 30: Time-resolved currents after applying a constant voltage of $150 \mathrm{mV}$ to both sides of the membrane with the incorporated transmembrane domain 21 (100 nM) with $1 \mathrm{M} \mathrm{KCl}$ buffer. Resulting channel opening events can be observed in different stages.

With these additional measurements, the selectivity of these channels can be determined. In order to gain more insight into the aggregation state of the transmembrane domain within lipid bilayers, FCS measurements have to be performed. There, after labeling of the transmembrane domain with Alexa488, the brightness of incorporated assemblies could reveal the aggregation state. Especially, measurements in dependency on the potassium concentration would be of interest. 


\subsection{Conclusion}

In the work of this chapter, transmembrane $\beta$-peptides were synthesized, inspired by extensive preliminary studies in the DIEDERICHSEN group. ${ }^{[12,74,90]}$ First, transmembrane peptide functionalization with cyanuric acid (CA) and melamine (M) was achieved by manual SPPS with an orthogonal protecting group strategy. Beforehand, all of the necessary $\beta^{3}$-D-amino acids were synthesized in sufficient yields. $\mathrm{CA} \cdot \mathrm{M}$ modified building blocks were synthesized according to KABATAS GLOWACKI with slight adjustments. ${ }^{[13]}$ For FRET analysis, labeling attempts of the CA.M modified transmembrane domains with TAMRA and NBD were performed in different approaches. However, no fluorophore attachment could be obtained. Subsequently, the peptides were synthesized without any labels for a variety of assays, directly aiming at potential channel activities of the modified transmembrane domain. In proton transport assays, performed by D. RUPPELT, proton translocation was monitored upon addition of the modified transmembrane peptides. Surprisingly, comparison with the pure, non-modified transmembrane domain lead to the same results. Therefore, further measurements were only performed with the standard model system. In addition to general proton transport, concentration dependency of the translocation on the used peptide concentration was observed. In order to gain insight in possible aggregation states of the transmembrane domain, which could enable this proton transport, FRET efficiency measurements were carried out similar to STOLLBERG (ROST) et al. ${ }^{[11]}$ A significant decrease in FRET efficiency was found in these experiments, indicating clear signs of peptide aggregation. Moreover, conductivity measurements of the transmembrane peptides were performed by A. MAZNICHENKO. Applying a $\mathrm{pH}$ gradient across the membrane, low concentrations of peptides induced a change of conductivity. Both, protons and potassium ions, appear to be contributing to the translocation process. Higher peptide concentrations in high-salt buffer even showed clear channel opening events. Combining the results of all performed assays, clear indication of peptide aggregation was found as well as the ability to translocate protons and potassium ions across the lipid membrane. According to these results, the $\beta$-peptide transmembrane domain seems to act as a channel- or carrier-like protein in lipid membranes. 


\section{Transmembrane $\beta$-Peptides as Near- Membrane Molecular Rulers}

The outstanding properties of $\beta$-peptides, being precisely modifiable and building up highly ordered 14-helices, lead to various possible applications. In the following chapter, the rigidity and stiffness of these 14-helices are used to introduce the concept of a peptidic molecular ruler. Two different 14-helices were synthesized, Atto643-labeled and, after incorporation into lipid bilayers, analyzed with grapheneMIET in regard to their distance to the substrate surface. The work of this chapter was performed in collaboration with A. SHARMA and is also published in Journal of Peptide Science. ${ }^{[146]}$

\subsection{FRET-based Molecular Rulers}

Since the introduction of the concept of FRET, it has been widely used to investigate biological processes. ${ }^{[147,148]}$ Thereby, the measurement of distinct distances is of special interest since it allows to determine structural and conformational conversions, e.g. of proteins and other biological macromolecules. ${ }^{[149-151]}$ In numerous studies, FRET has been utilized to analyze inter- and intramolecular distances and interactions, even in vivo. ${ }^{[152,153]}$ For instance, the green fluorescent protein (GFP) has been used for live-imaging of cells by analyzing the energy transfer between two GFPs or one GFP and another fluorophore. ${ }^{[154]}$ Thereby, mutants of the wild type generate different spectroscopic properties, being highly suitable for FRET (Figure 31). ${ }^{[155]}$ MIYAWAKI et al. took advantage of these GFPs by attaching two of them (BFP/GFP-pair or CFP/YFP-pair) to calmodulin and M13. ${ }^{[156]}$ Calcium-modulated 
protein (calmodulin) is a 148 residue, calcium-binding protein in the myosin light-chain kinase (MLCK), being responsible for $\mathrm{Ca}^{2+}$ concentration monitoring, whereas M13 is a 26residue synthetic peptide which is binding to the calmodulin. ${ }^{[157-159]}$ Upon addition of $\mathrm{Ca}^{2+}$, folding of the calmodulin around M13 occurred, bringing the GFP labels closer to each other.

a)

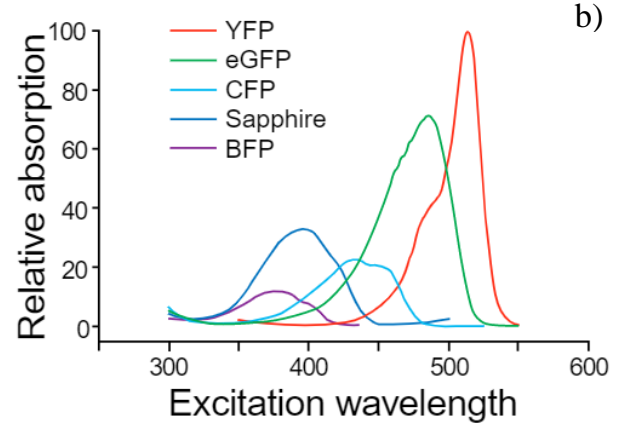

b)

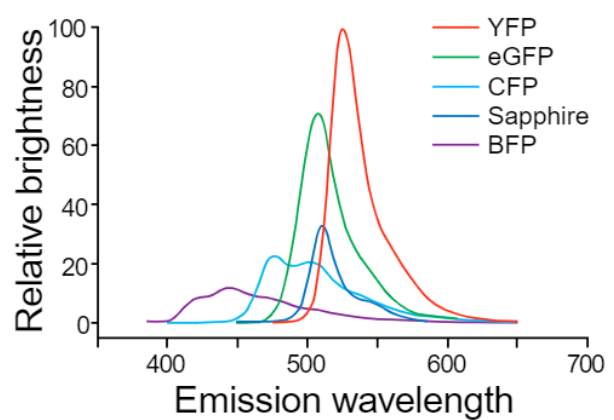

Figure 31: Excitation (a) and emission (b) spectra of modified GFPs: Y(ellow)FP, eGFP, C(yan)FP, Sapphire and B(lue)FP. ${ }^{[155]}$

Thus, the distance between the FRET pair decreased, leading to a more prominent and efficient energy transfer (Figure 32). After this proof of concept, the protein complex was expressed in HeLa cells. On the one hand, they could modulate the $\mathrm{Ca}^{2+}$ affinity of the protein complex by using mutants and on the other hand, they presented the FRET dependency of the $\mathrm{Ca}^{2+}$ concentration. With this, a powerful tool to measure free $\mathrm{Ca}^{2+}$ concentrations in compartments like the endoplasmic reticulum or the cytoplasm was created. ${ }^{[155,156]}$

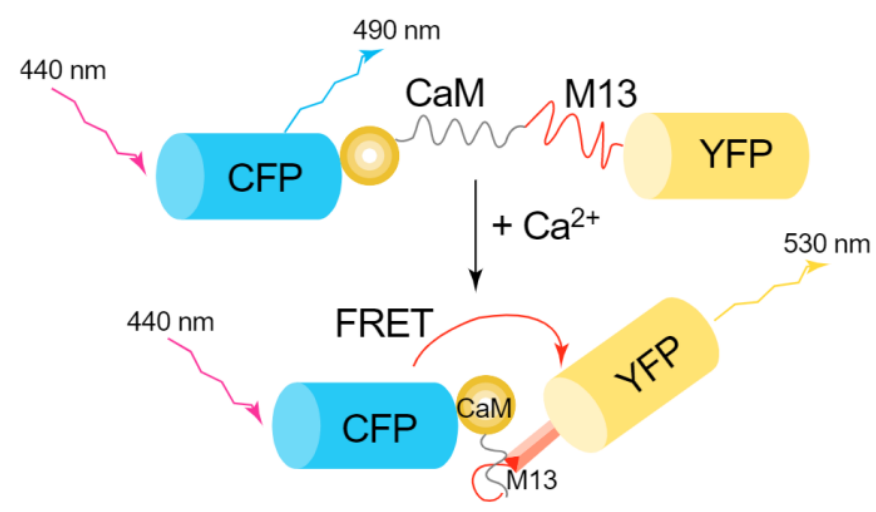

Figure 32: Calmodulin and M13 were $N$-terminally equipped with CFP and $C$-terminally equipped with YFP. Without present $\mathrm{Ca}^{2+}$, the protein complex remains unfolded and shows the CFP emission at $490 \mathrm{~nm}$ upon excitation at $440 \mathrm{~nm}$. After the addition of $\mathrm{Ca}^{2+}$, protein folding occurs, leading to a significantly less distance between CFP and YFP. FRET can take place, resulting in emission at $530 \mathrm{~nm}{ }^{[155,156]}$ 
Following a molecular ruler approach, ZHUANG et al. modified immobilized ribozymes with Cy3 and Cy5 dyes (Figure 33). ${ }^{[160]}$ The 5'-end of a Tetrahymena ribozyme was hybridized to an oligonucleotide with the donor dye. The 3'-end was hybridized to a DNA fragment with the acceptor dye as well as a biotin moiety. Due to the biotin-streptavidin interaction, the protein complex could then be immobilized on a surface. Protein folding and unfolding was followed in terms of FRET. Upon unfolding, FRET revealed a distance of roughly $7 \mathrm{~nm}$, whereas folding lead to distances between 1 and $2 \mathrm{~nm}$.

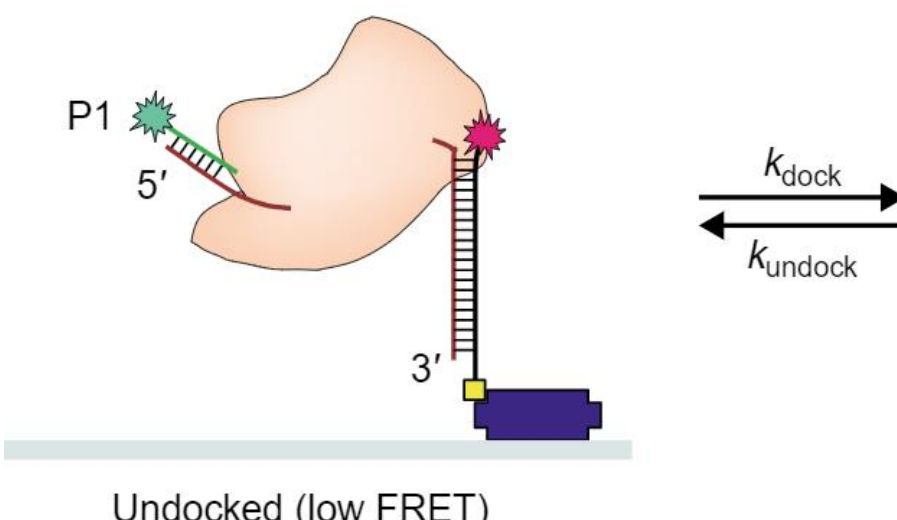

Undocked (low FRET)

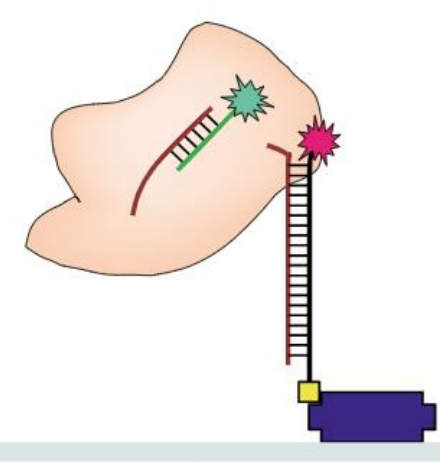

Docked (high FRET)

Figure 33: Schematic representation of the work of ZHUANG et al. The ribozyme is labeled with an oligonucleotide-bound FRET donor (green star) at the 5'-end and with an acceptor at the 3 '-end (red star). The DNA strand which is hybridized to the 3'-end also contains biotin (yellow square) to immobilize the complex on a streptavidin-coated (blue) surface. Upon folding, the distance between donor and acceptor decreases, leading to a more intense FRET signal. ${ }^{[160,161]}$

However, since the application of FRET is limited to the FÖRSTER radius of the respective FRET-pair, long-range molecular rulers have been developed. ${ }^{[162]}$ Applying plasmonic nanoparticle-based surface energy transfer (NSET), it is possible to enhance the measurable distance between two probes up to $100 \mathrm{~nm} \cdot{ }^{[162,163]}$ Other commonly used techniques to obtain end-to-end distance distributions rely on X-ray scattering, NMR or EPR spectroscopy. ${ }^{[17-19,164]}$ Just recently, the concept of MIET and especially grapheneMIET has been introduced into the field of molecular rulers. ${ }^{[165,166]}$ Thereby, distances up to $200 \mathrm{~nm}$ can be analyzed with remarkable resolution and accuracy. 


\subsection{Graphene-based Metal-Induced Energy Transfer}

In order to fully understand biochemical processes, spectroscopic and microscopic techniques have been vastly examined throughout the last century. ${ }^{[165]}$ Thereby, the characteristics of fluorescent dyes are highly dependent on their direct environment. The impact of these surroundings can be for example seen in FÖRSTER resonance energy transfer spectroscopy. ${ }^{[167,168]}$ When matching donor and acceptor fluorophores are in proximity to each other, electromagnetic coupling between them occurs which leads to an energy transfer from the donor to the acceptor. ${ }^{[169]}$ For this to happen, the emission spectrum of the donor has to overlap with the excitation spectrum of the acceptor fluorophore (Figure 34 ). ${ }^{[170]}$ Since the transfer is inversely dependent on the distance of both fluorophores with the power of six, the technique is limited to distances of $1-10 \mathrm{~nm} \cdot{ }^{[147,171,172]}$ However, numerous aggregation studies were performed utilizing this technique both in vitro and in vivo. ${ }^{[173-177]}$

Moving on to microscopy techniques, one has to overcome the natural resolution limit which was first described by ABBE. ${ }^{[178]}$ Techniques like interferometric photoactivated localization microscopy (PALM) and 4pi-stochastic optical reconstruction microscopy (STORM) use switchable fluorophores to surpass this resolution limit easily, reaching an axial accuracy of single fluorophores in the nanometer range. ${ }^{[179-181]}$

a)

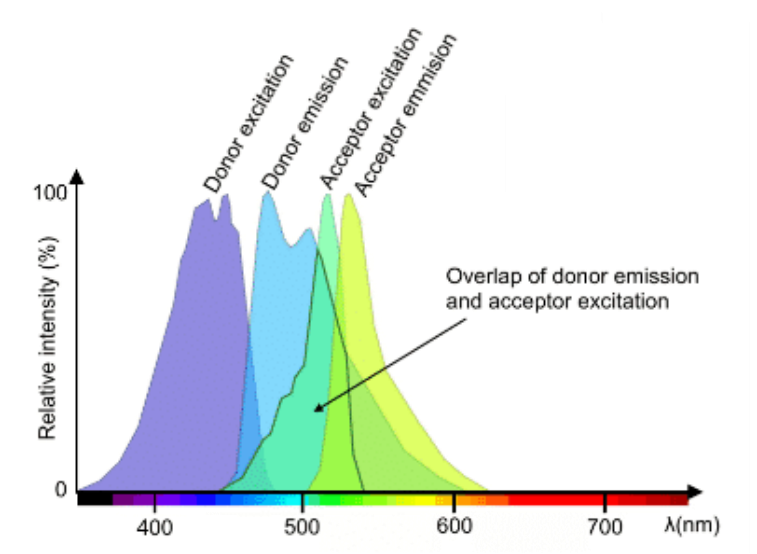

b)

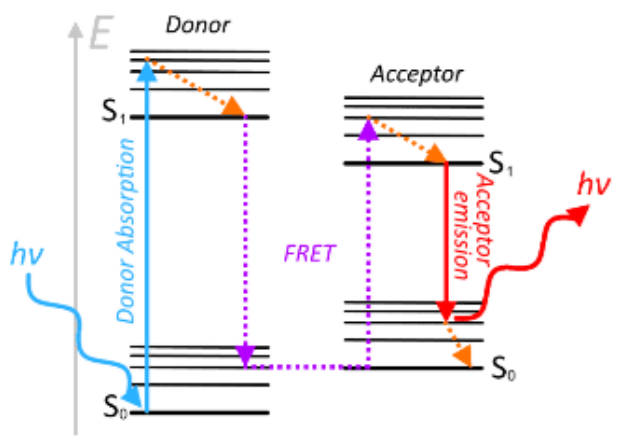

Figure 34: a) A FRET pair is matching when the donor emission is overlapping with the acceptor excitation wavelength, shown for the example of Cerulean and Venus (fluorescent proteins). b) The JABLONSKI diagram representing the FRET effect. The donor is excited to an upper electronic state and emits excess vibrational energy radiationlessly. Afterwards, the emission and relaxation into the ground state is leads to energy transfer from the donor to the acceptor fluorophore by dipole-dipole-interactions. The acceptor also emits excess vibrational energy before emitting a photon and relaxing into the ground state. ${ }^{[182]}$ 
Another feasible method, which also generates axial localization in the nanometer range, is metal-induced energy transfer. In comparison to FRET, fluorescent probes transfer their energy to surface plasmons of a metal film which is coated onto a glass substrate, thereby acting as an acceptor molecule. ${ }^{[165]}$ Due to the energy transfer, the fluorescence lifetime of the probe significantly decreases in dependence of distance to the metal film while the measurement itself is only dependent on the orientation of one dye, not dependent on two dyes like in FRET. With this method, distances up to $200 \mathrm{~nm}$ can be detected and calculated from fluorescence lifetime data. Furthermore, the ENDERLEIN group presented a graphene-based MIET technique, using a single sheet of graphene instead of a metal film. It was shown that the axial accuracy was enhanced almost tenfold, being able to measure thicknesses of lipid bilayers with remarkable resolution. ${ }^{[166]}$ Graphene sheets consist of pure carbon, arranged in a honeycomb structure with $\mathrm{sp}^{2}$ hybridization. ${ }^{[183]}$ Similar to benzene, $\pi$ electrons are delocalized throughout the lattice, with the $2 \mathrm{p}_{\mathrm{x}}$ orbitals being perpendicular to the sheet plane. ${ }^{[184]}$ Thereby emerging optical and electronical properties have been widely examined in the past years. ${ }^{[185-187]}$ The enhanced resolutional ability by performing MIET measurements with single sheets of graphene arises due to the significantly smaller coupling distance of the fluorophores with the graphene. In general, the achievable accuracy for the localization of fluorescent probes can be described depending on the interaction distance $L$ and the number of detected photons $N$ with $L / \sqrt{N}$. With this proportional correlation, the resolution is improved tenfold with the same amount of detected photons, assuming that $L$ is decreased tenfold when using graphene instead of metals in MIET. ${ }^{[166]}$ Experimentally, in grapheneMIET measurements the fluorescent probe is placed above a single sheet of graphene, which is surrounded by a $\mathrm{SiO}_{2}$ spacer and a glass substrate (Figure 35). Assuming the fluorophore to behave like an ideal electric dipole emitter, one can solve MAXWELL's equations to obtain the radiative emission power $S\left(\alpha, z_{0}\right)$, being dependent on the dipole distance $z_{0}$ to the surface and the orientation $\alpha \cdot{ }^{[165,166]}$ Since the fluorescence lifetime $\tau_{\mathrm{f}}$ is inversely proportional to the emission power, it can be expressed with:

$$
\frac{\tau_{\mathrm{f}}\left(\alpha, z_{0}\right)}{\tau_{0}}=\frac{S_{0}}{\Phi S\left(\alpha, z_{0}\right)+(1-\Phi) S_{0}}
$$

Thereby, $\tau_{0}$ describes the free-space fluorescence lifetime and $\Phi$ denotes the fluorescence quantum yield, which has to be considered for non-ideal fluorophores. $S_{0}$ is the emission 
power in free-space (without graphene) which is given by $S_{0}=c n k_{0}^{4} p^{2} / 3$ with $c$ being the speed of light in vacuum, $n$ is the refractive index, $k_{0}$ the wave vector and $p$ the amplitude of the dipole moment. Regarding the orientation $\alpha$, in the case of examining peptides, it can be assumed that fluorescent probes are rotationally diffusing on the substrate due to the carbon linker of respective dyes. This diffusion is expected to be much faster compared to the fluorescence lifetime, meaning that the orientation of the fluorophore can be averaged. The emission power can be expressed by distributing the total emission power into perpendicular $S_{\perp}\left(z_{0}\right)$ and parallel $S_{\|}\left(z_{0}\right)$ amounts in regard to the surface, leading to equation 4.2.

$$
S\left(z_{0}\right)=\frac{1}{3} S_{\perp}\left(z_{0}\right)+\frac{2}{3} S_{\|}\left(z_{0}\right)
$$

According to this, MIET curves can be calculated to give the distance of the fluorophore to the surface, depending on the fluorescence lifetime of the dye (Figure 35).

a)

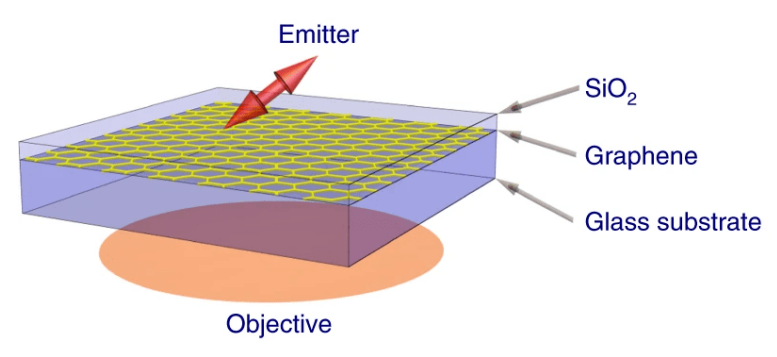

b)

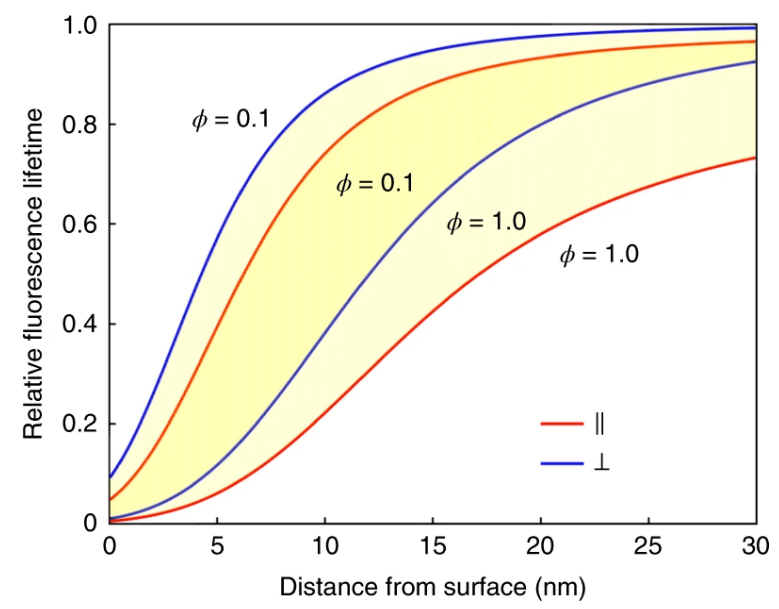

Figure 35: a) GrapheneMIET setup with an emitter being placed above a single sheet graphene which is surrounded by a $\mathrm{SiO}_{2}$ spacer and a glass substrate. b) A general view on the relative fluorescence lifetime depending on the distance $z_{0}$ to the sheet of graphene for quantum yields ranging from $\Phi=0.1$ to $\Phi=1.0$ as well as either parallel or perpendicular oriented emitters. ${ }^{[166]}$

In the context of near-membrane processes, one can clearly see that the application of MIET or grapheneMIET on single molecules can come in very handy to determine axial localization of fluorescent probes. For example, CHIZHIK et al. presented an approach of MIET imaging of the basal lipid membrane of living cells. ${ }^{[188]}$ MDA-MB-231 cells were monitored 
while moving across a surface with an axial resolution of $3 \mathrm{~nm}$. Shortly after, the concept of MIET was applied on single molecules, determining the distance of Atto655 dyes on different heights of $\mathrm{SiO}_{2}$ spacers in remarkable accuracy in the low nanometer range. ${ }^{[189]}$ Regarding grapheneMIET experiments, supported lipid bilayers (SLBs), DLPC and DOPC, were labeled with Atto655 and the respective lifetime data as well as end-to-end distances were measured and calculated. ${ }^{[166]}$ Comparing these results with the literature, the axial accuracy of MIET could be improved to be in the ångström region by using graphene-based MIET imaging. Based on these promising possibilities, grapheneMIET fulfills all requirements to study processes that are dependent on the distance to lipid membranes.

\subsection{Design and Synthesis of Atto643-labeled Transmem- brane $\beta$-Peptides}

The near-membrane environment delivers a fascinating field of research, providing the location for lots of essential biological processes. ${ }^{[190]}$ Especially, distance-dependent sensorial properties across the membrane surface are of interest, since a lot of processes, e.g. SNARE fusion, are linked to near-membrane ion concentrations like calcium or protons. ${ }^{[20,191-193]}$ Also, diseased tissue displays an increased acidic surface compared to its surroundings which delivers an interesting approach for the use of near-membrane $\mathrm{pH}$ sensors. ${ }^{[194]}$

However, determination of those parameters can be quite inaccessible. Bulk measurements can only reveal information across the overall environment, resulting in averaged parameters. Regarding lipid membranes, charges of the lipid head groups often play an important role for the near-membrane environment and function. ${ }^{[195]}$ For example, negatively charged head groups can cause an increased cation concentration in the proximal aqueous phase, comparable to the electrical double layer. ${ }^{[196-199]}$

In order to understand the mechanics and properties of the near-membrane environment, defined spatial placement of probes is key. ${ }^{[190,200]}$ In fact, distance-dependent analysis of the membrane environment can be used to obtain a deeper insight into its function and proximal ion concentrations, which are contributing to vital processes. ${ }^{[16,20]}$ End-to-end distances as well as distance-dependent interactions have been well examined over the course of the last decades. For instance, FRET played an immensely important role in these studies, being a powerful tool to investigate biological processes (also see chapter 4.1). 
Measurements of near-membrane ion concentrations were already examined in numerous studies. ${ }^{[201,202]}$ However, when based on membrane-bound ion sensors, these sensors are limited to the direct surface of the membrane. Therefore, the need for a molecular ruler arises which can be used for placing probes in distinct distances in regard to the lipid membrane. Requirements for this type of ruler can be described as the following:

First, the ruler needs to be structurally rigid, maintaining its straight and well-examined structure in all present environments. Second, when talking about near-membrane measurements, it has to have a defined length with a fixed position in regard to the membrane. With this, positioning of probes as well as the height in respect to the membrane can be controlled. Third, in order to use the ruler for a various number of experiments, it has to be adjustable in length to analyze different membrane distances. Finally, a molecular ruler has to be easily modifiable. Probes need to be attached to the ruler with ease to guarantee versatile applications.

Based on these requirements, 14-helices, as previously used for the organization in lipid membranes (see chapter 3), provide an excellent model system for such a ruler. As already mentioned, 14-helices are highly rigid in the hydrophobic environment. ${ }^{[8]}$ According to the studies of PAHLKE, these helices can also be formed in aqueous solutions if a certain number of amino acids in the sequence is exceeded. ${ }^{[61,74]}$ Also, 14-helices are well understood in their structure, delivering a defined helical pitch of roughly $5 \AA$ with a rise per residue of $1.56 \AA .{ }^{[65,66]}$ Transmembrane 14-helices can therefore be designed in a way that they accord to the membrane thickness and can then be elongated while providing full knowledge about their helical length. Especially, $\mathrm{N}$-terminal modifications with sensors or other functional groups can be easily realized on-resin with numerous known methods. ${ }^{[203-206]}$ As one can see, all established criteria for molecular rulers can be fulfilled by $\beta$-peptide 14 -helices, promoting them for the use in near-membrane investigations.

In order to show a proof of concept, two respective transmembrane 14-helices with an $N$-terminal $\beta$-alanine for labeling were synthesized (Figure 36). The first peptide 26, being shorter in length, consists of the $\beta$-alanine unit and the in chapter 3 described standard transmembrane domain which is built from 19 consecutive $\beta^{3}$-valines, flanked by two $\beta^{3}$-tryptophan and two $\beta^{3}$-lysine moieties each. Peptide 27 represents a sequence elongation by two turns (six amino acids) with an alternating sequence of $\beta^{3}$-valine and $\beta^{3}$-lysine. Since these two turns are representing the extra-membrane elongation after incorporation of the peptide into a DOPC bilayer, it has to be ensured that they also form a 14-helix in the presence of the aqueous medium. Therefore, the elongation design is chosen to be similar to the studies of 
PAHLKE. ${ }^{[74]}$ There, the same alternating sequence in a nona- $\beta$-peptide clearly indicated towards 14-helix formation.

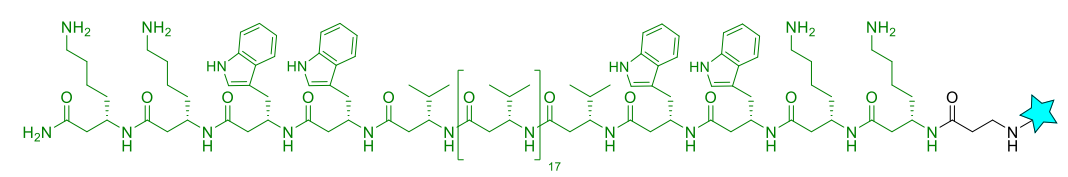

26

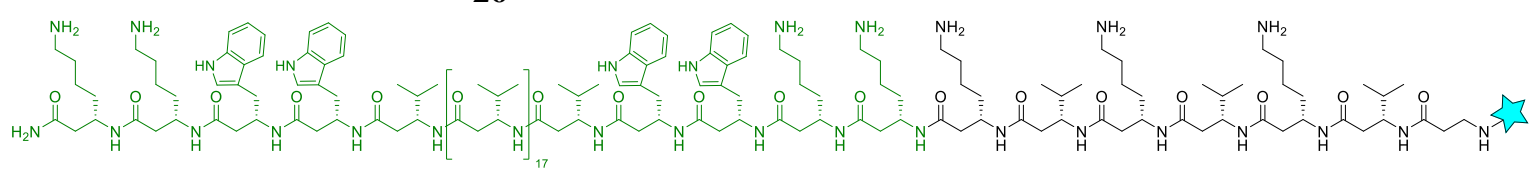

27

Figure 36: Structural design of synthesized 14-helices 26 and 27. The transmembrane part (green) consists of $19 \beta^{3}$-valine units, which are flanked by two $\beta^{3}$-tryptophans and two $\beta^{3}$-lysines each. Sequence elongation of 27 was achieved by introducing an alternating sequence of $\beta^{3}$-lysine and $\beta^{3}$-valine. For the use as molecular rulers, both peptides were modified with an $N$-terminal $\beta$-alanine which was further equipped with Atto643 (cyan star). ${ }^{[146]}$

According to 14-helix dimensions and considering the $16^{\circ}$ helical tilt of transmembrane $\beta$ peptides in DOPC, 26 is calculated to have a height of $4.42 \mathrm{~nm}$ in regard to the bottom leaflet, whereas the height of $\mathbf{2 7}$ is calculated to be $5.36 \mathrm{~nm}$ (Figure 37). ${ }^{[10,146]}$ Thereby, it is assumed that 27 is also tilted by $16^{\circ}$.

For analyzing the functionality of a 14-helix molecular ruler, the advantages of precise and accessible grapheneMIET measurements were utilized in cooperation with A. SHARMA from the ENDERLEIN group. Therefore, the peptides were $N$-terminally labeled with a fluorophore in order to facilitate energy transfer from the dye to the graphene surface. After consideration of the fact that the dye has to be mono-exponential, indicating only one excited state, different dyes were tested. Since other synthesized peptides with carboxyfluorescein or TAMRA labeling turned out to be not suitable for the use of grapheneMIET, Atto643 was used instead. Atto643 is a mono-exponential and $\mathrm{pH}$ independent dye, which has already utilized in various biochemical studies. ${ }^{[207-209]}$ 


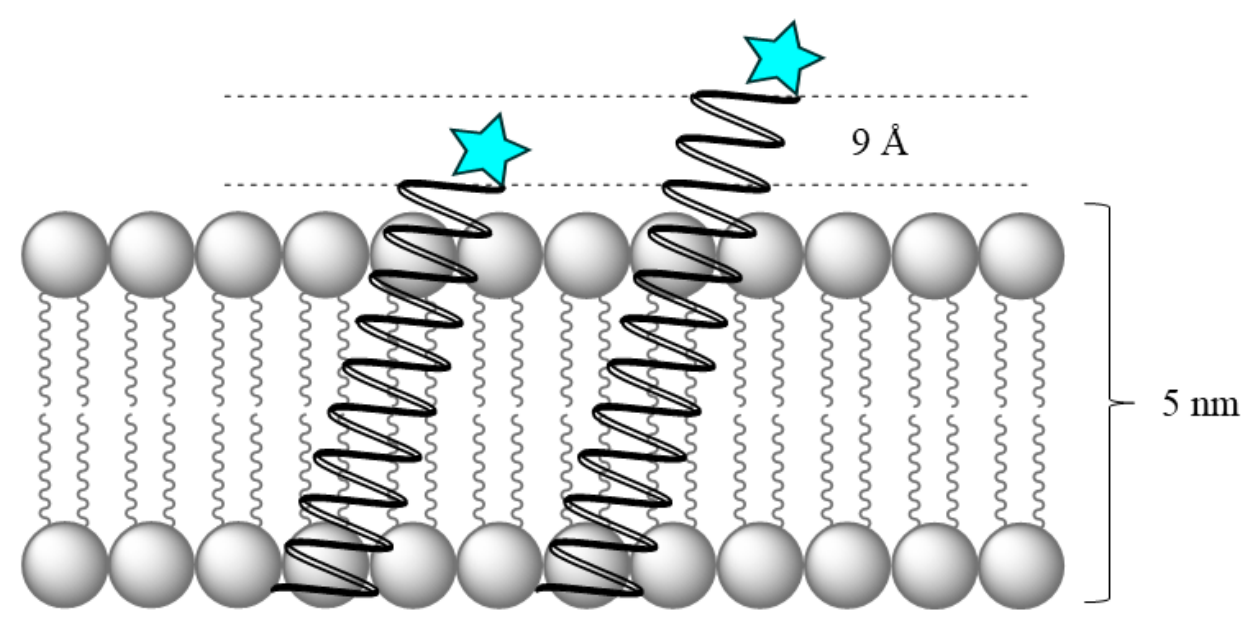

Figure 37: Schematic view on the concept of 14-helical molecular rulers. Two peptides were synthesized, consisting of the transmembrane domain and an Atto643 dye (cyan star). After incorporation into DOPC bilayers with a thickness of approximately $5 \mathrm{~nm}$, the respective dyes are in defined distances in regard to the lipid membrane. Thereby, the elongated peptide $\mathbf{2 7}$ shows a greater distance from the bottom leaflet compared to peptide 26. According to the $16^{\circ}$ tilt of 14-helices in DOPC membranes, this results in a theoretical height difference of approximately $9 \AA^{[10,146]}$

Peptide synthesis was achieved via manual SPPS according to chapter 3.2.3. Based on NovaPEG rink amide resin with an occupancy of $200 \mu \mathrm{mol} / \mathrm{g}, \mathbf{2 6}$ and 27 were synthesized by using orthogonally protected $\beta^{3}$-amino acids (5.00 eq) to guarantee full compatibility with the Fmoc-strategy. Therefore, Fmoc- $\beta^{3}$-D-Val-OH, Fmoc- $\beta^{3}$-D-Lys(Boc)-OH and Fmoc- $\beta^{3}$ D-Trp(Boc)-OH were synthesized via the ARNDT-EISTERT-homologation, starting from their respective $\alpha$-analogues.

After $N$-terminal coupling of Fmoc- $\beta$-alanine for both peptides, microwave-assisted Fmocdeprotection was performed with a solution of NMP, piperidine and DBU (79:20:1, v/v/v). The resulting unprotected $N$-terminus was then labeled with Atto643 in order to make the peptides accessible for grapheneMIET measurements. Therefore, adapting the recommendations from Aтто-TeC GmBH, Atto643-NHS ester (0.81 eq) was dissolved in dry and amine-free DMSO $(400 \mu \mathrm{L})$ and added to the resin. ${ }^{[210]}$ Activation took place by adding DIPEA (4.00 eq), followed by microwave-assisted heating to $37{ }^{\circ} \mathrm{C}$ for $2 \mathrm{~h}$. Afterwards, the resin was mechanically shaken overnight at $37{ }^{\circ} \mathrm{C} .{ }^{[146]}$ The labeled resin was then washed with $\mathrm{DMF}$ and $\mathrm{MeOH}(15 \times 5 \mathrm{~mL})$ and cleaved with a mixture of TFA/ $\mathrm{H}_{2} \mathrm{O} / \mathrm{TIS}(95: 2.5: 2.5$, $v / v / v)$. Evaporation of the solvent in a nitrogen stream, precipitation in cold diethyl ether and further purification via HPLC lead to $\mathbf{2 6}$ and $\mathbf{2 7}$, respectively.

Both peptides were verified via mass spectrometry and their capability of 14-helix formation 
was shown by CD spectroscopy (Figure 38). According to literature, these helices show minima at roughly $195 \mathrm{~nm}$, zero crossings at $200 \mathrm{~nm}$ and maxima at $210 \mathrm{~nm}$, indicating successful right-handed 14-helix formation. ${ }^{[63,126,127]}$

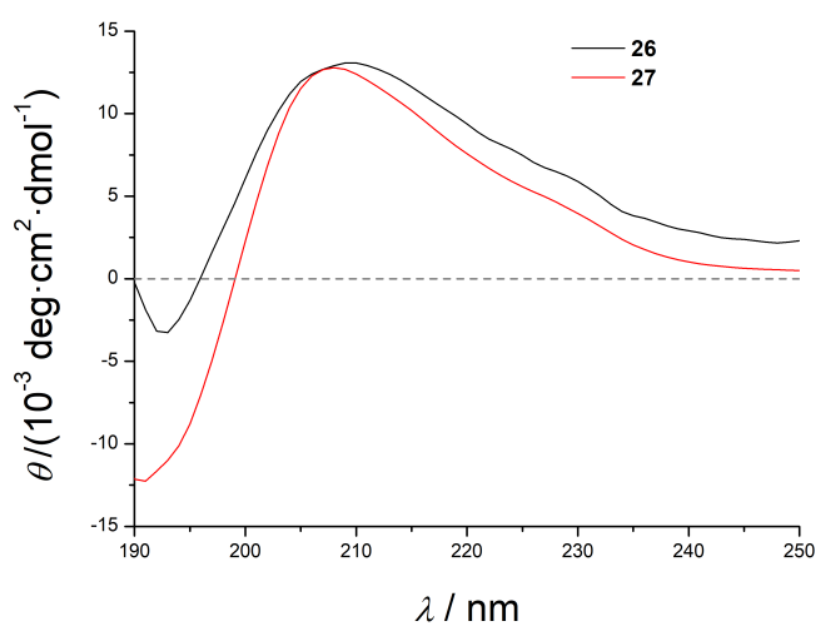

Figure 38: CD spectra of $26(\sim 8 \mu \mathrm{M})$ and $27(25 \mu \mathrm{M})$ in $\mathrm{MeOH}$ at $25^{\circ} \mathrm{C}$. 26 shows a minimum at $193 \mathrm{~nm}$ with a zero crossing at $196 \mathrm{~nm}$ and a maximum at $210 \mathrm{~nm}$. 27 shows a minimum at $191 \mathrm{~nm}$, a zero crossing at $199 \mathrm{~nm}$ and a maximum at $208 \mathrm{~nm}$. Both spectra were normalized according to GREENFIELD. ${ }^{[128]}$

\section{4 grapheneMIET Measurements of Atto643-labeled Transmembrane $\beta$-Peptides}

After successful synthesis and characterization of the Atto643-labeled peptides, grapheneMIET measurements were performed in collaboration with A. SHARMA. Peptides $\mathbf{2 6}$ and 27, separately, were incorporated into lipid bilayers with a peptide-to-lipid ratio of 1:25000. Lipid bilayers were obtained by spreading giant unilamellar vesicles (GUVs) onto the graphene-containing glass substrate from GRAPHENE LABORATORIES INC. (New York, USA). GUV formation was performed by heating a mixture of peptides in methanol and DOPC in chloroform under reduced pressure on an aluminum electrode to $30{ }^{\circ} \mathrm{C}$. After complete drying, a thin lipid film was gained which was rehydrated with $500 \mu \mathrm{L}$ of $300 \mathrm{mM}$ sucrose solution. For $3 \mathrm{~h}$, the solution was treated with an alternating current $(15 \mathrm{~Hz}, 1.6 \mathrm{~V}$ peak-topeak voltage). Then, it was further treated with $8 \mathrm{~Hz}$ for $30 \mathrm{~min}$. Finally, $500 \mu \mathrm{L}$ of PBS 
buffer was added.

Since the orientation $\alpha$ of the Atto643 dye is also contributing to radiative emission power $S\left(\alpha, z_{0}\right)$, a random orientation was assumed after analyzing GUVs with polarization-resolved fluorescence imaging (Figure 39). After determination of the fluorophore orientation, spreading of SLBs onto the graphene substrate was achieved by adding the GUV solution after 30-fold dilution to the surface. Formed bilayers were washed with PBS buffer after $1 \mathrm{~h}$, carefully but thoroughly. Thereby, incorporated peptides can align either with the fluorophore pointing above the membrane, penetrating the aqueous medium, or pointing below the membrane, interfering with the $\mathrm{SiO}_{2}$ spacer.

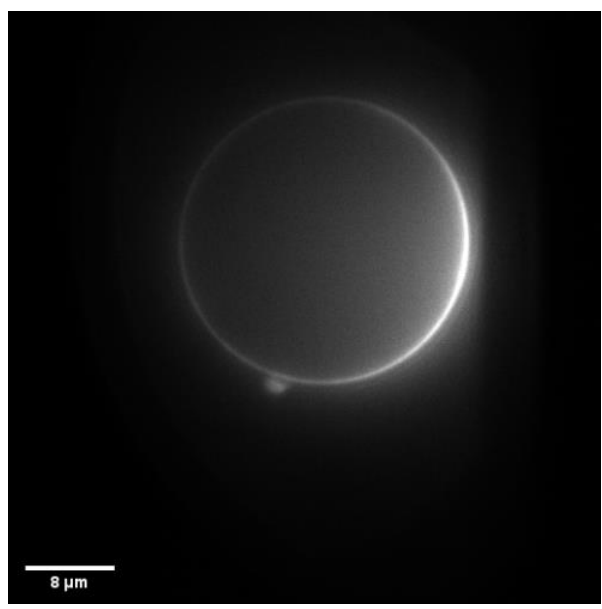

Figure 39: Linear polarized fluorescence imaging was utilized to obtain a GUV image to confirm randomly oriented fluorescent dyes. ${ }^{[146]}$

A schematic view on the setup can be seen in Figure 40. Here, 26 and 27 are embedded into the membrane and height differences in regard to the substrate surface can be seen. However, measurements were carried out with only one species of peptides being present in the lipid membrane at a time. 26 and 27 were prepared and measured in separate membranes. As already mentioned, the concept and $\beta$-peptide design relies on the outstanding stability of 14-helices. Since they are able to form rigid structures in organic and aqueous solutions, they can be reconstituted into lipid bilayers with ease. ${ }^{[10,11,74]}$ Transmembrane 14-helices, developed by STOLLBERG, showed a $16^{\circ}$ helical tilt when being reconstituted into DOPC lipid membranes. ${ }^{[10]}$ Due to the rigidity of those helices, this tilt can also be assumed for elongated peptides. Taking the tilt and literature-known dimensions of the 14-helix into account, one can calculate the maximum distance of the peptide termini to the surface after incorporation 
into the lipid membrane. For the labeled transmembrane domain 26, a height of $4.42 \mathrm{~nm}$ is expected, whereas the height of 27 increases to $5.36 \mathrm{~nm}$.

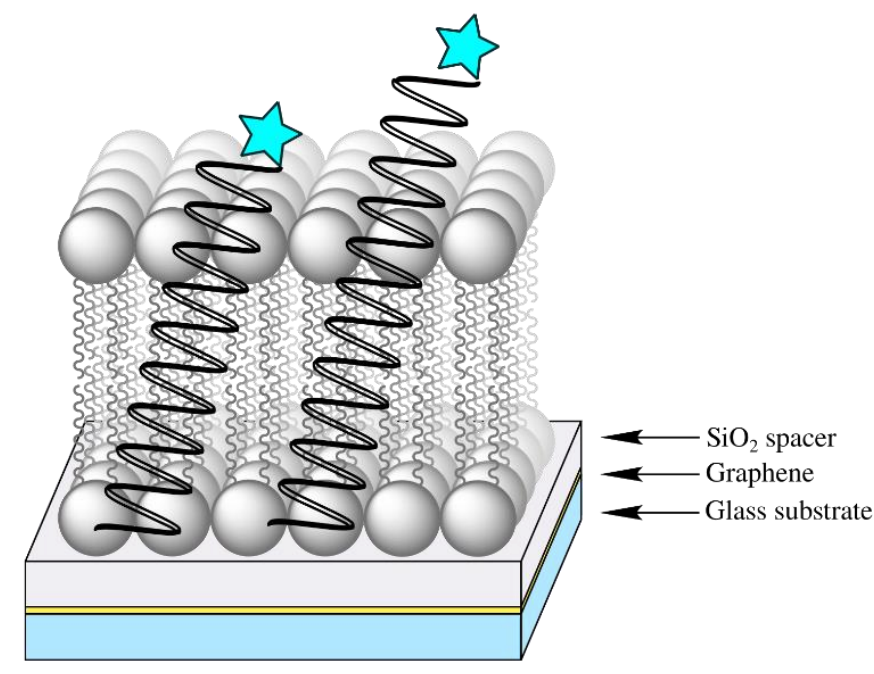

Figure 40: Experimental sample setup for MIET measurements of DOPC lipid bilayers with incorporated Atto643-labeled 14-helices. A single sheet of graphene is located between a $10 \mathrm{~nm} \mathrm{SiO}_{2}$ spacer and a glass substrate. GUVs, containing either $\mathbf{2 6}$ or $\mathbf{2 7}$, were spread onto the substrate to obtain lipid bilayers. Height differences of the Atto643 fluorophores (cyan stars) in regard to the surface were then determined with grapheneMIET, performed by A. SHARMA. In this figure, only one direction of peptide orientation is considered. ${ }^{[146]}$

The free-space lifetime of peptide-bound Atto643 in solution (4 ns) was determined by timecorrelated single photon counting (TCSPC) and using a given quantum yield (0.62) and the free-space lifetime of non-bound Atto643 (3.5 ns), the quantum yield of peptide-bound Atto643 was calculated to be 0.71 . Considering a bilayer thickness of around $5 \mathrm{~nm}$, a refractive index of 1.46 of the bilayer, a graphene layer thickness of $0.34 \mathrm{~nm}$ and its complex refractive index of $2.77+1.42 \mathrm{i}$ as well as a $\mathrm{SiO}_{2}$ spacer thickness of $10 \mathrm{~nm}$ with an refractive index of 1.46, the grapheneMIET curve was calculated (Figure 41).

After reconstitution of Atto643-labeled peptides into GUVs with a peptide to lipid ratio of 1:25000, the lipid was spread on the graphene-coated substrate to obtain a lipid bilayer. An area of $25 \mu \mathrm{m}^{2}$ was examined with a confocal laser scanning microscope (CLSM) in order to obtain fluorescence decay curves (Figure 41). The data was acquired from three different areas in three independent samples. After fitting with a decay function, the obtained lifetimes were then transferred into distances using the grapheneMIET curve. 

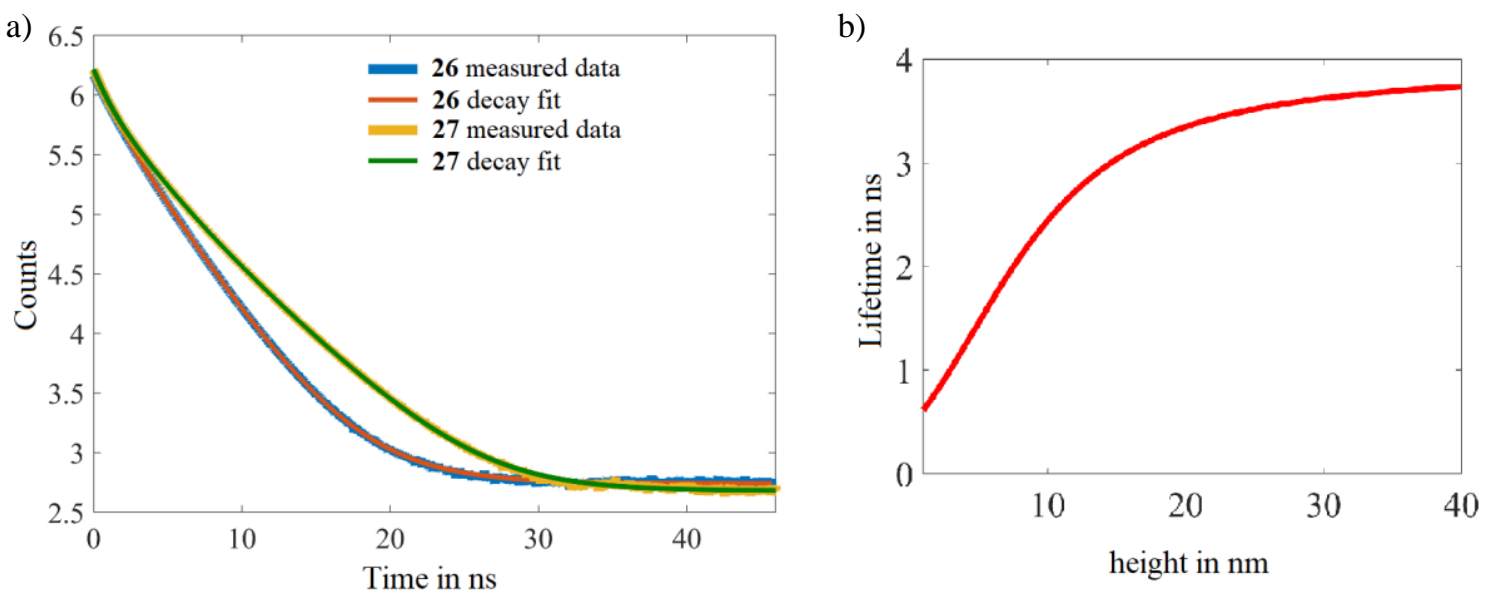

Figure 41: a) Obtained fluorescence decay data by using CLSM for 26 and 27. Measured data are depicted in blue and yellow, respectively, whereas triple exponential fits are given in red and green. b) Calculated grapheneMIET curve after consideration of thicknesses and refractive indices of the lipid membrane, a single sheet of graphene and the $\mathrm{SiO}_{2}$ spacer. ${ }^{[146]}$

Using the grapheneMIET curve, measured lifetimes of peptide-bound Atto643 can be converted into heights in regard to the surface. Thereby, two distances for each peptide can be found, one with the dye pointing above the bilayer and one with the dye pointing below the bilayer. For 26, distances of $2.9 \pm 0.3 \mathrm{~nm}$ and $8.4 \pm 0.1 \mathrm{~nm}$ can be found, leading to an endto-end height of $5.5 \pm 0.4 \mathrm{~nm}$. 27 shows heights of $1.70 \pm 0.03 \mathrm{~nm}$ and $7.90 \pm 0.27 \mathrm{~nm}$, resulting in a height difference of $6.2 \pm 0.2 \mathrm{~nm}$.

In the case of dyes pointing below the membrane, a difference between $2.9 \mathrm{~nm}$ and $1.70 \mathrm{~nm}$ seems quite large but could be theoretically explained by the different peptide lengths. Since 27 is elongated, it is closer to the substrate surface, leading to decreased distances in the measurement. However, the $\mathrm{SiO}_{2}$ is directly underlying the membrane bilayer, interacting with bottom-oriented peptides and dyes. Therefore, one would expect only minor differences in the cases of $\mathbf{2 6}$ and 27. Surface roughness of the $\mathrm{SiO}_{2}$ spacer can potentially play a role since varying surface thicknesses can lead to different experimental data. Therefore, end-toend distances or heights of the peptides were calculated.

In comparison to the estimated values (Table 2), the measured values appear larger which is most probably explained by the dimensions of the Atto643 dye and its three methylene unit linker. The same phenomenon was observed in previous grapheneMIET studies. ${ }^{[165,166]}$ 
Table 2: Comparison between estimated and experimental determined end-to-end height differences of $\mathbf{2 6}$ and 27.

Estimated height / nm

\begin{abstract}
26
\end{abstract}
27
4.42

5.36

\section{Experimental height / nm}

$5.5 \pm 0.4$

$6.2 \pm 0.2$

Peptide 26, being the non-elongated transmembrane domain, shows a height of $5.5 \pm 0.4 \mathrm{~nm}$. This is in perfect agreement with the DOPC bilayer thickness of $5.5 \pm 0.4 \mathrm{~nm}$ which was also investigated with grapheneMIET. ${ }^{[166]} 27$ shows an end-to-end difference of $6.2 \pm 0.2 \mathrm{~nm}$ which is increased compared to 26. According to the defined distance of 27, one can assume that it is successfully incorporated into the lipid membrane and remains its 14-helix rigidity throughout the change of medium from the membrane to the aqueous buffer. Distinct differences in the end-to-end heights of $\mathbf{2 6}$ and $\mathbf{2 7}$ also indicate that a use as molecular rulers is indeed possible for 14-helices.

\subsection{Conclusion}

In the work of this chapter, two transmembrane $\beta$-peptide 14 -helices were designed, synthesized with manual SPPS and characterized via CD spectroscopy and mass spectrometry. Differing in length, they were labeled with Atto643, which shows perfectly suitable spectroscopic properties in grapheneMIET measurements. On the one hand, the use of this highly precise technique enabled the determination, whether 14-helices are capable of being functionalized as molecular rulers. On the other hand, several other open questions could be addressed by the performed measurements. After incorporation of the labeled peptides into DOPC GUVs, they were spread on a substrate surface to obtain SLBs. In cooperation with A. SHARMA from the ENDERLEIN group, the labeled transmembrane domain $\mathbf{2 6}$ was determined with an end-to-end height of $5.5 \pm 0.4 \mathrm{~nm}$ which perfectly agrees with preliminary analyses of DOPC bilayers with grapheneMIET. ${ }^{[166]}$ The by two turns elongated peptide 27 is calculated to have an end-to-end height of $6.2 \pm 0.2 \mathrm{~nm}$, agreeing with theoretical estimations.

Regarding the distinct height differences compared to the substrate surface, a proof of concept was established which enables the use of transmembrane 14-helices as molecular rulers. 
Following up on these measurements, various sensorial probes can be attached to the easily modifiable 14-helices in order to investigate the near-membrane environment. Also, it was shown that elongated $\beta$-peptide 14-helices, which surpass the membrane-water interface, successfully incorporate into DOPC membranes. Finally, helical persistence for 14-helices in the extra-membrane environment could be shown by achieving distinct distance values. 


\section{Summary and Outlook}

The severe importance of protein-protein and protein-lipid interactions in living organisms lead to extensive research in order to understand and learn from biological processes. ${ }^{[211-213]}$ Especially in the last decades, biochemical phenomena caught scientist's attention. The aggregation of proteins and peptides plays a crucial role in their biochemical function. ${ }^{[96]}$ Since the size and complexity of these macromolecules hinder the accessibility of conclusive studies, different peptidic model systems, like the WALP peptides, have been developed. Simplification of these complicated structures enables specific targeting of research towards distinct areas or functional sites of a protein. Artificial model systems, consisting of $\beta$-amino acids, have been studied in the last years. Developed by STOLLBERG, a transmembrane model system has been established which is based on the well examined 14-helix. ${ }^{[10]}$ Relating to her work as well as KABATAS GLOWACKI's aggregation studies of $\beta$-peptides with incorporated cyanuric acid (CA) and melamine (M), this work dealt with the assembly of transmembrane $\beta$-peptides according to the $\mathrm{CA} \cdot \mathrm{M}$ rosette. ${ }^{[11,13]}$

First, transmembrane 14-helices with cyanuric acid or melamine modified $\beta^{3}$-D-lysine moieties were synthesized (Figure 42) in order to organize the peptides within lipid membranes. Successful synthesis as well as helix formation were confirmed via ESI-MS measurements and CD spectroscopy. For the analysis of non-labeled peptides, different assays were performed which directly aimed towards potential aggregation and channel or carrier functions of the incorporated peptides. First, a proton transport assay, which can monitor proton influx and efflux due to the presence of a $\mathrm{pH}$ dependent pyranine dye, was performed by $\mathrm{D}$. RUPPELT. Indeed, proton translocation was observed after incorporation of $\mathbf{1}$ and $\mathbf{2}$ into POPC vesicles. However, same experiments with the pure transmembrane domain 21 showed similar behavior in terms of proton translocation. Optimization of the experiment revealed concentration dependency of the proton transport on the used amount of peptide. 


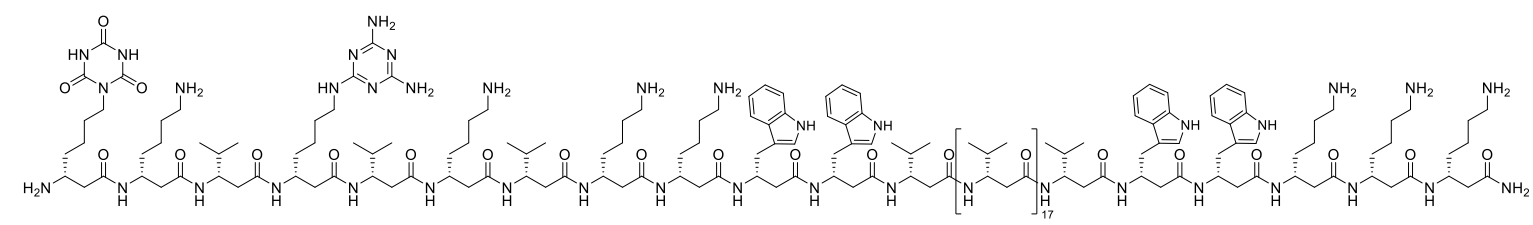

1

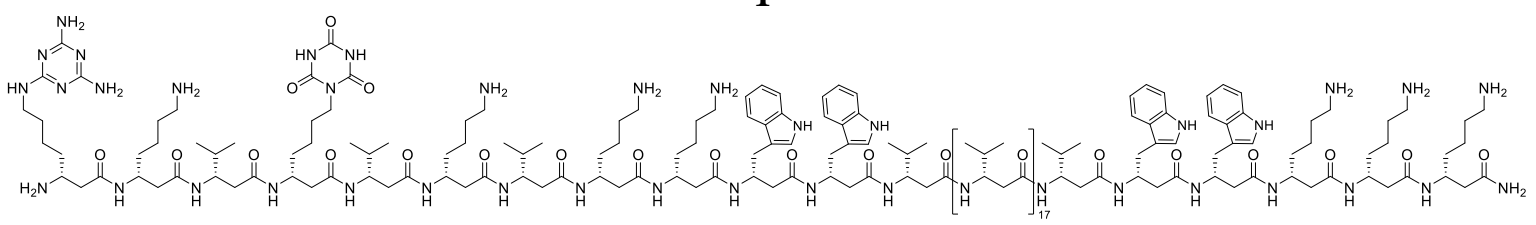

2

Figure 42: Synthesized transmembrane 14-helices with incorporated cyanuric acid and melamine for the organization as helix bundles in lipid membranes.

With these results in hand, one can assume that the translocation is based on the transmembrane domain itself and not on CA·M-induced aggregation of peptides. Furthermore, a dye leakage assay was performed in order to exclude false positive results, for example due to bursting vesicles. There, only 2-3\% of self-quenching dye were released from vesicles after peptide addition.

Peptide concentration dependency as well as intact vesicles indicated towards selective and systematic interactions in the lipid membrane. For this proton translocation to happen, peptide assemblies are needed which was analyzed in subsequent FRET measurements. Transmembrane domains were labeled with TAMRA and NBD, a common FRET pair in peptide analyses. In order to keep the total peptide concentration constant throughout the measurements, an acetylated transmembrane domain was also synthesized. FRET efficiency was monitored and showed a decrease in intensity, significantly more than compared to the statistical FRET, indicating successful aggregation of transmembrane peptides. Thus, two different assays were performed which indicated peptide-peptide interactions in the lipid membrane, being responsible for ion translocation.

More physiochemical analyses of $\mathbf{2 1}$ were executed by A. MAZNICHENKO via membrane conductivity measurements. Free-standing lipid membranes were incorporated with the transmembrane domain while measuring the change of conductivity after applying a voltage ramp from -60 to $+60 \mathrm{mV}$. By comparison with the NERNST potential, the change of the reversal potential showed that incorporated transmembrane domains indeed are able to allow ion translocation. However, not only protons but also potassium ions are contributing to this process. Also, the conductivity increases when potassium ions are present which indicates 
that potassium has a crucial role for the activity and stability of such carrier or channel structures. In addition, channel-like behavior was found for higher concentrations of peptides and potassium buffer. Single opening events were monitored by applying a constant voltage of $150 \mathrm{mV}$, indicating a much higher rate of translocation. However, the mechanism of the peptide-peptide interactions and the translocation of the ions remains unclear. In case of channel opening events, the question arises if the carrier or channel formation is induced by the higher concentration of peptide or the higher concentration of potassium buffer. Since the peptide concentration is only enhanced by four-fold in comparison to the other measurements, the high potassium concentration seems to be key for the structures to form, potentially stabilizing the formed aggregates. Further analyses have to be performed in order to characterize these channels, especially regarding the dependency on the potassium concentration and the aggregation state of the transmembrane domain. Common potassium channels consist of a quantity of two, four or six transmembrane helices. ${ }^{[145]}$ In this case, an aggregate of two transmembrane $\beta$-peptides can be excluded since the FRET efficiency (see chapter 3.4) was significantly higher than for a dimer which was calculated by STOLLBERG (ROST) et al. ${ }^{[11]}$ Further analysis on the aggregation state, next to FRET efficiency measurements, have to be carried out, for example via FCS, using a labeled transmembrane domain. In addition, the comparison between the transmembrane domain and the CA-M modified peptides would be interesting. Then, one could determine if the incorporation of such building blocks enhances the channel formation in terms of ion translocation efficiency. Additionally, the selectivity towards other small cations like magnesium or sodium has to be determined. A graphical overview of the results of this topic can be found in Figure 43.

The second part of this thesis dealt with a novel transmembrane $\beta$-peptide-based molecular ruler in order to investigate the near-membrane environment. The spatial positioning of molecular probes such as $\mathrm{pH}$ or calcium sensors is inherently important since ion concentrations are key to many relevant biochemical processes. ${ }^{[214]}$ Therefore, sensors have to be placed in distinct distances in relation to the lipid membrane. Here, a new approach was presented, utilizing rigid 14-helices and MIET measurements to determine distances in dependency on the peptide lengths. As a proof of concept, two peptides with different lengths were synthesized (Figure 44). 

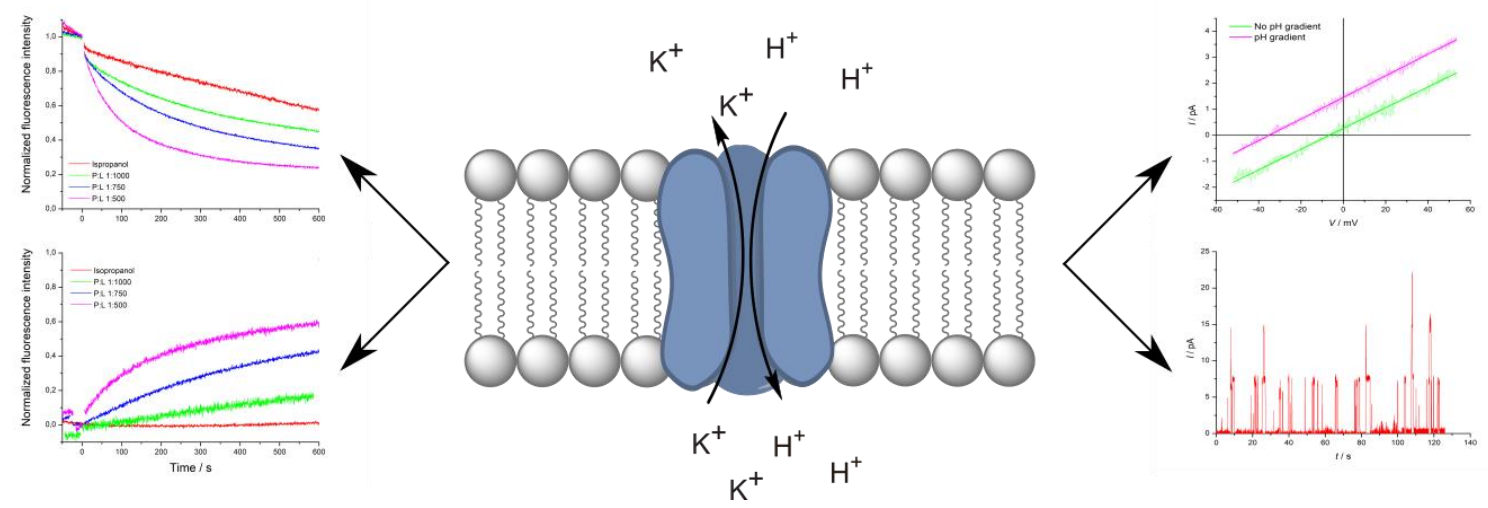

Figure 43: Schematic overview of ion translocation induced by transmembrane $\beta$-peptides and results from various assays. Proton influx and efflux was shown to be induced by the standard transmembrane domain model system upon incorporation into lipid membranes. Furthermore, conductivity measurements of lipid bilayers revealed that proton translocation as well as potassium ion translocation can take place with these peptides. In the case of high-salt buffers and higher concentrations of peptide, even single opening events can be monitored.

One was designed in a way that the height of the fluorophore accords to bilayer thickness upon peptide incorporation. The other peptide was synthesized with two additional turns. Considering a transmembrane peptide tilt of $16^{\circ}$, fluorophore heights of both peptides were calculated with $4.42 \mathrm{~nm}$ and $5.36 \mathrm{~nm}$, respectively. In MIET measurements, point-to-point distances of fluorescent probes can be determined in relation to a sheet of graphene. Performed by A. SHARMA, experimental end-to-end distances of $5.5 \pm 0.4 \mathrm{~nm}$ and $6.2 \pm 0.2 \mathrm{~nm}$ were calculated (Figure 45). However, slightly higher values were expected due to the size of the used Atto643 dye.

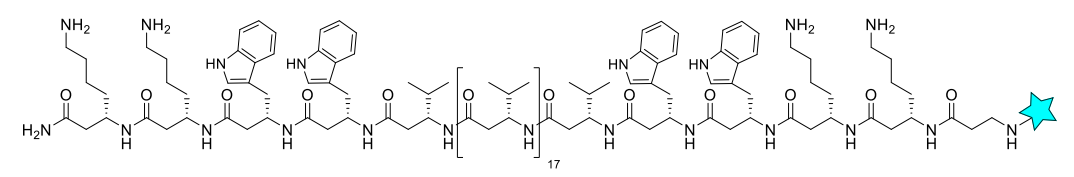

26

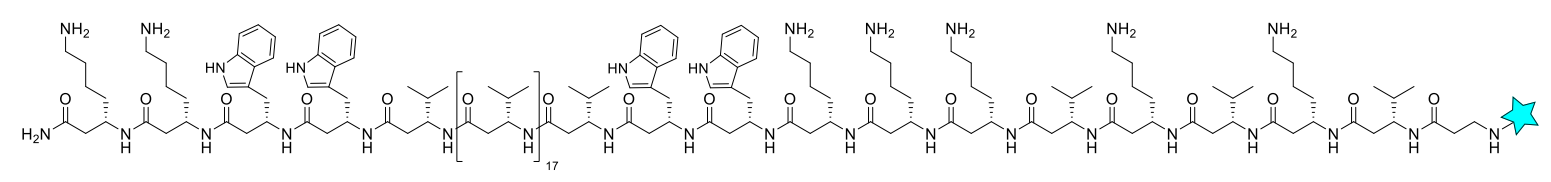

27

Figure 44: Chemical structures of synthesized and Atto643 labeled (cyan star) 14-helices for MIET measurements. 


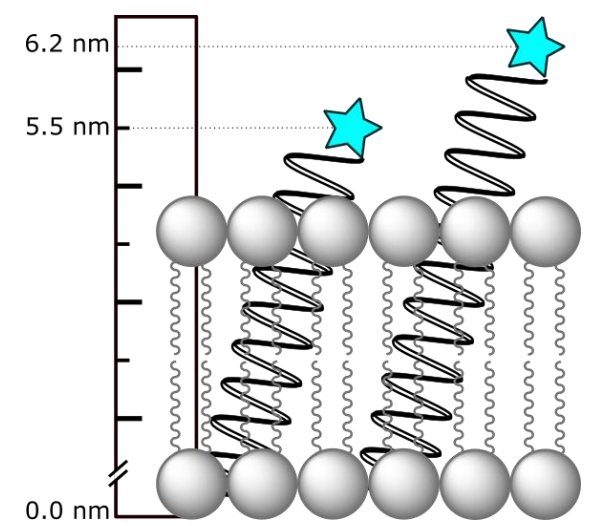

Figure 45: Schematic view on the developed molecular ruler based on transmembrane 14-helices.

Also, the distinct height distribution of elongated transmembrane 14-helices gives evidence that this peptide is successfully incorporated into lipid bilayers and remain their helical structure after penetration of the lipid-water interface. With this established proof of principle, one can modify the synthesized peptides with analytical probes in order to investigate the near-membrane environment as a function of the distance to the membrane. For example, sensors for protons, calcium or other ions can be attached to the 14-helices, determining present concentrations in fluorescence-based assays as already performed in the work of PAHLKE. 



\section{Experimental Part}

In the following chapter, all experimental details and procedures are listed which were applied in order to obtain all compounds and self-performed measurement data of this work. For general techniques, which were used in the laboratory, see section 6.1. Spectroscopic and spectrometric details and devices can be found in section 6.2, whereas all procedures, either for application of the compounds or syntheses can be found in sections 6.3 and 6.4 respectively.

\subsection{General}

\section{Chemicals}

All reagents were used as supplied. Amino acids and their respective derivatives were purchased from BLD PHARMATECH LTD. (Shanghai, China), IRIS BIOTECH (Marktredwitz, Germany) and CARBolution ChemicAls GMBH (St. Ingbert, Germany). Resins and coupling reagents were obtained from NovABIOCHEM (Darmstadt, Germany), GL BIOCHEM (Shanghai, China), Fluorochem Ltd (Hadfield, UK), CARL Roth GMBH (Karlsruhe, Germany), BACHEM (Bubendorf, Switzerland) and CARbolution ChEMICALs GMBH (St. Ingbert, Germany). Lipids were provided by AVANTI POLAR LIPIDS (Alabama, USA). Other chemicals and solvents were purchased from FLUKA (Taufkirchen, Germany), FISHER SCIENTIFIC U.K. LTD (Loughborough, UK), FluOROCHEM LTD (Hadfield, UK), TCI (Tokio, Japan), GRÜSSING GMBH (Filsum, Germany), VWR InTERnATIONAL (Fontenay-sous-Bois, France), Alfa AESAR (Karlsruhe, Germany) and Sigma-ALDRICH (Taufkirchen, Germany). Dry solvents were obtained from ACROS ORGANICS (Geel, Belgium) and stored over molecular 
sieves ( $4 \AA$ ). Technical grade solvents were purified prior to use. Atto fluorophores were provided by ATTO-TEC GMBH (Siegen, Germany) and ultra-pure water was obtained by using the water purification system arium ${ }^{\circledR}$ mini from SARTORIUS AG (Göttingen, Germany).

\section{Reactions}

Air and water sensitive reactions were accomplished by using the SCHLENK-technique. Thereby, the respective glass apparatus was heated to over $100{ }^{\circ} \mathrm{C}$ under reduced pressure. After cooling down and flushing the apparatus with argon gas (> 99.999\%), this process was repeated twice to obtain an air- and water-free atmosphere.

\section{Lyophilization}

For storage, building blocks and peptides were freeze-dried from aqueous solutions or dioxane containing aqueous solutions with a CHRIST Alpha-2-4-lyophilizer device (Osterode am Harz, Germany) which was connected to a high vacuum pump. For low amounts of solvents, the samples were transferred to EPPENDORF safe-lock tubes (Hamburg, Germany) and freeze-dried in a CHRIST RVC 2-18 CD plus centrifuge which was mounted to the lyophilizer.

\section{Storage}

Chemicals and solvents were stored according to the supplier's recommendations. Stock solutions of acids, bases and salts were stored at $\mathrm{rt}$, whereas aqueous buffers were stored at $+4{ }^{\circ} \mathrm{C}$. Modified resins were washed with $\mathrm{DCM}(3 \times 5 \mathrm{~mL})$ and $\mathrm{Et}_{2} \mathrm{O}(3 \times 5 \mathrm{~mL})$ prior to drying and storing them at rt under reduced pressure. Synthesized and cleaved peptides were lyophilized and kept at $-20{ }^{\circ} \mathrm{C}$ or under vacuum over $\mathrm{P}_{2} \mathrm{O}_{5}$ or $\mathrm{CaCl}_{2}$ at $\mathrm{rt}$.

\section{Thin layer chromatography (TLC)}

In order to monitor completion of reactions, TLC was performed using thin layer plates of silica gel (silica gel $60, \mathrm{~F}_{254}$, layer thickness $0.25 \mathrm{~mm}$ ) on aluminum foil from MERCK KGAA (Darmstadt, Germany). Fluorescent samples were monitored at $254 \mathrm{~nm}$ or were stained with $3 \%$ ninhydrin solution in ethanol followed by vigorous heating to detect amines. 


\section{Flash column chromatography}

Building blocks were purified by carrying out flash column chromatography with an overpressure of $0.5-0.8$ bar. A glass column was packed with wet silica gel (silica gel 60, F 254 , 40-63 $\mu \mathrm{m}$ ) and the sample was applied as a concentrated solution or adsorbed onto silica gel prior to use.

\section{High performance liquid chromatography (HPLC)}

Purification of peptides was carried out by using RP-HPLC with a MD-2010 Plus detector, PU-2080 Plus pumps, an LC-NetII/ADC interface and a DG-2080-53 degasser from Jasco (Tokyo, Japan). The software ChromNav 2.01.06 was used to analyze obtained chromatograms. Ultraviolet (UV)-absorption was detected at $215 \mathrm{~nm}, 254 \mathrm{~nm}$ and $280 \mathrm{~nm}$ for nonlabeled peptides. In presence of fluorophores, detection at $254 \mathrm{~nm}$ was replaced by the respective fluorophore absorption wavelength $(464 \mathrm{~nm}$ for NBD, $565 \mathrm{~nm}$ for TAMRA, $643 \mathrm{~nm}$ for Atto643).

For purification, a linear gradient from A (water $+0.1 \%$ TFA $+0.1 \%$ HFIP) to B (MeOH $+0.1 \%$ TFA $+0.1 \%$ HFIP) and subsequent washing with $100 \% \mathrm{~B}$ for 10 min while using a Eurosil Bioselect 300-5 C18 column from KNAUER (Berlin, Germany) was performed.

\subsection{Characterization}

\section{Nuclear magnetic resonance spectroscopy}

NMR spectroscopy was performed with a BRUKER (Billerica, USA) spectrometer (av300 or av301), respective spectra being recorded at ambient temperature. Chemical shifts $(\delta)$ are given in ppm in relation to TMS, whereas the used deuterated solvents are listed below the respective compounds. Coupling constants are given as ${ }^{\mathrm{n}} \boldsymbol{J}_{\mathrm{x}, \mathrm{y}}$ in $\mathrm{Hz}$ with $\mathrm{n}$ describing the order of coupling and $\mathrm{x}, \mathrm{y}$ denoting the coupling atoms. The following abbreviations are used for the listed multiplets: br (broad), s (singlet), d (doublet), t (triplet), q (quartet) or m (multiplet). 


\section{Mass spectrometry}

Mass spectra were obtained by using a BRUKER maXis or micrOTOF device (Billerica, USA) using the electrospray-ionization (ESI) technique. Respective samples were dissolved in $\mathrm{MeOH}$ and acidified with formic acid prior to the measurements. Mass-to-charge ratios as well as high resolution peaks are listed below the respective compounds.

\section{UV/Vis spectroscopy}

Peptide concentrations were determined in $\mathrm{MeOH}$ solutions by performing UV spectroscopy with a THERMO SCIENTIFIC Nanodrop ND-200c spectrophotometer (Waltham, USA) using a Suprasil@ quartz glass precision cell (type: 115B-QS, light path: $10.00 \mathrm{~mm}$ ) from HELLMA (Müllheim, Germany) at ambient temperature. According to Lambert-Beer's law (equation 6.1), intensities were used to calculate the peptide concentration in solution. Thereby, the concenctration $c$ was determined by dividing the absorbance $A$ by the extinction coefficient $\varepsilon$ and the light path $d$. Respective extinction coefficients at their specific wavelength are depicted in Table 3.

$$
c=\frac{A}{\varepsilon \cdot d}
$$

Table 3: Extinction coefficients for the determination of peptide concentrations according to Lambert-Beer's law. ${ }^{[215,216]}$
Absorption wavelength / nm
Extinction coefficient $/ \mathbf{c m} \cdot \mathbf{M}^{-1}$

\begin{tabular}{ccc}
\hline Tryptophan & 280 & 5690 \\
NBD & 466 & 22000 \\
TAMRA & 565 & 91000 \\
\hline
\end{tabular}

\section{Circular dichroism spectroscopy}

To ensure successful 14-helix formation of the synthesized peptides, CD spectroscopic measurements in $\mathrm{MeOH}$ were performed. The spectra were obtained by using a JASCO J- 
1500 device (Tokyo, Japan) with a Suprasil ${ }^{\circledR}$ quartz glass precision cell (type: 110-QS, light path: $0.5 \mathrm{~mm}$ or $1.0 \mathrm{~mm}$ ) from Hellma (Müllheim, Germany) at $25{ }^{\circ} \mathrm{C}$. The sample holder was flushed continuously with nitrogen, measurement parameters were as the following: measure range: $250-190 \mathrm{~nm}$, data pitch: $1.0 \mathrm{~nm}$, CD scale: $2000 \mathrm{mdeg} / 1.0 \mathrm{dOD}$, D.I.T.: $1 \mathrm{~s}$, bandwith: $1.0 \mathrm{~nm}$, start mode: immediately, scanning speed: $20 \mathrm{~nm} / \mathrm{min}$, accumulations: 10 . All measurements were background-corrected by subtracting the spectrum of the pure solvent. Finally, all resulting spectra were normalized according to GREENFIELD. ${ }^{[128]}$

\section{Dynamic light scattering}

Determination of size distribution of extruded vesicles was achieved by using a Zetasizer Nano S light scattering system from MALVERN INSTRUMENTS (Malvern, UK) with disposable PS cuvettes from BRAND (Wertheim, Germany). After application of a laser beam $(633 \mathrm{~nm}, 4 \mathrm{~mW})$, light scattering was measured at an angle of $173^{\circ}$ at $25^{\circ} \mathrm{C}$. All other measurement parameters were automatically set by the device.

\section{Fluorescence spectroscopy}

Fluorescence spectroscopic measurements were carried out on a JASCO FP-8200 device (Tokyo, Japan), equipped with an ETC-272T thermostat while using Suprasil ${ }^{\circledR}$ quartz glass precision cells (type: 119.004-QS or 111-QS, light path: $10.00 \mathrm{~mm}$ ) from HELLMA (Müllheim, Germany). For proton assays, time course fluorescence emission was measured at $512 \mathrm{~nm}$ with an excitation wavelength of $458 \mathrm{~nm}$ at $20^{\circ} \mathrm{C}$. The vesicle solution was transferred to the cuvette and diluted with buffer at $\mathrm{pH} 6.4$ or $8.4(5 \mathrm{mM} \mathrm{HEPES}, 100 \mathrm{mM} \mathrm{KCl})$ to a volume of $792 \mu \mathrm{L}$. After obtaining a steady baseline, $8 \mu \mathrm{L}$ of peptide solution in $\mathrm{PrOH}$ or DMSO in different concentrations was added, resulting in different peptide to lipid ratios with a final lipid concentration of $50 \mu \mathrm{M}$. After the measurements, $16 \mu \mathrm{L}$ of Triton ${ }^{\mathrm{TM}} \mathrm{X}-100$ (aq., $10 \%$ ) were added to lyze the liposomes. In terms of analysis, the fluorescence intensities were normalized to the resulting baseline or the initial one depending on whether proton efflux or influx was determined.

For FRET measurements, DOPC lipids $(2 \mathrm{mg} / \mathrm{mL})$ with a P/L ratio of 1:500 were used. The mole fraction of NBD-labeled peptides was kept at 0.5 through all measurements with varying amounts of labeled TAMRA peptide from 0-0.5. In order to keep the total peptide concentration constant, acetylated peptides were added when necessary. After excitation at 
$464 \mathrm{~nm}$, emission spectra were recorded in a range from $500-650 \mathrm{~nm}$ at $25^{\circ} \mathrm{C}$ as well as at $60{ }^{\circ} \mathrm{C}$. Excitation and emission bandwidth of $5.0 \mathrm{~nm}$, data pitch of $1.0 \mathrm{~nm}$, 'fast' response mode and 'high' or 'medium' sensitivity mode lead to the obtained spectra. All spectra were background corrected and referenced by subtracting the emission of vesicle solution with no peptide content.

\subsection{Standard Operating Procedures (SOPs)}

\subsubsection{Synthesis of $\beta^{3}$-D-Amino Acids}

SOP1: Titration of ethereal diazomethane solutions ${ }^{[217,218]}$

Diazomethane for $\beta^{3}$-D-amino acid syntheses was kindly provided by D. FRANK in diethyl ether solutions. In order to determine the concentration of diazomethane, a titration according to ARNDT was performed. Thereby, benzoic acid (1.30 g) was dissolved in diethyl ether $(50 \mathrm{~mL})$ and cooled to $0{ }^{\circ} \mathrm{C}$. Diazomethane $(3.00 \mathrm{~mL})$ was added at $0{ }^{\circ} \mathrm{C}$ and the mixture was titrated with phenolphthalein against $\mathrm{KOH}(85 \%, 1.30 \mathrm{~g}$ in $100 \mathrm{~mL}$ water) until a color change appeared (colorless to pink). According to equation 6.2, the concentration of diazomethane was determined with $V_{\mathrm{KOH}}$ being the used amount of $\mathrm{KOH}$ solution until color change appears.

$$
c_{\text {diazomethane }}=\left(n_{\text {benzoic acid }}-c_{\mathrm{KOH}} \cdot V_{\mathrm{KOH}}\right) \cdot V_{\text {diazomethane }}^{-1}
$$

SOP2: Synthesis of $N$-protected D-amino acid diazo ketones ${ }^{[219,220]}$<smiles></smiles>

Adapting the procedure of GUICHARD et al., under an argon atmosphere, the respective $N$ terminally protected $\alpha$-D-amino acid (1.00 eq) was dissolved in dry THF ( $4.7 \mathrm{~mL} / \mathrm{mmol})$ and cooled to $0{ }^{\circ} \mathrm{C}$. After addition of triethylamine (1.10 eq) and isobutyl chloroformate 
(1.10 eq) at $0{ }^{\circ} \mathrm{C}$, the reaction mixture was stirred vigorously for $30 \mathrm{~min}$ at $0{ }^{\circ} \mathrm{C}$. Diazomethane in diethyl ether (2.00 eq, see SOP1) was added under the exclusion of light, followed by stirring at rt until complete conversion was monitored via TLC (usually $4-5$ hours). The reaction was quenched with glacial acetic acid $(0.11 \mathrm{~mL} / \mathrm{mmol})$ and taken up in $6 \%$ $\mathrm{NaHCO}_{3}$ solution (aq., $\left.8.1 \mathrm{~mL} / \mathrm{mmol}\right)$. After extraction with ethyl acetate $(3 \times 100 \mathrm{~mL})$, the organic phases were dried over $\mathrm{MgSO}_{4}$ and the solvent was removed under reduced pressure to obtain the D-amino acid diazo ketones as a yellow solid or oil in quantitative yield.

SOP3: Synthesis of $N$-protected $\beta^{3}$-D-amino acid derivatives via sonication ${ }^{[219,220]}$<smiles>[R]C(CC(=O)O)NP(=O)(O)O</smiles>

Based on procedures of GUICHARD et al., respective D-amino acid diazo ketones (1.00 eq) were dissolved in a mixture of THF and water $(9: 1, v / v, 6.1 \mathrm{~mL} / \mathrm{mmol})$ and silver benzoate $(0.10$ eq) was added under the exclusion of light. The mixture was sonicated until completion was observed via TLC (usually $2 \mathrm{~h}$ ). Water $(50 \mathrm{~mL}$ ) was added, the $\mathrm{pH}$ was adjusted to 2-3 with $1 \mathrm{M} \mathrm{HCl}$ solution (aq.) and the mixture was extracted with ethyl acetate $(3 \times 100 \mathrm{~mL})$. After drying over $\mathrm{MgSO}_{4}$ and concentrating the organic phases under reduced pressure, the raw product was added dropwise to cold pentane $\left(-22^{\circ} \mathrm{C}\right)$ to obtain the respective $\beta^{3}$-Damino acid as a light yellow or colorless solid.

SOP4: Synthesis of $N$-protected $\beta^{3}$-D-amino acid derivatives via microwave irradiation ${ }^{\text {[221] }}$<smiles>[R]C(CC(=O)O)NP(=O)(O)O</smiles>

According to PATIL et al., respective D-amino acid diazo ketones (1.00 eq) were dissolved in a mixture of 1,4-dioxane and water $(2: 1, v / v, 12.1 \mathrm{~mL} / \mathrm{mmol})$ and silver benzoate $(0.10 \mathrm{eq})$ was added under the exclusion of light. The reaction mixture was irradiated in a domestic microwave oven at $460 \mathrm{~W}$ for $1 \mathrm{~min}$. The organic solvent was removed under reduced pressure and the residual solution was diluted with water $(50 \mathrm{~mL})$. After adjusting the $\mathrm{pH}$ to $2-3$ with $1 \mathrm{M} \mathrm{HCl}$ solution (aq.), the mixture was extracted with ethyl acetate $(3 \times 100 \mathrm{~mL})$ and the organic phases were concentrated under reduced pressure. Dropwise addition to cold 
pentane $\left(-22{ }^{\circ} \mathrm{C}\right)$ resulted in the respective $\beta^{3}$-D-amino acid derivatives as a light yellow or colorless solid.

\subsubsection{Synthesis of $\beta^{3}$-Peptides}

SOP5: Manual solid-phase peptide synthesis ${ }^{[74,220]}$

Manual SPPS was performed in a BECTON-DICKINSON Discardit II syringe (Heidelberg, Germany) equipped with a PE-filter. The NovABIOCHEM ${ }^{\circledR}$ NovaPEG rink amide resin LL (Darmstadt, Germany) with an initial occupancy between 170 and $200 \mu \mathrm{mol} / \mathrm{g}$ was swollen in DMF for $2 \mathrm{~h}$ prior to use. Coupling syntheses were performed in a Discover microwave device from CEM (Kamp-Lintfort, Germany). The following set of steps was repeated for all respective $\beta^{3}$-D-amino acids (also see SOP6) until the desired peptide sequence was achieved:

1. Fmoc-deprotection was obtained by two microwave assisted steps $\left(50 \mathrm{~W}, 65^{\circ} \mathrm{C}, 30 \mathrm{~s}\right.$ and $\left.25 \mathrm{~W}, 65^{\circ} \mathrm{C}, 3 \mathrm{~min}\right)$. Thereby, deprotection solution consisting of NMP, piperidine and DBU (79:20:1, v/v/v) was added until the resin was covered. After successful deprotection, the resin was washed with $\mathrm{MeOH}(3 \times 5 \mathrm{~mL})$ and $\mathrm{DMF}(3 \times 5 \mathrm{~mL})$.

2. Desired $\beta^{3}$-D-amino acids (5.00 eq) were activated with $500 \mathrm{~mm}$ HOAt (5.00 eq), $500 \mathrm{mM}$ HATU (5.00 eq) and 2.00 M DIPEA (10.0 eq) in NMP. After addition to the resin and double coupling $\left(25 \mathrm{~W}, 65^{\circ} \mathrm{C}, 15 \mathrm{~min}\right)$, the resin was washed with $\mathrm{MeOH}$ $(3 \times 5 \mathrm{~mL})$ and $\mathrm{DMF}(3 \times 5 \mathrm{~mL})$.

3. Free remaining amino groups were capped $\left(25 \mathrm{~W}, 65^{\circ} \mathrm{C}, 3 \mathrm{~min}\right)$ with a solution consisting of acetic anhydride and NMP $(1: 4, v / v)$. Afterwards, the resin was washed with $\mathrm{MeOH}(3 \times 5 \mathrm{~mL})$ and $\mathrm{DMF}(3 \times 5 \mathrm{~mL})$.

Once the desired sequence was achieved, the resin was washed with $\mathrm{MeOH}(3 \times 5 \mathrm{~mL})$, $\mathrm{DMF}(3 \times 5 \mathrm{~mL}), \mathrm{MeOH}(3 \times 5 \mathrm{~mL}), \mathrm{DCM}(3 \times 5 \mathrm{~mL})$ and $\mathrm{Et}_{2} \mathrm{O}(3 \times 5 \mathrm{~mL})$ before drying under reduced pressure at $\mathrm{rt}$.

SOP6: Occupancy determination of rink amide resins ${ }^{[222]}$

After coupling of the first amino acid, the occupancy of the resin was determined according to a procedure of GUDE et al. $5.0 \mathrm{mg}$ of resin $\left(m_{\text {resin }}\right)$ were added to a graduated flask $(10 \mathrm{~mL})$, 
followed by addition of $2 \% \mathrm{DBU}$ solution in DMF $(2.00 \mathrm{~mL})$. The mixture was shaken for $1 \mathrm{~h}$ at $\mathrm{rt}$ and then diluted with $\mathrm{MeCN}$ to achieve a final volume of $10 \mathrm{~mL}$. After further dilution (dilution factor $f: 12.5$ ) with $\mathrm{MeCN}$, the mixture was transferred to a quartz glass precision cell with a specific volume $V$. At $304 \mathrm{~nm}$, the formed Fmoc-dibenzofulven moiety was UV spectroscopically examined as well as a blank solution without resin. The blank spectrum was subtracted to obtain the absorbance $a b s_{304}$ and the occupancy $\rho$ was determined in $\mathrm{mmol} / \mathrm{g}$ according to equation 6.3 using the extinction coefficient $\varepsilon$ and the light path $d$.

$$
\rho=m_{\mathrm{resin}}^{-1} \cdot \frac{a b s_{304} \cdot V \cdot f}{\varepsilon \cdot d}
$$

SOP7: Automated SPPS ${ }^{[74]}$

$\beta^{3}$-D-Peptides were also synthesized on a Liberty Blue ${ }^{\mathrm{TM}}$ synthesizer equipped with a Discover microwave device from CEM (Kamp-Lintfort, Germany). For a $0.04 \mathrm{mmol}$ scale, the swollen resin was filled into the reaction vessel, amino acid concentrations were set to $0.2 \mathrm{M}$ in DMF. Deprotection was carried out twice by using a solution of DMF, piperidine and DBU (79:20:1, v/v/v). For every amino acid, double coupling was performed. The first coupling step was achieved by activation with $500 \mathrm{~mm}$ DIC (10.0 eq), 1.00 м Oxyma (5.00 eq) and 100 mM DIPEA (0.50 eq) in DMF, whereas the second one was performed comparable to the manual SPPS with $500 \mathrm{~mm}$ HATU (5.00 eq), $500 \mathrm{~mm}$ HOAt $(5.00 \mathrm{eq})$ and $2.00 \mathrm{M}$ DIPEA (10.0 eq). Capping was carried out with a solution of acetic anhydride and DMF $(1: 4, v / v)$. After completion of the peptide synthesis, the resin was transferred into a BECTONDICKINSON Discardit II syringe (Heidelberg, Germany) equipped with a PE-filter. Finally, the resin was washed with $\mathrm{MeOH}(3 \times 5 \mathrm{~mL}), \mathrm{DMF}(3 \times 5 \mathrm{~mL}), \mathrm{MeOH}(3 \times 5 \mathrm{~mL}), \mathrm{DCM}$ $(3 \times 5 \mathrm{~mL})$ and $\mathrm{Et}_{2} \mathrm{O}(3 \times 5 \mathrm{~mL})$ before drying under reduced pressure at $\mathrm{rt}$. Respective microwave methods for each step are listed in Table 4. 
Table 4: Applied microwave methods for automated SPPS.

\section{Microwave methods}

\begin{tabular}{cl}
\hline Deprotection & $1.140 \mathrm{~W}, 70{ }^{\circ} \mathrm{C}, 180 \mathrm{~s}$ \\
& $1.0 \mathrm{~W}, 25^{\circ} \mathrm{C}, 60 \mathrm{~s}$ \\
First coupling & $2.190 \mathrm{~W}, 75^{\circ} \mathrm{C}, 15 \mathrm{~s}$ \\
& $3.35 \mathrm{~W}, 90^{\circ} \mathrm{C}, 285 \mathrm{~s}$ \\
& $4.0 \mathrm{~W}, 25^{\circ} \mathrm{C}, 60 \mathrm{~s}$ \\
Second coupling & $1.0 \mathrm{~W}, 25^{\circ} \mathrm{C}, 60 \mathrm{~s}$ \\
& $2.43 \mathrm{~W}, 75^{\circ} \mathrm{C}, 1140 \mathrm{~s}$ \\
& $1.65 \mathrm{~W}, 65^{\circ} \mathrm{C}, 30 \mathrm{~s}$ \\
Capping & $2.0 \mathrm{~W}, 65^{\circ} \mathrm{C}, 30 \mathrm{~s}$ \\
& $3.65 \mathrm{~W}, 65^{\circ} \mathrm{C}, 30 \mathrm{~s}$ \\
& $4.0 \mathrm{~W}, 65^{\circ} \mathrm{C}, 30 \mathrm{~s}$ \\
\hline
\end{tabular}

SOP8: 4-Methyltrityl (Mtt) deprotection ${ }^{[223]}$

According to the NOVABIOCHEM ${ }^{\circledR}$ Peptide Synthesis catalog, Mtt protecting groups were cleaved by adding a mixture of TFA, DCM and $\mathrm{MeOH}(1: 98: 1, v / v / v, 15 \mathrm{mg} / \mathrm{mL})$. The resin was drained after $1 \mathrm{~min}$ and fresh deprotection solution was added, leaving the resin to agitate for $16 \mathrm{~h}$ at rt. Completion of the reaction was monitored by performing the trityl test. Therefore, a small sample of the resin was washed with DCM and TFA was added to this sample. Remaining trityl groups lead to an instant color change to yellow or orange. If this was the case, the resin was shaken for another $1 \mathrm{~h}$ at $\mathrm{rt}$. Once the trityl test was negative, the resin was drained completely and washed with DMF $(3 \times 5 \mathrm{~mL}), 10 \%$ DIPEA in DMF $(3 \times 5 \mathrm{~mL})$ and $\mathrm{DMF}(3 \times 5 \mathrm{~mL})$ again.

SOP9: $p$-Nitrobenzyloxycarbonyl (pNZ) deprotection ${ }^{[124]}$

Adapting the procedure of ISIDRO-LLOBET et al., pNZ deprotection was achieved by addition of a mixture of $6 \mathrm{M} \mathrm{SnCl}_{2}$ and $1.6 \mathrm{mM} \mathrm{HCl} /$ dioxane in DMF to the resin until it was covered completely. After shaking for $30 \mathrm{~min}$ at $\mathrm{rt}$, the process was repeated once and the resin was drained. Thorough washing with $\mathrm{DMF}, \mathrm{DMF} / \mathrm{H}_{2} \mathrm{O}(1: 1, v / v), \mathrm{THF} / \mathrm{H}_{2} \mathrm{O}(1: 1, v / v), \mathrm{DMF}$, $\mathrm{DCM}, \mathrm{MeOH}$ and DMF $(3 \times 5 \mathrm{~mL}$ each $)$ lead to the $\mathrm{pNZ}$-deprotected resin. 
SOP10: Cleavage

$\beta^{3}$-Peptides were cleaved from the dry rink amide resin by adding a mixture TFA/TIS/ $\mathrm{H}_{2} \mathrm{O}$ $(95: 2.5: 2.5, v / v / v)$ and shaking for $2 \mathrm{~h}$ at $\mathrm{rt}$. The drained solution was then concentrated under a nitrogen stream and cold ether $\left(-20^{\circ} \mathrm{C}\right)$ was added. The resulting precipitate was centrifuged $\left(9000 \mathrm{rpm}, 15 \mathrm{~min},-5^{\circ} \mathrm{C}\right.$ ) and washed with cold ether. After decantation, the crude peptide was dried under reduced pressure at rt. It has to be noted that all acid-labile protecting groups (Boc and $\mathrm{Mtt}$ ) are deprotected during the course of a cleavage for final peptides as well as intermediate products and are therefore not detectable in mass spectrometry.

\subsubsection{Preparation of Large Unilamellar Vesicles (LUVs)}

SOP11: Vesicle preparation via extrusion ${ }^{[224,225]}$

For establishing LUVs via the extrusion method, lipid films of defined lipid compositions were prepared in small test tubes. Therefore, lipids were dissolved in chloroform $(2 \mathrm{mg} / \mathrm{mL}$ or $10 \mathrm{mg} / \mathrm{mL}$ ) at $0{ }^{\circ} \mathrm{C}$ and if desired, peptide solutions in methanol were added to obtain a certain $\mathrm{P} / \mathrm{L}$ ratio. Afterwards, the mixture shaken at $300 \mathrm{rpm}$ at $50{ }^{\circ} \mathrm{C}$ under a nitrogen stream, resulting in a thin lipid film on the wall of the test tube. Complete drying was achieved with a vacuum oven which was used overnight at $50{ }^{\circ} \mathrm{C}$. To obtain a vesicle solution, the lipid film was then rehydrated with buffer (500 or $1000 \mu \mathrm{L})$ and gently shaken for at least $1 \mathrm{~h}$ at $40{ }^{\circ} \mathrm{C}$. Prior to extrusion, 5 cycles of vortexing for $1 \mathrm{~min}$ and shaking for $4 \mathrm{~min}$ at $40{ }^{\circ} \mathrm{C}$ were performed. Finally, the lipid suspension was extruded 31 times with a LiposoFast-Basic extruder from Avestin (Ottawa, Canada) and transferred to a glass vial. For defined vesicle sizes, polycarbonate membranes with a specific pore size as well as Whatman polyester drain discs from GE HEALTHCARE (Little Chalfont, UK) were used.

SOP12: Size exclusion chromatography of LUVs

Prepared LUVs were purified by using a the respective buffer and Sephadex ${ }^{\circledR}$ G-50 gel filtration medium from SigMA-ALDRICH (Taufkirchen, Germany). A small glass column was packed with the wet dextran gel and size exclusion chromatography was performed at atmospheric pressure with the sample being added in buffer solution onto the column. 
SOP13: Phosphate test ${ }^{[226]}$

Lipid concentrations of extruded LUVs were determined by analyzing the amount of phosphorus in the lipid solution. Therefore, a stock solution of $\mathrm{NaH}_{2} \mathrm{PO}_{4} \cdot \mathrm{H}_{2} \mathrm{O}(89.0 \mathrm{mg} / \mathrm{L})$ was used to create calibration samples with phosphorus contents ranging from 0 to $2 \mu \mathrm{g}$, diluting every sample with ultra-pure water to a total volume of $100 \mu \mathrm{L}$. Then, $22.0 \mu \mathrm{L}$ of the respective vesicle solution was treated with $200 \mu \mathrm{L}$ of $70 \%$ perchloric acid (aq.). After heating all samples to $220^{\circ} \mathrm{C}$ for $1 \mathrm{~h}$, they were cooled down to rt again and treated with $700 \mu \mathrm{L}$ of an aqueous solution consisting of $0.45 \% \mathrm{NH}_{4} \mathrm{MoO}_{4}$ and $12.6 \% \mathrm{HClO}_{4}$ as well as $700 \mu \mathrm{L}$ of an aqueous solution of $1.70 \%$ ascorbic acid. After vortexing every sample, they were incubated for $7.5 \mathrm{~min}$ at $80{ }^{\circ} \mathrm{C}$ in a water bath. The resulting molybdenum complex was then analyzed via UV/Vis spectroscopy, measuring the absorbance at $820 \mathrm{~nm}$. Using the calibration samples, a linear fit was calculated to derive the phosphorus content depending on the measured intensity. 


\subsection{Synthetic Procedures}

\subsubsection{Synthesis of Cyanuric Acid and Melamine modified $\beta^{3}$-Amino Acids}

(R)-7-Benzyloxycarbonylamino-3-tert-butoxycarbonylaminoheptanoic acid (9)

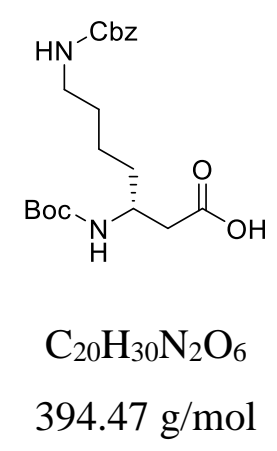

9

Conversion of Boc-D-Lys(Cbz)-OH (7.60 g, $20.0 \mathrm{mmol}, 1.00 \mathrm{eq})$ was achieved by following SOP2 and SOP3, resulting in product $9(7.39 \mathrm{~g}, 18.7 \mathrm{mmol}, 93 \%)$ as a colorless solid.

${ }^{1}$ H-NMR (300 MHz, DMSO- $\left.d_{6}\right): \delta / \mathrm{ppm}=12.2(\mathrm{sbr}, 1 \mathrm{H}, \mathrm{COOH}), 7.40-7.28(\mathrm{~m}, 5 \mathrm{H}, 5 \times$ Cbz-CHar), 7.24-7.15 (m, $1 \mathrm{H}, \mathrm{Cbz}-\mathrm{NH}), 6.66\left(\mathrm{~d}, 1 \mathrm{H},{ }^{3} \mathrm{~J}_{\mathrm{H}, \mathrm{H}}=8.7 \mathrm{~Hz}, \mathrm{Boc}-\mathrm{NH}\right), 4.99(\mathrm{~s}, 2 \mathrm{H}$, Cbz-CH $\mathrm{CH}_{2}$, 3.79-3.63 (m, $\left.1 \mathrm{H}, \beta-\mathrm{CH}\right), 3.00-2.86$ (m, $\left.2 \mathrm{H}, \zeta-\mathrm{CH}_{2}\right), 2.39-2.17$ (m, $2 \mathrm{H}, \alpha-\mathrm{CH}_{2}$ ), $1.42-1.16\left(\mathrm{~m}, 15 \mathrm{H}, 3 \times \mathrm{CH}_{3}, \gamma-\mathrm{CH}_{2}, \delta-\mathrm{CH}_{2}, \varepsilon-\mathrm{CH}_{2}\right)$.

ESI-MS $(\mathrm{m} / \mathrm{z}): 393.2[\mathrm{M}-\mathrm{H}]^{-}, 395.2[\mathrm{M}+\mathrm{H}]^{+}, 417.4[\mathrm{M}+\mathrm{Na}]^{+}, 811.7[2 \mathrm{M}+\mathrm{Na}]^{+}$. HR-MS (ESI): calc. for $\left[\mathrm{C}_{20} \mathrm{H}_{29} \mathrm{~N}_{2} \mathrm{O}_{6}\right]^{-}\left([\mathrm{M}-\mathrm{H}]^{-}\right)$: 393.2031, found: 393.2027, calc. for $\left[\mathrm{C}_{20} \mathrm{H}_{31} \mathrm{~N}_{2} \mathrm{O}_{6}\right]^{+}\left([\mathrm{M}+\mathrm{H}]^{+}\right):$395.2177, found: 395.2193, calc. for $\left[\mathrm{C}_{20} \mathrm{H}_{30} \mathrm{~N}_{2} \mathrm{O}_{6} \mathrm{Na}\right]^{+}$ $\left([\mathrm{M}+\mathrm{Na}]^{+}\right)$: 417.1996, found: 417.1978 . 
(R)-7-Amino-3-tert-butoxycarbonylaminoheptanoic acid (11) ${ }^{[227]}$

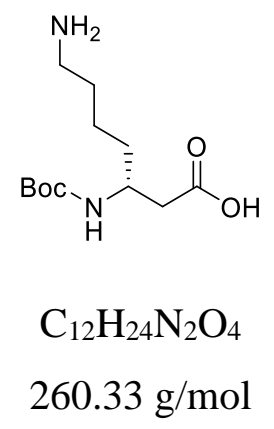

11

Boc- $\beta^{3}$-D-Lys(Cbz)-OH (13.5 g, $\left.34.2 \mathrm{mmol}, 1.00 \mathrm{eq}\right)$ was dissolved in degassed ethanol $(230 \mathrm{~mL})$ and $\mathrm{Pd} / \mathrm{C}(5 \%, 3.64 \mathrm{~g})$ was added to the solution. The mixture was stirred overnight with an overpressure of 4.5 bar of hydrogen gas at rt. Then, it was filtered through Celite $^{\circledR}$, followed by removal of the organic solvent under reduced pressure. Compound 11 (8.32 g, $32.0 \mathrm{mmol}, 94 \%$ ) was obtained as a colorless solid.

${ }^{1} \mathbf{H}-N M R\left(300 \mathrm{MHz}\right.$, methanol- $\left.d_{4}\right): \delta / \mathrm{ppm}=3.90-3.76\left(\mathrm{~m}, 1 \mathrm{H}, \beta-\mathrm{CH}_{2}\right), 2.97-2.86(\mathrm{~m}, 2 \mathrm{H}$, $\left.\zeta-\mathrm{CH}_{2}\right), 2.41-2.21\left(\mathrm{~m}, 2 \mathrm{H}, \alpha-\mathrm{CH}_{2}\right), 1.74-1.36\left(\mathrm{~m}, 15 \mathrm{H}, 3 \times \mathrm{CH}_{3}, \gamma-\mathrm{CH}_{2}, \delta-\mathrm{CH}_{2}, \varepsilon-\mathrm{CH}_{2}\right)$. ESI-MS $(m / z): 261.2[\mathrm{M}+\mathrm{H}]^{+}, 283.2[\mathrm{M}+\mathrm{Na}]^{+}$.

HR-MS (ESI): calc. for $\left[\mathrm{C}_{12} \mathrm{H}_{25} \mathrm{~N}_{2} \mathrm{O}_{4}\right]^{+}\left([\mathrm{M}+\mathrm{H}]^{+}\right): 261.1809$, found: 261.1812, calc. for $\left[\mathrm{C}_{12} \mathrm{H}_{24} \mathrm{~N}_{2} \mathrm{O}_{4} \mathrm{Na}\right]^{+}\left([\mathrm{M}+\mathrm{Na}]^{+}\right): 283.1628$, found: 283.1632 . 
(R)-7-(4,6-Diamino-1,3,5-triazine-2-yl)-amino-3-tert-butoxycarbonylaminoheptanoic acid (12) ${ }^{[228]}$

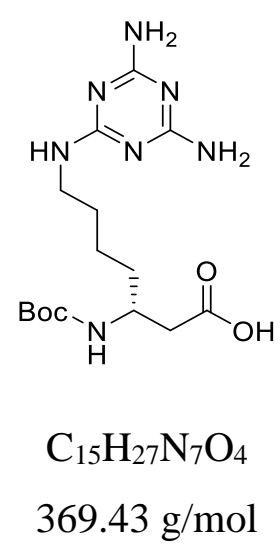

12

Boc- $\beta^{3}$-D-Lys-OH (4.99 g, $\left.19.2 \mathrm{mmol}, 1.00 \mathrm{eq}\right)$ was dissolved in $\mathrm{H}_{2} \mathrm{O}(54 \mathrm{~mL})$ and added to a suspension of 2,4-diamino-6-chlorotriazine (3.35 g, $23.0 \mathrm{mmol}, 1.20 \mathrm{eq})$ in $\mathrm{H}_{2} \mathrm{O}(13 \mathrm{~mL})$. $\mathrm{NaOH}(1.53 \mathrm{~g}, 38.3 \mathrm{mmol}, 2.00 \mathrm{eq})$ in $\mathrm{H}_{2} \mathrm{O}(38 \mathrm{~mL})$ was added dropwise and the mixture was stirred overnight at $85^{\circ} \mathrm{C}$. After cooling to $\mathrm{rt}$, the solution was filtered and adjusted to pH 5 with $1 \mathrm{M} \mathrm{HCl}$ (aq.) at $0{ }^{\circ} \mathrm{C}$. The resulting precipitate was filtered, washed with $\mathrm{H}_{2} \mathrm{O}$ $(2 \times 15 \mathrm{~mL})$ and dried under reduced pressure to obtain compound $\mathbf{1 2}$ as a colorless solid $(2.49 \mathrm{~g}, 6.74 \mathrm{mmol}, 35 \%)$.

${ }^{1}$ H-NMR (300 MHz, DMSO- $\left.d_{6}\right): \delta / p p m=6.66\left(\mathrm{~d}, 1 \mathrm{H},{ }^{3} J_{\mathrm{H}, \mathrm{H}}=8.7 \mathrm{~Hz}, \mathrm{Boc}-\mathrm{NH}\right), 6.42(\mathrm{t}$, $1 \mathrm{H},{ }^{3} J_{\mathrm{H}, \mathrm{H}}=5.8 \mathrm{~Hz}$, melamine-NH), 6.18-5.83 (m, $\left.4 \mathrm{H}, 2 \times \mathrm{NH}_{2}\right), 3.77-3.63(\mathrm{~m}, 1 \mathrm{H}, \beta-\mathrm{CH})$, 3.15-3.06 (m, $\left.2 \mathrm{H}, \zeta-\mathrm{CH}_{2}\right), 2.37-2.20\left(\mathrm{~m}, 2 \mathrm{H}, \alpha-\mathrm{CH}_{2}\right), 1.41-1.29\left(\mathrm{~m}, 15 \mathrm{H}, 3 \times \mathrm{CH}_{3}, \gamma-\mathrm{CH}_{2}\right.$, $\left.\delta-\mathrm{CH}_{2}, \varepsilon-\mathrm{CH}_{2}\right)$.

ESI-MS $(m / z): 370.2[\mathrm{M}+\mathrm{H}]^{+}, 392.2[\mathrm{M}+\mathrm{Na}]^{+}$.

HR-MS (ESI): calc. for $\left[\mathrm{C}_{15} \mathrm{H}_{28} \mathrm{~N}_{7} \mathrm{O}_{4}\right]^{+}\left([\mathrm{M}+\mathrm{H}]^{+}\right)$: 370.2197 , found: 370.2207 , calc. for $\left[\mathrm{C}_{15} \mathrm{H}_{27} \mathrm{~N}_{7} \mathrm{O}_{4} \mathrm{Na}\right]^{+}\left([\mathrm{M}+\mathrm{Na}]^{+}\right): 392.2017$, found: 392.2027 . 
(R)-7-(4,6-Diamino-1,3,5-triazine-2-yl)-amino-3-(9-fluorenylmehyloxycarbonyl)-aminoheptanoic acid (13) ${ }^{[228]}$

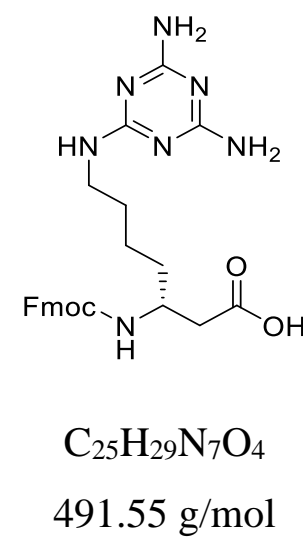

13

Boc- $\beta^{3}$-D-Lys(M)-OH (568 mg, $1.54 \mathrm{mmol}, 1.00$ eq) was dissolved in TFA (5 mL) and $\mathrm{H}_{2} \mathrm{O}$ $(100 \mu \mathrm{L})$ and stirred for $1 \mathrm{~h}$ at rt. After removing TFA in a nitrogen stream, the residue was suspended in $\mathrm{H}_{2} \mathrm{O}(50 \mathrm{~mL})$ and adjusted to $\mathrm{pH} 7$ with saturated $\mathrm{NaHCO}_{3}$ solution (aq.). $\mathrm{NaHCO}_{3}$ (194 mg, $\left.2.31 \mathrm{mmol}, 1.50 \mathrm{eq}\right)$ was added and Fmoc-OSu (795 mg, $2.31 \mathrm{mmol}$, $1.50 \mathrm{eq})$ in 1,4 -dioxane $(11 \mathrm{~mL})$ was added dropwise at $0{ }^{\circ} \mathrm{C}$. The mixture was stirred for $1 \mathrm{~h}$ at $0{ }^{\circ} \mathrm{C}$ and then at $\mathrm{rt}$ overnight. Afterwards, $\mathrm{H}_{2} \mathrm{O}(25 \mathrm{~mL})$ was added and the organic solvent was removed under reduced pressure. The aqueous phase was extracted with ethyl acetate $(2 \times 100 \mathrm{~mL})$ and then adjusted to $\mathrm{pH} 1$ with $1 \mathrm{M} \mathrm{HCl}$ (aq.) at $0{ }^{\circ} \mathrm{C}$. The resulting precipitate was filtered, washed with $\mathrm{H}_{2} \mathrm{O}(2 \times 15 \mathrm{~mL})$ and dried under reduced pressure to gain compound $\mathbf{1 3}$ (440 mg, $895 \mu \mathrm{mol}, 58 \%$ ) as a colorless solid.

${ }^{1} \mathbf{H}-N M R\left(300 \mathrm{MHz}, \mathrm{DMSO}-d_{6}\right): \delta / \mathrm{ppm}=7.91-7.76\left(\mathrm{~m}, 2 \mathrm{H}, 2 \times \mathrm{Fmoc}_{-} \mathrm{CH}_{\mathrm{ar}}\right.$ ), 7.69-7.57 (m, 2 H, $2 \times$ Fmoc-CH $\mathrm{CH}_{\mathrm{ar}}$ ), 7.43-7.31 (m, 4 H, $4 \times$ Fmoc- $\mathrm{CH}_{\mathrm{ar}}$ ), 4.34-4.13 (m, 3 H, Fmoc-CH, Fmoc- $\mathrm{CH}_{2}$ ), 3.81-3.67 (m, $\left.1 \mathrm{H}, \beta-\mathrm{CH}\right), 2.38-2.27$ (m, $\left.2 \mathrm{H}, \zeta-\mathrm{CH}_{2}\right), 2.25-2.19(\mathrm{~m}, 2 \mathrm{H}, \alpha-$ $\left.\mathrm{CH}_{2}\right), 1.50-1.12\left(\mathrm{~m}, 6 \mathrm{H}, \gamma-\mathrm{CH}_{2}, \delta-\mathrm{CH}_{2}, \varepsilon-\mathrm{CH}_{2}\right)$.

ESI-MS $(m / z): 492.2[\mathrm{M}+\mathrm{H}]^{+}, 983.5[2 \mathrm{M}+\mathrm{H}]^{+}, 490.2[\mathrm{M}-\mathrm{H}]^{-}$.

HR-MS (ESI): calc. for $\left[\mathrm{C}_{25} \mathrm{H}_{30} \mathrm{~N}_{7} \mathrm{O}_{4}\right]^{+}\left([\mathrm{M}+\mathrm{H}]^{+}\right)$: 492.2354, found: 492.2357, calc. for $\left[\mathrm{C}_{25} \mathrm{H}_{28} \mathrm{~N}_{7} \mathrm{O}_{4}\right]^{-}\left([\mathrm{M}-\mathrm{H}]^{-}\right): 490.2208$, found: 490.2195 . 
(R)-3-tert-Butoxycarbonylamino-7-hydroxyheptanoic acid (14) ${ }^{[229]}$

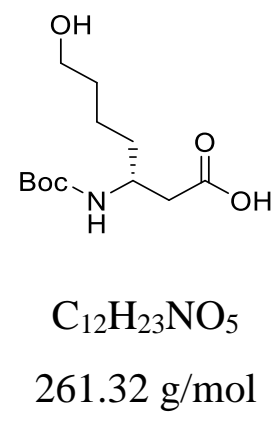

14

Boc- $\beta^{3}$-D-Lys-OH $(5.00 \mathrm{~g}, 19.2 \mathrm{mmol}, 1.00 \mathrm{eq})$ was dissolved in $\mathrm{H}_{2} \mathrm{O}(74 \mathrm{~mL})$ and $4 \mathrm{M}$ $\mathrm{NaOH}$ (aq., $7.4 \mathrm{~mL}$ ) was added at $60{ }^{\circ} \mathrm{C}$. Sodium nitroprusside $(8.74 \mathrm{~g}, 29.3 \mathrm{mmol}, 1.53 \mathrm{eq})$ and $4 \mathrm{M} \mathrm{NaOH}$ (aq., $7.4 \mathrm{~mL}$ ) were added in small portions over $1 \mathrm{~h}$ and the mixture was stirred for $5 \mathrm{~h}$ at $60{ }^{\circ} \mathrm{C}$. After cooling to $10{ }^{\circ} \mathrm{C}$ and adjusting the $\mathrm{pH}$ to $2-3$ with $1 \mathrm{M} \mathrm{HCl}$ (aq.), the aqueous solution was extracted with ethyl acetate $(3 \times 100 \mathrm{~mL})$, dried over $\mathrm{MgSO}_{4}$ and the solvent was removed under reduced pressure. Flash column chromatography of the residue $(\mathrm{DCM} / \mathrm{MeOH}=24: 1+0.25 \% \mathrm{AcOH} \rightarrow 9: 1+1.00 \% \mathrm{AcOH})$ lead to compound 14 $(2.51 \mathrm{~g}, 9.61 \mathrm{mmol}, 50 \%)$ as a yellow oil.

${ }^{1}$ H-NMR (300 MHz, DMSO- $\left.d_{6}\right): \delta / \mathrm{ppm}=6.64\left(\mathrm{~d}, 1 \mathrm{H},{ }^{3} J_{\mathrm{H}, \mathrm{H}}=8.9 \mathrm{~Hz}\right.$, Boc-NH), 3.81-3.63 $(\mathrm{m}, 1 \mathrm{H}, \beta-\mathrm{CH}), 3.35\left(\mathrm{t}, 2 \mathrm{H},{ }^{3} J_{\mathrm{H}, \mathrm{H}}=6.3 \mathrm{~Hz}, \zeta-\mathrm{CH}_{2}\right), 2.32-2.24\left(\mathrm{~m}, 2 \mathrm{H}, \alpha-\mathrm{CH}_{2}\right), 1.47-1.22$ (m, $15 \mathrm{H}, 3 \times \mathrm{CH}_{3}, \gamma-\mathrm{CH}_{2}, \delta-\mathrm{CH}_{2}, \varepsilon-\mathrm{CH}_{2}$ ).

ESI-MS $(\mathrm{m} / z): 262.2[\mathrm{M}+\mathrm{H}]^{+}, 284.2[\mathrm{M}+\mathrm{Na}]^{+}, 545.3[2 \mathrm{M}+\mathrm{Na}]^{+}$.

HR-MS (ESI): calc. for $\left[\mathrm{C}_{12} \mathrm{H}_{24} \mathrm{NO}_{5}\right]^{+}\left([\mathrm{M}+\mathrm{H}]^{+}\right)$: 262.1649, found: 262.1657 , calc. for $\left[\mathrm{C}_{12} \mathrm{H}_{23} \mathrm{NO}_{5} \mathrm{Na}\right]^{+}\left([\mathrm{M}+\mathrm{Na}]^{+}\right): 284.1468$, found: 284.1480 . 
(R)-7-Bromo-3-tert-butoxycarbonylaminoheptanoic acid (15) $)^{[230,231]}$

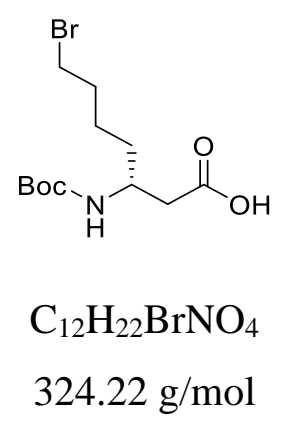

15

Under an argon atmosphere, Boc- $\beta^{3}$-D-Lys(OH)-OH (232 mg, $\left.888 \mu \mathrm{mol}, 1.00 \mathrm{eq}\right)$ was dissolved in THF $(10 \mathrm{~mL})$ and $\mathrm{CBr}_{4}(422 \mathrm{mg}, 1.27 \mathrm{mmol}, 1.45 \mathrm{eq})$ was added at $0{ }^{\circ} \mathrm{C}$. After stirring for $30 \mathrm{~min}$ at $0{ }^{\circ} \mathrm{C}$, a $\mathrm{PPh}_{3}$-Polymer $(1.90 \mathrm{~g}, 1.0-1.5 \mathrm{mmol} / \mathrm{g}, 2.10 \mathrm{eq})$ was added and the mixture was stirred for $1 \mathrm{~h}$ at $0{ }^{\circ} \mathrm{C}$ and then overnight at $\mathrm{rt}$. The suspension was filtered through Celite ${ }^{\circledR}$, washed with THF $(3 \times 5 \mathrm{~mL})$ and the solvent was removed under reduced pressure. Flash column chromatography $(\mathrm{DCM} / \mathrm{MeOH}=24: 1+0.40 \% \mathrm{AcOH})$ lead to compound 15 (171 mg, $529 \mu \mathrm{mol}, 60 \%)$ as a colorless solid.

${ }^{1}$ H-NMR $\left(300 \mathrm{MHz}, \mathrm{DMSO}-d_{6}\right): \delta / \mathrm{ppm}=12.1(\mathrm{sbr}, 1 \mathrm{H}, \mathrm{COOH}), 6.69\left(\mathrm{~d}, 1 \mathrm{H},{ }^{3} J_{\mathrm{H}, \mathrm{H}}=\right.$ $9.0 \mathrm{~Hz}$, Boc-NH), 3.83-3.65 (m, $1 \mathrm{H}, \beta-\mathrm{CH}), 3.50\left(\mathrm{t}, 2 \mathrm{H},{ }^{3} J_{\mathrm{H}, \mathrm{H}}=6.6 \mathrm{~Hz}, \zeta-\mathrm{CH}_{2}\right), 2.38-2.21$ (m, $\left.2 \mathrm{H}, \alpha-\mathrm{CH}_{2}\right), 1.38-1.35\left(\mathrm{~m}, 15 \mathrm{H}, 3 \times \mathrm{CH}_{3}, \gamma-\mathrm{CH}_{2}, \delta-\mathrm{CH}_{2}, \varepsilon-\mathrm{CH}_{2}\right.$ ).

ESI-MS $(m / z): 346.1\left[\mathrm{M}\left({ }^{79} \mathrm{Br}\right)+\mathrm{Na}\right]^{+}, 348.1\left[\mathrm{M}\left({ }^{81} \mathrm{Br}\right)+\mathrm{Na}\right]^{+}$.

HR-MS (ESI): calc. for $\left[\mathrm{C}_{12} \mathrm{H}_{22}{ }^{79} \mathrm{BrNO}_{4} \mathrm{Na}\right]^{+}\left([\mathrm{M}+\mathrm{Na}]^{+}\right)$: 346.0624, found: 346.0625 , calc. for $\left[\mathrm{C}_{12} \mathrm{H}_{22}{ }^{81} \mathrm{BrNO}_{4} \mathrm{Na}\right]^{+}\left([\mathrm{M}+\mathrm{Na}]^{+}\right)$: 348.0604 , found: 348.0607 . 
(R)-3-tert-Butoxycarbonylamino-7-(2,4,6-trioxo-1,3,5-triazine-1-yl)heptanoic acid (16) ${ }^{[232]}$

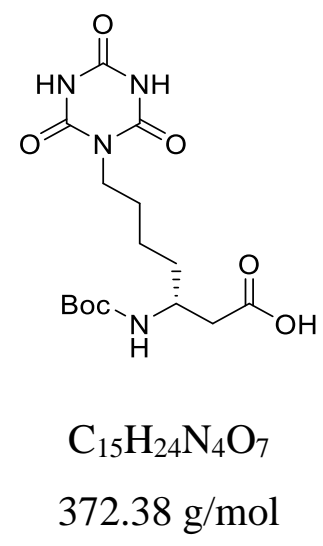

16

Under an argon atmosphere, Boc- $\beta^{3}$-D-Lys(Br)-OH (1.01 g, $\left.3.12 \mathrm{mmol}, 1.00 \mathrm{eq}\right)$ and cyanuric acid (2.01 g, $15.6 \mathrm{mmol}, 5.00 \mathrm{eq})$ were dissolved in dry DMF (20 mL) and DBU (470 $\mu \mathrm{L}, 3.12 \mathrm{mmol}, 1.00 \mathrm{eq})$ was added dropwise at $\mathrm{rt}$. The mixture was stirred for $2 \mathrm{~d}$ at $70{ }^{\circ} \mathrm{C}$ and the solvent was then removed under reduced pressure. The residue was suspended in $\mathrm{H}_{2} \mathrm{O}(50 \mathrm{~mL})$ and the $\mathrm{pH}$ was adjusted to 5 with $1 \mathrm{M} \mathrm{HCl}$ (aq.). DCM (50 mL) was added and excessive cyanuric acid was separated via filtration. The mixture was extracted with $\operatorname{DCM}(3 \times 50 \mathrm{~mL})$, dried over $\mathrm{MgSO}_{4}$ and purified by performing flash column chromatography $(\mathrm{DCM} / \mathrm{MeOH}=24: 1+0.50 \% \mathrm{AcOH} \rightarrow 9: 1+0.50 \% \mathrm{AcOH})$. Product $16(275 \mathrm{mg}$, $738 \mu \mathrm{mol}, 24 \%$ ) was obtained as a colorless solid.

${ }^{1}$ H-NMR (300 MHz, DMSO- $\left.d_{6}\right): \delta / p p m=6.81-6.59(\mathrm{~m}, 1 \mathrm{H}$, Boc-NH), 3.80-3.50 (m, $3 \mathrm{H}$, $\left.\beta-\mathrm{CH}, \zeta-\mathrm{CH}_{2}\right), 2.27-2.01\left(\mathrm{~m}, 2 \mathrm{H}, \alpha-\mathrm{CH}_{2}\right), 1.51-1.11\left(\mathrm{~m}, 15 \mathrm{H}, 3 \times \mathrm{CH}_{3}, \gamma-\mathrm{CH}_{2}, \delta-\mathrm{CH}_{2}, \varepsilon-\right.$ $\left.\mathrm{CH}_{2}\right)$.

ESI-MS $(m / z): 373.2[\mathrm{M}+\mathrm{H}]^{+}, 395.2[\mathrm{M}+\mathrm{Na}]^{+}$.

HR-MS (ESI): calc. for $\left[\mathrm{C}_{15} \mathrm{H}_{25} \mathrm{~N}_{4} \mathrm{O}_{7}\right]^{+}\left([\mathrm{M}+\mathrm{H}]^{+}\right)$: 373.1718 , found: 373.1701 , calc. for $\left[\mathrm{C}_{15} \mathrm{H}_{24} \mathrm{~N}_{4} \mathrm{O}_{7} \mathrm{Na}\right]^{+}\left([\mathrm{M}+\mathrm{Na}]^{+}\right): 395.1537$, found: 395.1543 . 
(R)-3-(9-Fluorenylmehyloxycarbonyl)-amino-7-(2,4,6-trioxo-1,3,5-triazine-1-yl)-heptanoic $\operatorname{acid}(\mathbf{1 7})^{[13]}$

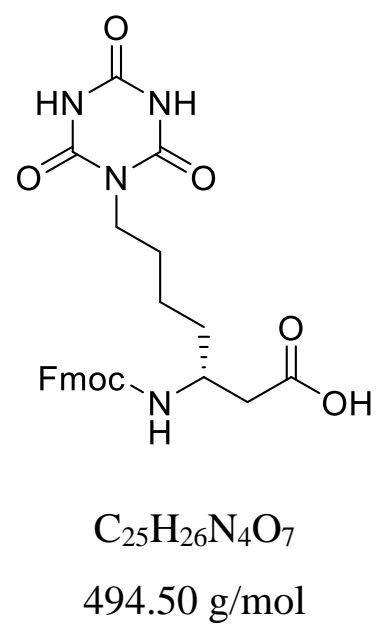

17

Boc- $\beta^{3}$-D-Lys(CA)-OH (267 mg, $\left.717 \mu \mathrm{mol}, 1.00 \mathrm{eq}\right)$ was dissolved in a mixture of TFA and $\mathrm{H}_{2} \mathrm{O}(95: 5, v / v, 10.5 \mathrm{~mL})$ and stirred for $1 \mathrm{~h}$ at $0{ }^{\circ} \mathrm{C}$, followed by stirring for $1 \mathrm{~h}$ at $\mathrm{rt}$. Excessive TFA was removed in a nitrogen stream and coevaporated with toluene $(3 \times 25 \mathrm{~mL})$. After lyophilization, the residue was dissolved in $\mathrm{H}_{2} \mathrm{O}(5 \mathrm{~mL})$, neutralized with saturated $\mathrm{NaHCO}_{3}$ solution (aq.) and $\mathrm{NaHCO}_{3}(91.0 \mathrm{mg}, 1.08 \mathrm{mmol}, 1.51 \mathrm{eq})$ was added. Fmoc-OSu (363 mg, $1.08 \mathrm{mmol}, 1.51 \mathrm{eq})$ in 1,4-dioxane $(5 \mathrm{~mL})$ was added dropwise at $0{ }^{\circ} \mathrm{C}$ and the mixture was stirred for $1 \mathrm{~h}$ at $0{ }^{\circ} \mathrm{C}$, followed by stirring overnight at $\mathrm{rt}$. The solvent was removed under reduced pressure and the remaining product was purified via flash column chromatography $(\mathrm{DCM} / \mathrm{MeOH}=24: 1+0.25 \% \mathrm{AcOH} \rightarrow 9: 1+1.00 \% \mathrm{AcOH})$ to obtain product 17 (274 mg, $554 \mu \mathrm{mol}, 77 \%)$ as a colorless solid.

${ }^{1} \mathbf{H}-N M R\left(300 \mathrm{MHz}, \mathrm{DMSO}-d_{6}\right): \delta / \mathrm{ppm}=7.88\left(\mathrm{~d}, 2 \mathrm{H},{ }^{3} J_{\mathrm{H}, \mathrm{H}}=7.4 \mathrm{~Hz}, 2 \times\right.$ Fmoc-CH $_{\mathrm{ar}}$ ), $7.68\left(\mathrm{~d}, 2 \mathrm{H},{ }^{3} J_{\mathrm{H}, \mathrm{H}}=7.4 \mathrm{~Hz}, 2 \times\right.$ Fmoc- $\left.\mathrm{CH}_{\mathrm{ar}}\right), 7.44-7.28\left(\mathrm{~m}, 4 \mathrm{H}, 4 \times\right.$ Fmoc-CH $\left.\mathrm{CH}_{\mathrm{ar}}\right), 7.23(\mathrm{~d}$, $1 \mathrm{H},{ }^{3} J_{\mathrm{H}, \mathrm{H}}=8.5 \mathrm{~Hz}$, Fmoc-NH), 4.35-4.16 (m, $3 \mathrm{H}$, Fmoc-CH, Fmoc-CH $\left.\mathrm{CH}_{2}\right)$, 3.77-3.68 (m, $1 \mathrm{H}, \beta-\mathrm{CH}), 3.63-3.57\left(\mathrm{~m}, 2 \mathrm{H}, \zeta-\mathrm{CH}_{2}\right), 2.35-2.15\left(\mathrm{~m}, 2 \mathrm{H}, \alpha-\mathrm{CH}_{2}\right), 1.56-1.13(\mathrm{~m}, 6 \mathrm{H}, \gamma-$ $\left.\mathrm{CH}_{2}, \delta-\mathrm{CH}_{2}, \varepsilon-\mathrm{CH}_{2}\right)$.

ESI-MS $(\mathrm{m} / \mathrm{z}): 495.3[\mathrm{M}+\mathrm{H}]^{+}, 517.3[\mathrm{M}+\mathrm{Na}]^{+}$.

HR-MS (ESI): calc. for $\left[\mathrm{C}_{25} \mathrm{H}_{27} \mathrm{~N}_{4} \mathrm{O}_{7}\right]^{+}\left([\mathrm{M}+\mathrm{H}]^{+}\right)$: 495.1874, found: 495.1877, calc. for $\left[\mathrm{C}_{25} \mathrm{H}_{26} \mathrm{~N}_{4} \mathrm{O}_{7} \mathrm{Na}\right]^{+}\left([\mathrm{M}+\mathrm{Na}]^{+}\right): 517.1694$, found: 517.1691 . 


\subsubsection{Synthesis of other $\beta^{3}$-Amino Acids}

(R)-3-(9-Fluorenylmehyloxycarbonyl)-amino-4-methyl-pentanoic acid (3)

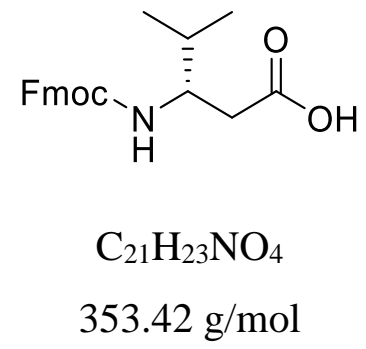

3

Starting from Fmoc-D-Val-OH (10.0 g, $29.5 \mathrm{mmol}, 1.00 \mathrm{eq})$, compound 3 (7.98 g, $22.6 \mathrm{mmol}, 77 \%$ ) was obtained by following SOP2 and SOP4 as a colorless solid.

${ }^{1}$ H-NMR (300 MHz, DMSO- $\left.d_{6}\right): \delta / p p m=12.1(\mathrm{sbr}, 1 \mathrm{H}, \mathrm{OH}), 7.89\left(\mathrm{~d}, 2 \mathrm{H},{ }^{3} J_{\mathrm{H}, \mathrm{H}}=7.4 \mathrm{~Hz}\right.$, $2 \times$ Fmoc- $\mathrm{CH}_{\mathrm{ar}}$ ), 7.74-7.66 (m, 2 H, $2 \times$ Fmoc- $\mathrm{CH}_{\mathrm{ar}}$ ), 7.46-7.26 (m, 4 H, $4 \times$ Fmoc-CHar), $7.24\left(\mathrm{~d}, 1 \mathrm{H},{ }^{3} J_{\mathrm{H}, \mathrm{H}}=9.0 \mathrm{~Hz}, \mathrm{NH}\right), 4.36-4.16$ (m, $3 \mathrm{H}$, Fmoc- $\mathrm{CH}_{2}$, Fmoc-CH), 3.78-3.67 (m, $1 \mathrm{H}, \beta-\mathrm{CH}), 2.44-2.23\left(\mathrm{~m}, 2 \mathrm{H}, \alpha-\mathrm{CH}_{2}\right), 1.77-1.64(\mathrm{~m}, 1 \mathrm{H}, \gamma-\mathrm{CH}), 0.88-0.77(\mathrm{~m}, 6 \mathrm{H}, 2 \times$ $\left.\mathrm{CH}_{3}\right)$.

ESI-MS $(\mathrm{m} / \mathrm{z}): 354.2[\mathrm{M}+\mathrm{H}]^{+}, 376.3[\mathrm{M}+\mathrm{Na}]^{+}, 729.5[2 \mathrm{M}+\mathrm{Na}]^{+}$.

HR-MS (ESI): calc. for $\left[\mathrm{C}_{21} \mathrm{H}_{24} \mathrm{NO}_{4}\right]^{+}\left([\mathrm{M}+\mathrm{H}]^{+}\right)$: 354.1700, found: 354.1699 , calc. for $\left[\mathrm{C}_{21} \mathrm{H}_{23} \mathrm{NO}_{4} \mathrm{Na}\right]^{+}\left([\mathrm{M}+\mathrm{Na}]^{+}\right): 376.1519$, found: 376.1516 . 
(R)-7-tert-Butoxycarbonylamino-3-(9-fluorenylmethyloxycarbonyl)aminoheptanoic acid (6)

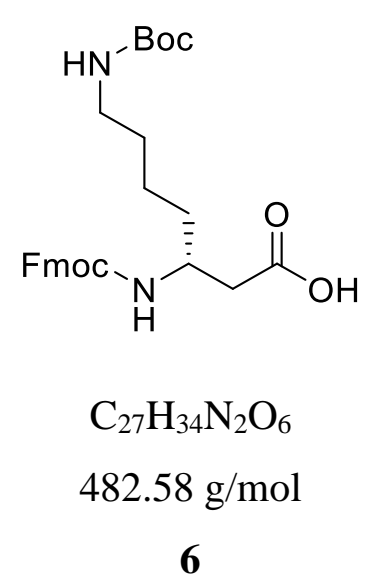

Starting from Fmoc-D-Lys(Boc)-OH (10.0 g, $21.3 \mathrm{mmol}, 1.00 \mathrm{eq})$, compound 6 (8.15 g, $16.9 \mathrm{mmol}, 79 \%$ ) was obtained by following SOP2 and SOP3 as a light yellow solid.

${ }^{1} \mathbf{H}-N M R\left(300 \mathrm{MHz}, \mathrm{DMSO}-d_{6}\right): \delta / \mathrm{ppm}=12.2(\mathrm{sbr}, 1 \mathrm{H}, \mathrm{OH}), 7.89\left(\mathrm{~d}, 2 \mathrm{H},{ }^{3} J_{\mathrm{H}, \mathrm{H}}=7.7 \mathrm{~Hz}\right.$, $2 \times$ Fmoc- $\mathrm{CH}_{\mathrm{ar}}$ ), $7.68\left(\mathrm{~d}, 2 \mathrm{H},{ }^{3} \mathrm{~J}_{\mathrm{H}, \mathrm{H}}=7.5 \mathrm{~Hz}, 2 \times\right.$ Fmoc-CHar $), 7.46-7.28(\mathrm{~m}, 4 \mathrm{H}, 4 \times$ Fmoc$\left.\mathrm{CH}_{\mathrm{ar}}\right), 7.21\left(\mathrm{~d}, 1 \mathrm{H},{ }^{3} J_{\mathrm{H}, \mathrm{H}}=8.6 \mathrm{~Hz}, \mathrm{NH}\right), 6.82-6.72(\mathrm{~m}, 1 \mathrm{H}, \mathrm{NH}), 4.32-4.16$ (m, $3 \mathrm{H}$, Fmoc$\mathrm{CH}_{2}$, Fmoc-CH), 3.81-3.68 (m, $\left.1 \mathrm{H}, \beta-\mathrm{CH}\right), 2.92-2.83$ (m, $\left.2 \mathrm{H}, \alpha-\mathrm{CH}_{2}\right), 2.42-2.24(\mathrm{~m}, 2 \mathrm{H}$, $\left.\zeta-\mathrm{CH}_{2}\right), 1.44-1.15\left(\mathrm{~m}, 15 \mathrm{H}, 3 \times \mathrm{CH}_{3}, \gamma-\mathrm{CH}_{2}, \delta-\mathrm{CH}_{2}, \varepsilon-\mathrm{CH}_{2}\right)$.

ESI-MS $(m / z): 483.2[\mathrm{M}+\mathrm{H}]^{+}, 505.2[\mathrm{M}+\mathrm{Na}]^{+}, 987.5[2 \mathrm{M}+\mathrm{Na}]^{+}$.

HR-MS (ESI): calc. for $\left[\mathrm{C}_{27} \mathrm{H}_{35} \mathrm{~N}_{2} \mathrm{O}_{6}\right]^{+}\left([\mathrm{M}+\mathrm{H}]^{+}\right)$: 483.2490, found: 483.2494, calc. for $\left[\mathrm{C}_{27} \mathrm{H}_{38} \mathrm{~N}_{3} \mathrm{O}_{6}\right]^{+}\left(\left[\mathrm{M}+\mathrm{NH}_{4}\right]^{+}\right): 500.2755$, found: 500.2752, calc. for $\left[\mathrm{C}_{27} \mathrm{H}_{34} \mathrm{~N}_{2} \mathrm{O}_{6} \mathrm{Na}\right]^{+}$ $\left([\mathrm{M}+\mathrm{Na}]^{+}\right):$505.2309, found: 505.2315. 
(R)-7-tert-Butoxycarbonylamino-3-tert-butoxycarbonylaminoheptanoic acid (8)

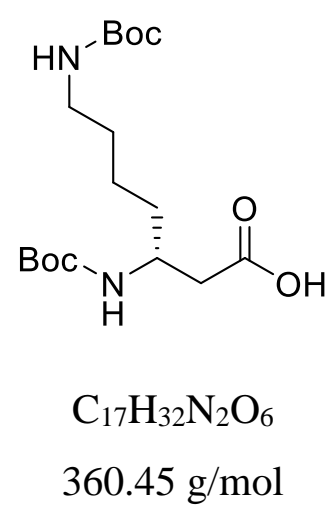

8

Starting from Boc-D-Lys(Boc)-OH (5.00 g, $14.4 \mathrm{mmol}$, $1.00 \mathrm{eq})$, compound 8 (4.80 g, $13.3 \mathrm{mmol}, 92 \%$ ) was obtained by following SOP2 and SOP3 as a light yellow solid.

${ }^{1}$ H-NMR (300 MHz, DMSO- $\left.d_{6}\right): \delta / p p m=12.2(\mathrm{sbr}, 1 \mathrm{H}, \mathrm{OH}), 6.76-6.68(\mathrm{~m}, 1 \mathrm{H}, \mathrm{NH}), 6.63$ $\left(\mathrm{d}, 1 \mathrm{H},{ }^{3} J_{\mathrm{H}, \mathrm{H}}=8.7 \mathrm{~Hz}, \mathrm{NH}\right), 3.77-3.61(\mathrm{~m}, 1 \mathrm{H}, \beta-\mathrm{CH}), 2.94-2.80\left(\mathrm{~m}, 2 \mathrm{H}, \alpha-\mathrm{CH}_{2}\right), 2.40-$ $2.16\left(\mathrm{~m}, 2 \mathrm{H}, \zeta-\mathrm{CH}_{2}\right), 1.37-1.26\left(\mathrm{~m}, 24 \mathrm{H}, 6 \times \mathrm{CH}_{3}, \gamma-\mathrm{CH}_{2}, \delta-\mathrm{CH}_{2}, \varepsilon-\mathrm{CH}_{2}\right)$.

ESI-MS $(\mathrm{m} / \mathrm{z}): 361.3[\mathrm{M}+\mathrm{H}]^{+}, 378.3\left[\mathrm{M}+\mathrm{NH}_{4}\right]^{+} 383.2[\mathrm{M}+\mathrm{Na}]^{+}$.

HR-MS (ESI): calc. for $\left[\mathrm{C}_{17} \mathrm{H}_{33} \mathrm{~N}_{2} \mathrm{O}_{6}\right]^{+}\left([\mathrm{M}+\mathrm{H}]^{+}\right)$: 361.2333, found: 361.2339 , calc. for $\left[\mathrm{C}_{17} \mathrm{H}_{36} \mathrm{~N}_{3} \mathrm{O}_{6}\right]^{+}\left(\left[\mathrm{M}+\mathrm{NH}_{4}\right]^{+}\right): 378.2599$, found: 378.2597 , calc. for $\left[\mathrm{C}_{17} \mathrm{H}_{32} \mathrm{~N}_{2} \mathrm{O}_{6} \mathrm{Na}\right]^{+}$ $\left([\mathrm{M}+\mathrm{Na}]^{+}\right)$: 383.2153, found: 383.2156. 
(R)-4-(1'-tert-Butoxycarbonyl-indo-3'-yl)-3-(9-fluorenylmethyloxycarbonyl)-aminobutanoic acid (5)

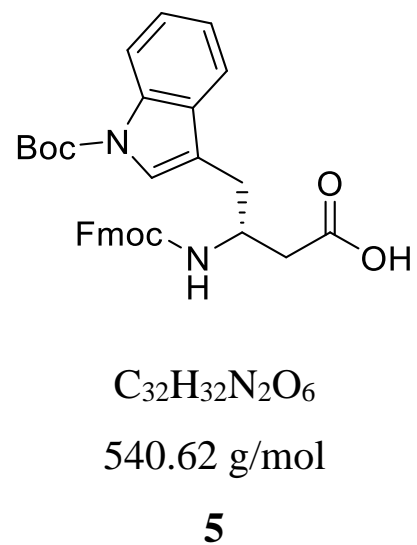

Starting from Fmoc-D-Trp(Boc)-OH (5.02 g, $9.53 \mathrm{mmol}, 1.00 \mathrm{eq})$, compound 5 (4.58 g, $8.47 \mathrm{mmol}, 89 \%$ ) was obtained by following SOP2 and SOP3 as a light yellow solid.

${ }^{1}$ H-NMR (300 MHz, DMSO-d6): $\delta / \mathrm{ppm}=12.3(\mathrm{sbr}, 1 \mathrm{H}, \mathrm{OH}), 8.06-7.13(\mathrm{~m}, 14 \mathrm{H}, 4 \times$ Fmoc- $\mathrm{CH}_{\mathrm{ar}}$, Fmoc-NH, $2 \times$ Fmoc- $\mathrm{CH}_{\mathrm{ar}}, 2 \times$ Fmoc- $\mathrm{CH}_{\mathrm{ar}}, 5 \times \mathrm{CH}_{\mathrm{Trp}}$ ), 4.25-4.06 (m, $3 \mathrm{H}$, Fmoc- $\mathrm{CH}_{2}$, Fmoc-CH), 3.69-3.61 (m, $\left.1 \mathrm{H}, \mathrm{CH}\right), 3.39-3.25$ (m, $\left.3 \mathrm{H}, \alpha-\mathrm{CH}_{2}, \gamma-\mathrm{CH}_{2}\right), 2.91-$ $2.80\left(\mathrm{~m}, 1 \mathrm{H}, \alpha-\mathrm{CH}_{2}\right), 1.60-1.50\left(\mathrm{~m}, 9 \mathrm{H}, 3 \times \mathrm{CH}_{3}\right)$.

ESI-MS $(m / z): 541.2[\mathrm{M}+\mathrm{H}]^{+}, 563.2[\mathrm{M}+\mathrm{Na}]^{+}, 1103.5[2 \mathrm{M}+\mathrm{Na}]^{+}$.

HR-MS (ESI): calc. for $\left[\mathrm{C}_{32} \mathrm{H}_{33} \mathrm{~N}_{2} \mathrm{O}_{6}\right]^{+}\left([\mathrm{M}+\mathrm{H}]^{+}\right)$: 541.2333, found: 541.2327, calc. for $\left[\mathrm{C}_{32} \mathrm{H}_{32} \mathrm{~N}_{2} \mathrm{O}_{6} \mathrm{Na}\right]^{+}\left([\mathrm{M}+\mathrm{Na}]^{+}\right): 563.2153$, found: 563.2158. 
$(R)-2-(p-N i t r o b e n z y l o x y c a r b o n y l)-a m i n o-3-m e t h y l-b u t a n o i c ~ a c i d ~(28)^{[124]}$<smiles>CC(C)[C@H](NC(=O)OCc1ccc([N+](=O)[O-])cc1)C(=O)O</smiles>

28

To a solution of 4-nitrobenzyl chloroformate $(9.20 \mathrm{~g}, 42.7 \mathrm{mmol}, 1.00 \mathrm{eq})$ in 1,4-dioxane (19 mL), $\mathrm{NaN}_{3}(3.33 \mathrm{~g}, 51.2 \mathrm{mmol}, 1.20 \mathrm{eq})$ in $\mathrm{H}_{2} \mathrm{O}(13 \mathrm{~mL})$ was added. The emulsion was stirred at $\mathrm{rt}$ until completion was detected via TLC $(2 \mathrm{~h})$. The resulting pNZ-azide was then treated with a solution of $\mathrm{H}-\mathrm{D}-\mathrm{Val}-\mathrm{OH}(5.00 \mathrm{~g}, 42.7 \mathrm{mmol}, 1.00 \mathrm{eq})$ in $2 \% \mathrm{Na}_{2} \mathrm{CO}_{3}$ solution (aq.) and 1,4-dioxane $(1: 1, v / v, 54 \mathrm{~mL})$. The mixture was stirred for $24 \mathrm{~h}$ at $\mathrm{rt}$, keeping the $\mathrm{pH}$ at 9-10 with $10 \% \mathrm{Na}_{2} \mathrm{CO}_{3}$ solution (aq.). After completion of the reaction, $\mathrm{H}_{2} \mathrm{O}(400 \mathrm{~mL})$ was added and the solution was extracted with methyl tert-butyl ether $(3 \times 200 \mathrm{~mL})$. The aqueous solution was adjusted to $\mathrm{pH} 2-3$ with $3 \mathrm{M} \mathrm{HCl}$ (aq.), extracted with ethyl acetate $(3 \times 200 \mathrm{~mL})$, dried over $\mathrm{MgSO}_{4}$ and the solvent was removed under reduced pressure. The crude product was purified via flash column chromatography $\left(\mathrm{Et}_{2} \mathrm{O} / \mathrm{EtOAc}=1: 1+1.00 \%\right.$ $\mathrm{AcOH})$ and compound 28 (7.75 g, $26.2 \mathrm{mmol}, 62 \%)$ was obtained as a colorless solid.

${ }^{1}$ H-NMR (300 MHz, DMSO-d $\left.)\right): \delta / p p m=12.4(\mathrm{sbr}, 1 \mathrm{H}, \mathrm{OH}), 8.23\left(\mathrm{~d}, 2 \mathrm{H},{ }^{3} J_{\mathrm{H}, \mathrm{H}}=8.7 \mathrm{~Hz}\right.$, $2 \times \mathrm{pNZ}-\mathrm{CH}_{\mathrm{ar}}$ ), 7.67-7.60 (m, $\left.2 \mathrm{H}, 2 \times \mathrm{pNZ}-\mathrm{CH}_{\mathrm{ar}}\right), 5.20\left(\mathrm{~s}, 2 \mathrm{H}, \mathrm{pNZ}-\mathrm{CH}_{2}\right), 3.92(\mathrm{dd}, 1 \mathrm{H}$, $\left.{ }^{3} J_{\mathrm{H}, \mathrm{H}}=8.6 \mathrm{~Hz}, 5.8 \mathrm{~Hz}, \alpha-\mathrm{CH}\right), 2.17-1.99(\mathrm{~m}, 1 \mathrm{H}, \beta-\mathrm{CH}), 0.99-0.86\left(\mathrm{~m}, 6 \mathrm{H}, 2 \times \mathrm{CH}_{3}\right)$.

ESI-MS $(\mathrm{m} / \mathrm{z}): 297.1[\mathrm{M}+\mathrm{H}]^{+}, 319.1[\mathrm{M}+\mathrm{Na}]^{+}, 615.2[2 \mathrm{M}+\mathrm{Na}]^{+}$.

HR-MS (ESI): calc. for $\left[\mathrm{C}_{13} \mathrm{H}_{17} \mathrm{~N}_{2} \mathrm{O}_{6}\right]^{+}\left([\mathrm{M}+\mathrm{H}]^{+}\right)$: 297.1081, found: 297.1095, calc. for $\left[\mathrm{C}_{13} \mathrm{H}_{16} \mathrm{~N}_{2} \mathrm{O}_{6} \mathrm{Na}\right]^{+}\left([\mathrm{M}+\mathrm{Na}]^{+}\right): 319.0901$, found: 319.0914 . 
(R)-3-(p-Nitrobenzyloxycarbonyl)-amino-4-methyl-pentanoic acid (4)<smiles>CC(C)[C@H](CC(=O)O)NC(=O)OCc1ccc([N+](=O)[O-])cc1</smiles>

$$
\begin{aligned}
& \mathrm{C}_{14} \mathrm{H}_{18} \mathrm{~N}_{2} \mathrm{O}_{6} \\
& 310.31 \mathrm{~g} / \mathrm{mol}
\end{aligned}
$$

4

Starting from pNZ-D-Val-OH (7.75 g, $26.2 \mathrm{mmol}, 1.00 \mathrm{eq})$, compound 4 (5.20 g, $16.9 \mathrm{mmol}, 64 \%$ ) was obtained as a colorless solid by following SOP2 and SOP3 and purification via flash column chromatography (EtOAc/pentane $=1: 1+1.00 \% \mathrm{AcOH})$.

${ }^{1} \mathbf{H}-\mathbf{N M R}\left(300 \mathrm{MHz}, \mathrm{DMSO}-d_{6}\right): \delta / \mathrm{ppm}==12.1(\mathrm{sbr}, 1 \mathrm{H}, \mathrm{OH}), 8.23\left(\mathrm{~d}, 2 \mathrm{H},{ }^{3} J_{\mathrm{H}, \mathrm{H}}=8.7 \mathrm{~Hz}\right.$, $\left.2 \times \mathrm{pNZ}-\mathrm{CH}_{\mathrm{ar}}\right), 7.59\left(\mathrm{~d}, 2 \mathrm{H},{ }^{3} \mathrm{~J}_{\mathrm{H}, \mathrm{H}}=8.5 \mathrm{~Hz}, 2 \times \mathrm{pNZ}-\mathrm{CH}_{\mathrm{ar}}\right), 7.34\left(\mathrm{~d}, 1 \mathrm{H},{ }^{3} J_{\mathrm{H}, \mathrm{H}}=9.0 \mathrm{~Hz}\right.$, pNZ-NH), 5.16 (s, $\left.2 \mathrm{H}, \mathrm{pNZ}-\mathrm{CH}_{2}\right), 3.79-3.64$ (m, $\left.1 \mathrm{H}, \beta-\mathrm{CH}\right), 2.45-2.21$ (m, $\left.2 \mathrm{H}, \alpha-\mathrm{CH}_{2}\right)$, 1.77-1.63 (m, $1 \mathrm{H}, \gamma-\mathrm{CH}), 0.88-0.76\left(\mathrm{~m}, 6 \mathrm{H}, 2 \times \mathrm{CH}_{3}\right)$.

ESI-MS $(m / z): 311.1[\mathrm{M}+\mathrm{H}]^{+}, 333.1[\mathrm{M}+\mathrm{Na}]^{+}, 643.2[2 \mathrm{M}+\mathrm{Na}]^{+}$.

HR-MS (ESI): calc. for $\left[\mathrm{C}_{14} \mathrm{H}_{19} \mathrm{~N}_{2} \mathrm{O}_{6}\right]^{+}\left([\mathrm{M}+\mathrm{H}]^{+}\right)$: 311.1238 , found: 311.1236 , calc. for $\left[\mathrm{C}_{14} \mathrm{H}_{18} \mathrm{~N}_{2} \mathrm{O}_{6} \mathrm{Na}\right]^{+}\left([\mathrm{M}+\mathrm{Na}]^{+}\right): 333.1057$, found: 333.1058 . 
(R)-3-(9-Fluorenylmethyloxycarbonyl)-amino-7-(4-methyltrityl)-aminoheptanoic acid (7)

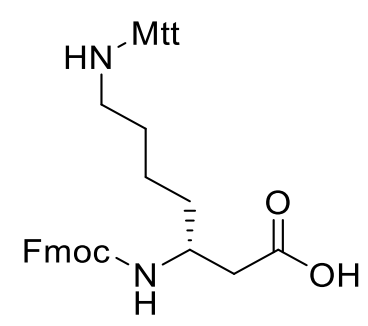

$\mathrm{C}_{42} \mathrm{H}_{42} \mathrm{~N}_{2} \mathrm{O}_{4}$

$638.81 \mathrm{~g} / \mathrm{mol}$

7

Starting from Fmoc-D-Lys(Mtt)-OH (10.1 g, $16.2 \mathrm{mmol}$, $1.00 \mathrm{eq})$, compound 7 (8.11 g, $12.7 \mathrm{mmol}, 78 \%$ ) was obtained by following SOP2 and SOP3 as a light yellow solid.

${ }^{1}$ H-NMR (300 MHz, DMSO- $\left.d_{6}\right): \delta / p p m=7.87\left(\mathrm{~d}, 2 \mathrm{H},{ }^{3} J_{\mathrm{H}, \mathrm{H}}=7.5 \mathrm{~Hz}\right), 7.75-6.94(\mathrm{~m}, 20 \mathrm{H}$, $6 \times$ Fmoc- $\mathrm{CH}_{\mathrm{ar}}, 14 \times$ Mtt-CH $\mathrm{ar}$ ), 4.28-4.19 (m, $3 \times$ H, Fmoc-CH $\mathrm{CH}_{2}$ Fmoc-CH), 3.57-3.56 (m, $1 \mathrm{H}, \beta-\mathrm{CH}), 3.22-3.14\left(\mathrm{~m}, 2 \mathrm{H}, \alpha-\mathrm{CH}_{2}\right), 2.38 .2 .32\left(\mathrm{~m}, 2 \mathrm{H}, \zeta-\mathrm{CH}_{2}\right), 1.53-1.30(\mathrm{~m}, 6 \mathrm{H}, \gamma-$ $\left.\mathrm{CH}_{2}, \delta-\mathrm{CH}_{2}, \varepsilon-\mathrm{CH}_{2}\right)$.

ESI-MS $(\mathrm{m} / \mathrm{z}): 639.4[\mathrm{M}+\mathrm{H}]^{+}, 637.4[\mathrm{M}-\mathrm{H}]^{-}$.

HR-MS (ESI): calc. for $\left[\mathrm{C}_{42} \mathrm{H}_{43} \mathrm{~N}_{2} \mathrm{O}_{4}\right]^{+}\left([\mathrm{M}+\mathrm{H}]^{+}\right)$: 639.3217, found: 639.3204, calc. for $\left[\mathrm{C}_{42} \mathrm{H}_{41} \mathrm{~N}_{2} \mathrm{O}_{4}\right]^{-}\left([\mathrm{M}-\mathrm{H}]^{-}\right): 637.3072$, found: 637.3055. 


\subsubsection{Synthesis of $\beta^{3}$-Peptides}

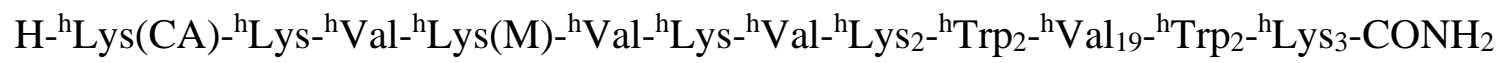

(1)

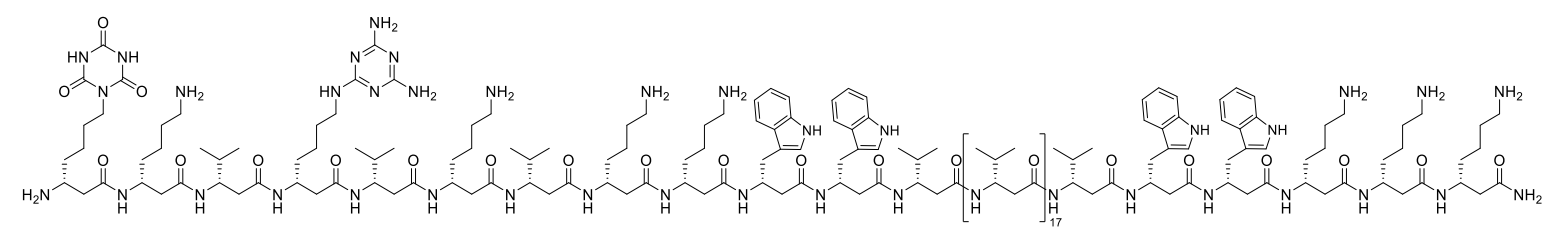

$\mathrm{C}_{249} \mathrm{H}_{422} \mathrm{~N}_{56} \mathrm{O}_{38}$

$4808.47 \mathrm{~g} / \mathrm{mol}$

1

NovaPEG rink amide resin LL (85.0 mg, $15.3 \mu \mathrm{mol}, 180 \mu \mathrm{mol} / \mathrm{g}, 1.00 \mathrm{eq})$ was modified according to SOP5 with Fmoc- $\beta^{3}$-D-Lys(Mtt)-OH (48.9 mg, $76.5 \mu \mathrm{mol}, 5.00$ eq), Fmoc- $\beta^{3}$-DLys(Boc)-OH $\quad(36.9 \mathrm{mg}, \quad 76.5 \mu \mathrm{mol}, \quad 5.00 \mathrm{eq}), \quad$ Fmoc- $\beta^{3}$-D-Trp(Boc)-OH $\quad(41.3 \mathrm{mg}$, $76.5 \mu \mathrm{mol}, 5.00 \mathrm{eq})$, Fmoc- $\beta^{3}$-D-Val-OH $(27.0 \mathrm{mg}, 76.5 \mu \mathrm{mol}, 5.00 \mathrm{eq})$, Fmoc- $\beta^{3}$-DLys(M)-OH $\quad(37.6 \mathrm{mg}, \quad 76.5 \mu \mathrm{mol}, \quad 5.00 \mathrm{eq}) \quad$ and $\quad$ Boc- $\beta^{3}$-D-Lys(CA)-OH $\quad(28.5 \mathrm{mg}$, $76.5 \mu \mathrm{mol}, 5.00 \mathrm{eq})$. After cleavage from the resin, which was achieved by following SOP10, the peptide was purified via semi-preparative HPLC to obtain compound $\mathbf{1}$ as a colorless solid.

HPLC (semi-preparative, 80-100\% B in $30 \mathrm{~min}, \lambda / \mathrm{nm}: 215,254,280$ ): $t_{\mathrm{R}}=18.38 \mathrm{~min}$. ESI-MS $(m / z): 602.0[\mathrm{M}+8 \mathrm{H}]^{8+}, 687.9[\mathrm{M}+7 \mathrm{H}]^{7+}, 802.4[\mathrm{M}+6 \mathrm{H}]^{6+}, 962.6[\mathrm{M}+5 \mathrm{H}]^{5+}, 1203.0$ $[\mathrm{M}+4 \mathrm{H}]^{4+}, 1603.7[\mathrm{M}+3 \mathrm{H}]^{3+}$.

HR-MS (ESI): calc. for $\left[\mathrm{C}_{249} \mathrm{H}_{430} \mathrm{~N}_{56} \mathrm{O}_{38}\right]^{8+}\left([\mathrm{M}+8 \mathrm{H}]^{8+}\right)$ : 601.6674, found: 601.6654 , calc. for $\left[\mathrm{C}_{249} \mathrm{H}_{429} \mathrm{~N}_{56} \mathrm{O}_{38}\right]^{7+}\left([\mathrm{M}+7 \mathrm{H}]^{7+}\right): 687.4760$, found: 687.4744 , calc. for $\left[\mathrm{C}_{249} \mathrm{H}_{428} \mathrm{~N}_{56} \mathrm{O}_{38}\right]^{6+}$ $\left([\mathrm{M}+6 \mathrm{H}]^{6+}\right): 801.8875$, found: 801.8863 . 


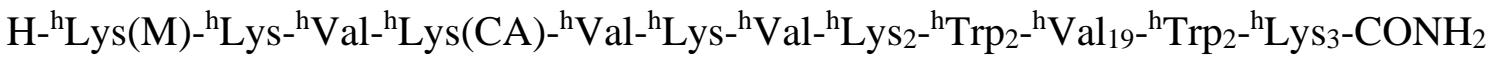

(2)

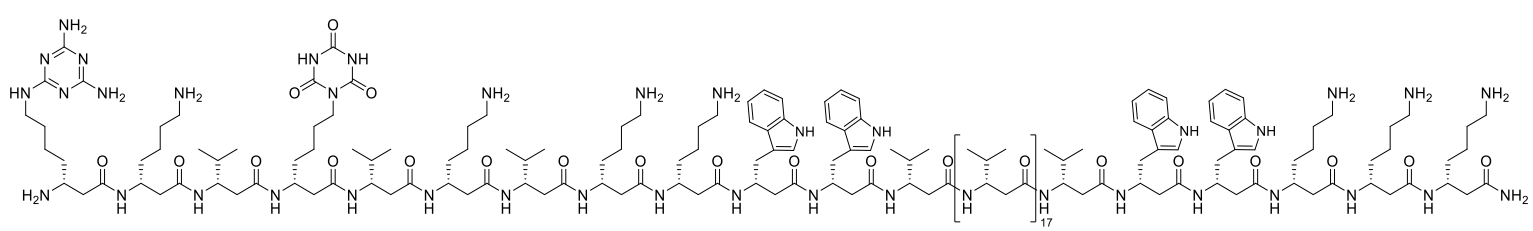

$\mathrm{C}_{249} \mathrm{H}_{422} \mathrm{~N}_{56} \mathrm{O}_{38}$

$4808.47 \mathrm{~g} / \mathrm{mol}$

NovaPEG rink amide resin LL $(85.0 \mathrm{mg}, 15.3 \mu \mathrm{mol}, 180 \mu \mathrm{mol} / \mathrm{g}, 1.00 \mathrm{eq})$ was modified according to SOP5 with Fmoc- $\beta^{3}$-D-Lys(Mtt)-OH (48.9 mg, $\left.76.5 \mu \mathrm{mol}, 5.00 \mathrm{eq}\right)$, Fmoc- $\beta^{3}$-DLys(Boc)-OH $\quad(36.9 \mathrm{mg}, \quad 76.5 \mu \mathrm{mol}, \quad 5.00 \mathrm{eq}), \quad$ Fmoc- $\beta^{3}$-D-Trp(Boc)-OH $\quad(41.3 \mathrm{mg}$, $76.5 \mu \mathrm{mol}, 5.00 \mathrm{eq})$, Fmoc- $\beta^{3}$-D-Val-OH $(27.0 \mathrm{mg}, 76.5 \mu \mathrm{mol}, 5.00 \mathrm{eq})$, Fmoc- $\beta^{3}$-DLys(M)-OH (37.6 mg, $76.5 \mu \mathrm{mol}, \quad 5.00 \mathrm{eq})$ and Boc- $\beta^{3}$-D-Lys(CA)-OH $\quad(28.5 \mathrm{mg}$, $76.5 \mu \mathrm{mol}, 5.00 \mathrm{eq})$. After cleavage from the resin, which was achieved by following SOP10, the peptide was purified via semi-preparative HPLC to obtain compound 2 as a colorless solid.

HPLC (semi-preparative, 80-100 \% B in $30 \mathrm{~min}, \lambda / \mathrm{nm}: 215,254,280$ ): $t_{\mathrm{R}}=18.45 \mathrm{~min}$. ESI-MS $(\mathrm{m} / \mathrm{z}): 602.0[\mathrm{M}+8 \mathrm{H}]^{8+}, 687.9[\mathrm{M}+7 \mathrm{H}]^{7+}, 802.4[\mathrm{M}+6 \mathrm{H}]^{6+}, 962.6[\mathrm{M}+5 \mathrm{H}]^{5+}, 1203.0$ $[\mathrm{M}+4 \mathrm{H}]^{4+}$.

HR-MS (ESI): calc. for $\left[\mathrm{C}_{249} \mathrm{H}_{430} \mathrm{~N}_{56} \mathrm{O}_{38}\right]^{8+}\left([\mathrm{M}+8 \mathrm{H}]^{8+}\right)$ : 601.6674, found: 601.6665 , calc. for $\left[\mathrm{C}_{249} \mathrm{H}_{429} \mathrm{~N}_{56} \mathrm{O}_{38}\right]^{7+}\left([\mathrm{M}+7 \mathrm{H}]^{7+}\right): 687.4760$, found: 687.4753 , calc. for $\left[\mathrm{C}_{249} \mathrm{H}_{428} \mathrm{~N}_{56} \mathrm{O}_{38}\right]^{6+}$ $\left([\mathrm{M}+6 \mathrm{H}]^{6+}\right): 801.8875$, found: 801.8869 . 
pNZ- ${ }^{\mathrm{h}}$ Val- ${ }^{\mathrm{h}} \mathrm{Lys}_{-}{ }^{\mathrm{h}} \mathrm{Val}_{-}{ }^{\mathrm{h}} \mathrm{Lys}_{2}{ }^{\mathrm{h}}{ }^{\mathrm{h}} \operatorname{Trp}_{2}-{ }^{\mathrm{h}} \mathrm{Val}_{19-}{ }^{\mathrm{h}} \mathrm{Trp}_{2}{ }^{\mathrm{h}}{ }^{\mathrm{h}} \mathrm{Lys}_{3}-\mathrm{CONH}_{2}$ (29)

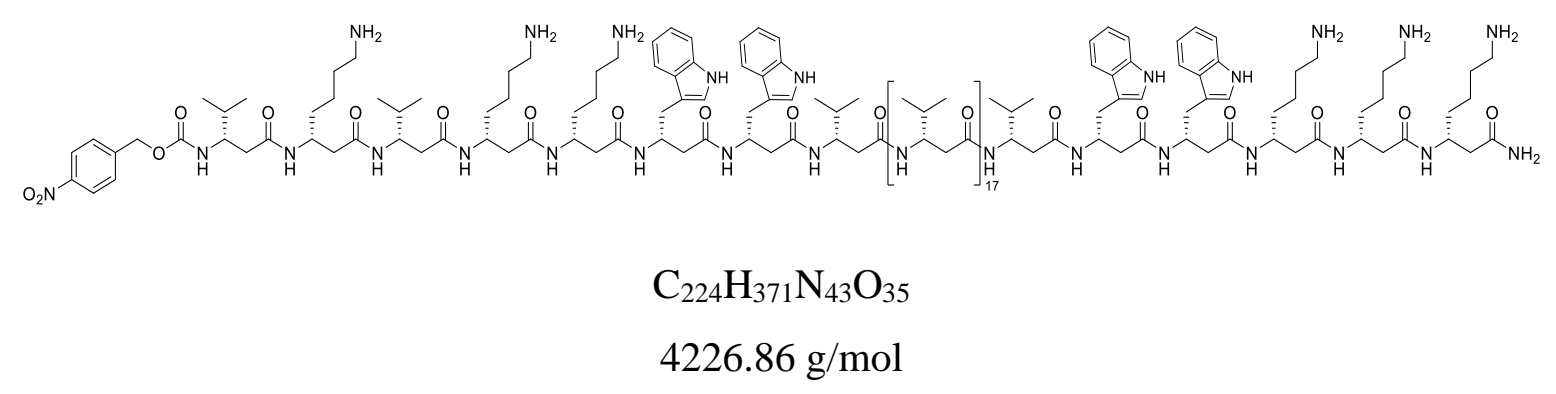

29

NovaPEG rink amide resin LL (558 mg, $100 \mu \mathrm{mol}, 180 \mu \mathrm{mol} / \mathrm{g}, 1.00 \mathrm{eq})$ was modified according to SOP5 with Fmoc- $\beta^{3}$-D-Lys(Mtt)-OH (321 mg, $\left.502 \mu \mathrm{mol}, 5.00 \mathrm{eq}\right)$, Fmoc- $\beta^{3}$-DLys(Boc)-OH (242 mg, $502 \mu \mathrm{mol}, 5.00$ eq), Fmoc- $\beta^{3}$-D-Trp(Boc)-OH (271 mg, $502 \mu \mathrm{mol}$, $5.00 \mathrm{eq})$, Fmoc- $\beta^{3}$-D-Val-OH (178 mg, $\left.502 \mu \mathrm{mol}, 5.00 \mathrm{eq}\right)$ and pNZ- $\beta^{3}-\mathrm{D}-\mathrm{Val}-\mathrm{OH}(156 \mathrm{mg}$, $502 \mu \mathrm{mol}, 5.00 \mathrm{eq})$. Compound 29 was obtained as a colorless solid and verified via mass spectrometry. Being an intermediate for further modifications, 29 was not purified at this stage.

ESI-MS $(m / z): 705.0[\mathrm{M}+6 \mathrm{H}]^{6+}, 846.2[\mathrm{M}+5 \mathrm{H}]^{5+}, 1057.5[\mathrm{M}+4 \mathrm{H}]^{4+}, 1409.6[\mathrm{M}+3 \mathrm{H}]^{3+}$.

HR-MS (ESI): calc. for $\left[\mathrm{C}_{224} \mathrm{H}_{377} \mathrm{~N}_{43} \mathrm{O}_{35}\right]^{6+}\left([\mathrm{M}+6 \mathrm{H}]^{6+}\right)$ : 704.9835 , found: 704.9803 , calc. for $\left[\mathrm{C}_{224} \mathrm{H}_{376} \mathrm{~N}_{43} \mathrm{O}_{35}\right]^{5+}\left([\mathrm{M}+5 \mathrm{H}]^{5+}\right): 845.7787$, found: 845.7791 , calc. for $\left[\mathrm{C}_{224} \mathrm{H}_{375} \mathrm{~N}_{43} \mathrm{O}_{35}\right]^{4+}$ $\left([\mathrm{M}+4 \mathrm{H}]^{4+}\right): 1056.9716$, found: 1056.9712 . 


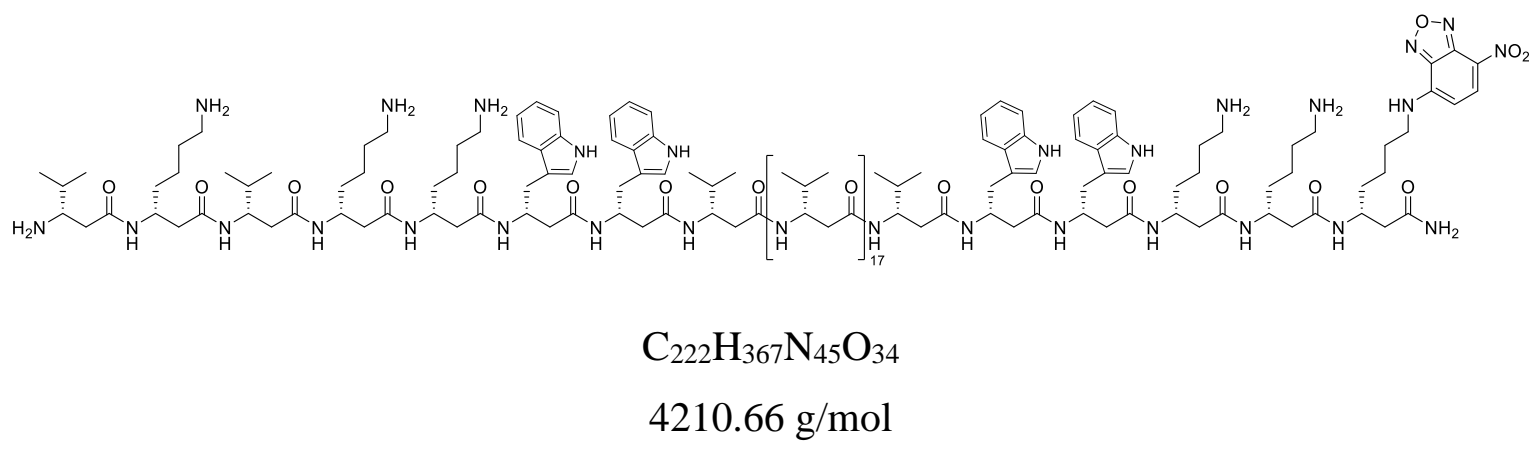

20

Peptide intermediate $\mathbf{2 0}$ was achieved by modification of $\mathbf{2 9}$ according to SOP8 and subsequent NBD-labeling. Therefore, the resin ( $255 \mathrm{mg}, 45.9 \mu \mathrm{mol}, 180 \mu \mathrm{mol} / \mathrm{g}, 1.00 \mathrm{eq})$ was treated with NBD-F (42.1 mg, $230 \mu \mathrm{mol}, 5.00 \mathrm{eq})$ and DIPEA (159 $\mu \mathrm{L}, 115 \mathrm{mg}, 918 \mu \mathrm{mol}$, $20.0 \mathrm{eq})$ in DMF $(1.0 \mathrm{~mL})$ for $2 \mathrm{~h}$ at $65^{\circ} \mathrm{C}$ under microwave irradiation $(15 \mathrm{~W})$. Afterwards, the resin was washed with DMF $(15 \times 5 \mathrm{~mL})$ and $\mathrm{MeOH}(15 \times 5 \mathrm{~mL})$. pNZ deprotection was carried out by following SOP9, cleavage by following SOP10. Compound 20 was obtained as a yellow/brown solid and verified via mass spectrometry. Being an intermediate for further modifications, 20 was not purified at this stage.

ESI-MS $(\mathrm{m} / \mathrm{z}): 702.7[\mathrm{M}+6 \mathrm{H}]^{6+}, 710.0\left[\mathrm{M}+6 \mathrm{H}+\mathrm{CO}_{2}\right]^{6+}, 717.3\left[\mathrm{M}+6 \mathrm{H}+2 \mathrm{CO}_{2}\right]^{6+}, 843.0$ $[\mathrm{M}+5 \mathrm{H}]^{5+}, 851.8\left[\mathrm{M}+5 \mathrm{H}+\mathrm{CO}_{2}\right]^{5+}, 860.6\left[\mathrm{M}+5 \mathrm{H}+2 \mathrm{CO}_{2}\right]^{5+}, 1053.5[\mathrm{M}+4 \mathrm{H}]^{4+}, 1064.5$ $\left[\mathrm{M}+4 \mathrm{H}+\mathrm{CO}_{2}\right]^{4+}, 1075.5\left[\mathrm{M}+4 \mathrm{H}+2 \mathrm{CO}_{2}\right]^{4+}, 1404.3[\mathrm{M}+3 \mathrm{H}]^{3+}$.

HR-MS (ESI): calc. for $\left[\mathrm{C}_{222} \mathrm{H}_{373} \mathrm{~N}_{45} \mathrm{O}_{34}\right]^{6+}\left([\mathrm{M}+6 \mathrm{H}]^{6+}\right)$ : 702.3135 , found: 702.3116 , calc. for $\left[\mathrm{C}_{223} \mathrm{H}_{373} \mathrm{~N}_{45} \mathrm{O}_{36}\right]^{6+}\left(\left[\mathrm{M}+6 \mathrm{H}+\mathrm{CO}_{2}\right]^{6+}\right): 709.6451$, found: 709.6433, calc. for $\left[\mathrm{C}_{224} \mathrm{H}_{373} \mathrm{~N}_{45} \mathrm{O}_{38}\right]^{6+}\left(\left[\mathrm{M}+6 \mathrm{H}+2 \mathrm{CO}_{2}\right]^{6+}\right):$ 716.9768, found: 716.9755 . 


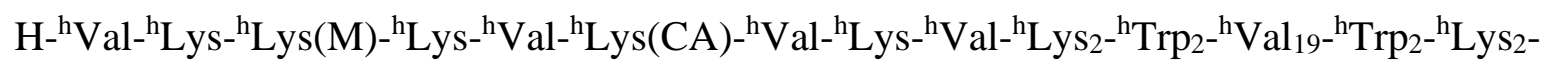
$\mathrm{CONH}_{2}(\mathbf{3 0})$

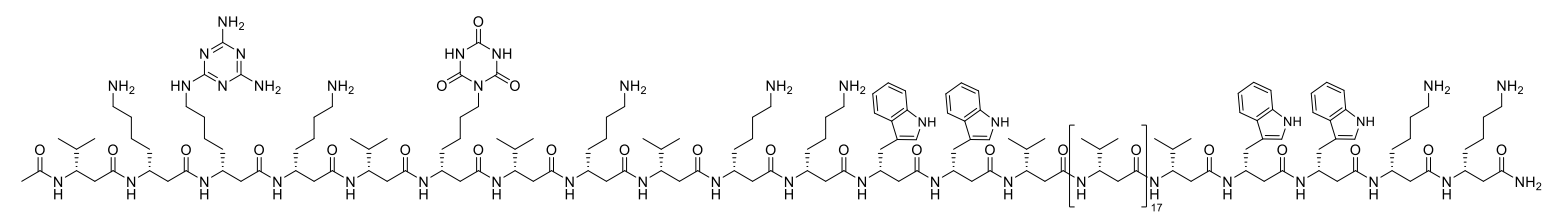

$\mathrm{C}_{257} \mathrm{H}_{435} \mathrm{~N}_{57} \mathrm{O}_{40}$

$4963.67 \mathrm{~g} / \mathrm{mol}$

NovaPEG rink amide resin LL (100 mg, $18.0 \mu \mathrm{mol}, 180 \mu \mathrm{mol} / \mathrm{g}, 1.00 \mathrm{eq})$ was modified according to SOP5 with Fmoc- $\beta^{3}$-D-Lys(Boc)-OH (43.4 mg, $\left.90.0 \mu \mathrm{mol}, 5.00 \mathrm{eq}\right)$, Fmoc- $\beta^{3}$-DTrp(Boc)-OH (48.6 mg, $90.0 \mu \mathrm{mol}, 5.00$ eq), Fmoc- $\beta^{3}$-D-Val-OH (31.8 mg, $90.0 \mu \mathrm{mol}$, 5.00 eq), Fmoc- $\beta^{3}$-D-Lys(CA)-OH (44.5 mg, $90.0 \mu$ mol, 5.00 eq), Fmoc- $\beta^{3}$-D-Lys(M)-OH (44.2 mg, $90.0 \mu \mathrm{mol}, 5.00 \mathrm{eq})$ and Fmoc- $\beta^{3}$-D-Lys(Mtt)-OH (57.5 mg, $\left.90.0 \mu \mathrm{mol}, 5.00 \mathrm{eq}\right)$. Compound 30 was obtained as a colorless solid and verified via mass spectrometry. Being an intermediate for further modifications, $\mathbf{3 0}$ was not purified at this stage.

ESI-MS $(m / z): 709.9[\mathrm{M}+7 \mathrm{H}]^{7+}, 828.2[\mathrm{M}+6 \mathrm{H}]^{6+}, 993.7[\mathrm{M}+5 \mathrm{H}]^{5+}, 1241.9[\mathrm{M}+4 \mathrm{H}]^{4+}$.

HR-MS (ESI): calc. for $\left[\mathrm{C}_{257} \mathrm{H}_{442} \mathrm{~N}_{57} \mathrm{O}_{40}\right]^{7+}\left([\mathrm{M}+7 \mathrm{H}]^{7+}\right)$ : 709.6324 , found: 709.6353 , calc. for $\left[\mathrm{C}_{257} \mathrm{H}_{441} \mathrm{~N}_{57} \mathrm{O}_{40}\right]^{6+}\left([\mathrm{M}+6 \mathrm{H}]^{6+}\right): 827.7366$, found: 827.7443 , calc. for $\left[\mathrm{C}_{257} \mathrm{H}_{440} \mathrm{~N}_{57} \mathrm{O}_{40}\right]^{5+}$ $\left([\mathrm{M}+5 \mathrm{H}]^{5+}\right)$ : 993.0824 , found: 993.0802 . 
H- ${ }^{\mathrm{h}} \mathrm{Lys}_{2-}{ }_{-}^{\mathrm{h}} \mathrm{Trp}_{2-}{ }^{\mathrm{h}} \mathrm{Val}_{19-}{ }^{\mathrm{h}} \mathrm{Trp}_{2-}{ }^{\mathrm{h}} \mathrm{Lys}_{2}-\mathrm{CONH}_{2}(\mathbf{2 1})$

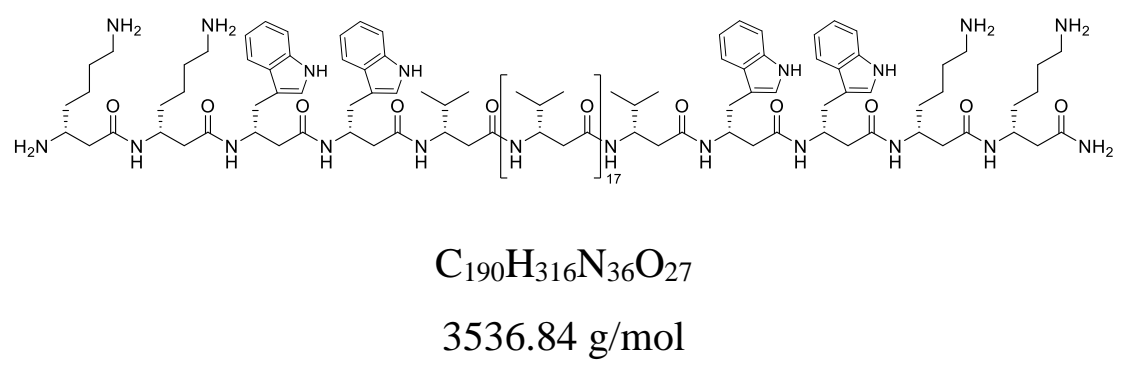

21

NovaPEG rink amide resin LL (300 mg, $60.0 \mu \mathrm{mol}, 200 \mu \mathrm{mol} / \mathrm{g}, 1.00 \mathrm{eq}$ ) was modified according to SOP5 with Fmoc- $\beta^{3}$-D-Lys(Boc)-OH (145 mg, $300 \mu$ mol, 5.00 eq), Fmoc- $\beta^{3}$-D$\operatorname{Trp}($ Boc)-OH (162 mg, $300 \mu \mathrm{mol}, 5.00 \mathrm{eq})$ and Fmoc- $\beta^{3}$-D-Val-OH (106 mg, $300 \mu \mathrm{mol}$, $5.00 \mathrm{eq})$. After cleavage from the resin, which was achieved by following SOP10, the peptide was purified via semi-preparative HPLC to obtain compound $\mathbf{2 1}$ as a colorless solid.

HPLC (semi-preparative, 80-100 \% B in $30 \mathrm{~min}, \lambda / \mathrm{nm}: 215,254,280$ ): $t_{\mathrm{R}}=30.76 \mathrm{~min}$. ESI-MS $(\mathrm{m} / \mathrm{z}): 708.3[\mathrm{M}+5 \mathrm{H}]^{5+}, 885.1[\mathrm{M}+4 \mathrm{H}]^{4+}, 1179.8[\mathrm{M}+3 \mathrm{H}]^{3+}, 1769.2[\mathrm{M}+2 \mathrm{H}]^{2+}$.

HR-MS (ESI): calc. for $\left[\mathrm{C}_{190} \mathrm{H}_{321} \mathrm{~N}_{36} \mathrm{O}_{27}\right]^{5+}\left([\mathrm{M}+5 \mathrm{H}]^{5+}\right)$ : 707.8965, found: 707.8961, calc. for $\left[\mathrm{C}_{190} \mathrm{H}_{320} \mathrm{~N}_{36} \mathrm{O}_{27}\right]^{4+}\left([\mathrm{M}+4 \mathrm{H}]^{4+}\right): 884.6188$, found: 884.6178 , calc. for $\left[\mathrm{C}_{190} \mathrm{H}_{319} \mathrm{~N}_{36} \mathrm{O}_{27}\right]^{3+}$ $\left([\mathrm{M}+3 \mathrm{H}]^{3+}\right):$ 1179.1560, found: 1179.1546 . 
H- ${ }^{\mathrm{h}} \operatorname{Lys}(\mathrm{NBD})-{ }^{\mathrm{h}} \mathrm{Lys}_{2}{ }^{-}{ }^{\mathrm{h}} \mathrm{Trp}_{2}-{ }^{\mathrm{h}} \mathrm{Val}_{19-}{ }^{-}{ }^{\mathrm{h}} \operatorname{Trp}_{2}-{ }^{\mathrm{h}} \mathrm{Lys}_{2}-\mathrm{CONH}_{2}(\mathbf{2 3})$

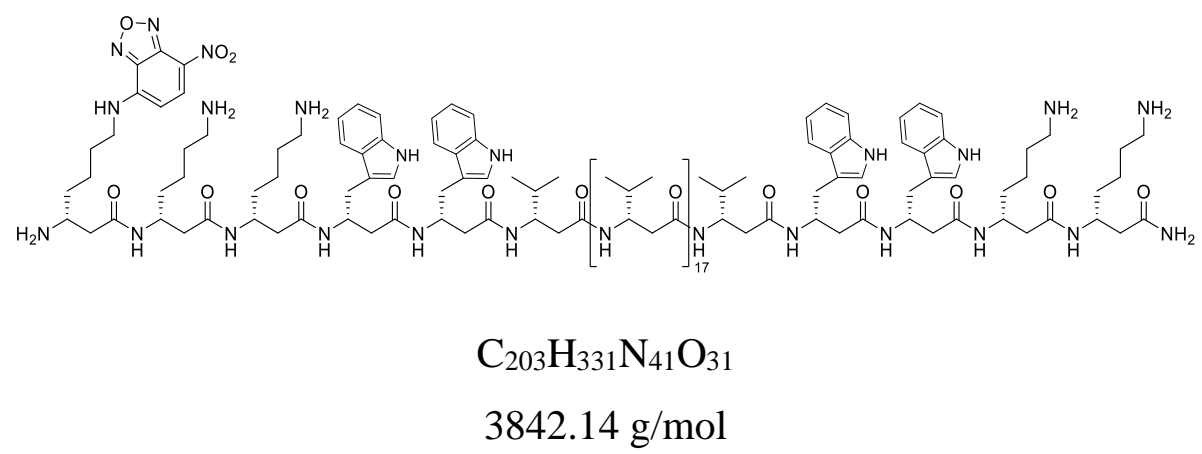

23

NovaPEG rink amide resin LL (200 mg, $40.0 \mu \mathrm{mol}, 200 \mu \mathrm{mol} / \mathrm{g}, 1.00 \mathrm{eq}$ ) was modified according to SOP5 with Fmoc- $\beta^{3}$-D-Lys(Boc)-OH (96.5 mg, $\left.200 \mu \mathrm{mol}, 5.00 \mathrm{eq}\right)$, Fmoc- $\beta^{3}$-DTrp(Boc)-OH (108 mg, $200 \mu \mathrm{mol}, 5.00$ eq), Fmoc- $\beta^{3}$-D-Val-OH (70.7 mg, $200 \mu \mathrm{mol}$, $5.00 \mathrm{eq})$ and Boc- $\beta^{3}$-D-Lys(Fmoc)-OH (96.5 mg, $\left.200 \mu \mathrm{mol}, 5.00 \mathrm{eq}\right)$, followed by NBD-labeling. Therefore, the resin was treated with NBD-Cl $(24.0 \mathrm{mg}, 120 \mu \mathrm{mol}, 3.00 \mathrm{eq})$ and DIPEA $(136 \mu \mathrm{L}, 103 \mathrm{mg}, 800 \mu \mathrm{mol}, 20.0 \mathrm{eq})$ in DMF $(500 \mu \mathrm{L})$ for $2 \mathrm{~h}$ at $65^{\circ} \mathrm{C}$ under microwave irradiation $(15 \mathrm{~W})$. Afterwards, the resin was washed with DMF $(15 \times 5 \mathrm{~mL})$ and $\mathrm{MeOH}(15 \times 5 \mathrm{~mL})$ and the peptide was cleaved according to SOP10. The crude peptide was purified via semi-preparative HPLC to obtain compound $\mathbf{2 3}$ as a yellow/brown solid.

HPLC (semi-preparative, 80-100\% B in $30 \mathrm{~min}, \lambda / \mathrm{nm}: 215,280,464): t_{\mathrm{R}}=22.06 \mathrm{~min}$. ESI-MS $(m / z): 769.3[\mathrm{M}+5 \mathrm{H}]^{5+}, 961.4[\mathrm{M}+4 \mathrm{H}]^{4+}, 1281.6[\mathrm{M}+3 \mathrm{H}]^{3+}, 1921.9[\mathrm{M}+2 \mathrm{H}]^{2+}$.

HR-MS (ESI): calc. for $\left[\mathrm{C}_{203} \mathrm{H}_{336} \mathrm{~N}_{41} \mathrm{O}_{31}\right]^{5+}\left([\mathrm{M}+5 \mathrm{H}]^{5+}\right)$ : 768.9190 , found: 768.9174 , calc. for $\left[\mathrm{C}_{203} \mathrm{H}_{335} \mathrm{~N}_{41} \mathrm{O}_{31}\right]^{4+}\left([\mathrm{M}+4 \mathrm{H}]^{4+}\right)$ : 960.8969 , found: 960.8945 , calc. for $\left[\mathrm{C}_{203} \mathrm{H}_{334} \mathrm{~N}_{41} \mathrm{O}_{31}\right]^{3+}$ $\left([\mathrm{M}+3 \mathrm{H}]^{3+}\right): 1280.8601$, found: 1280.8571 . 
H- ${ }^{\mathrm{h}} \operatorname{Lys}(\mathrm{TAMRA})-{ }^{\mathrm{h}} \mathrm{Lys}_{2}-{ }^{\mathrm{h}} \operatorname{Trp}_{2-}{ }^{\mathrm{h}} \operatorname{Val}_{19-}{ }^{\mathrm{h}} \mathrm{Trp}_{2-}{ }^{\mathrm{h}} \mathrm{Lys}_{2}-\mathrm{CONH}_{2}$ (22)

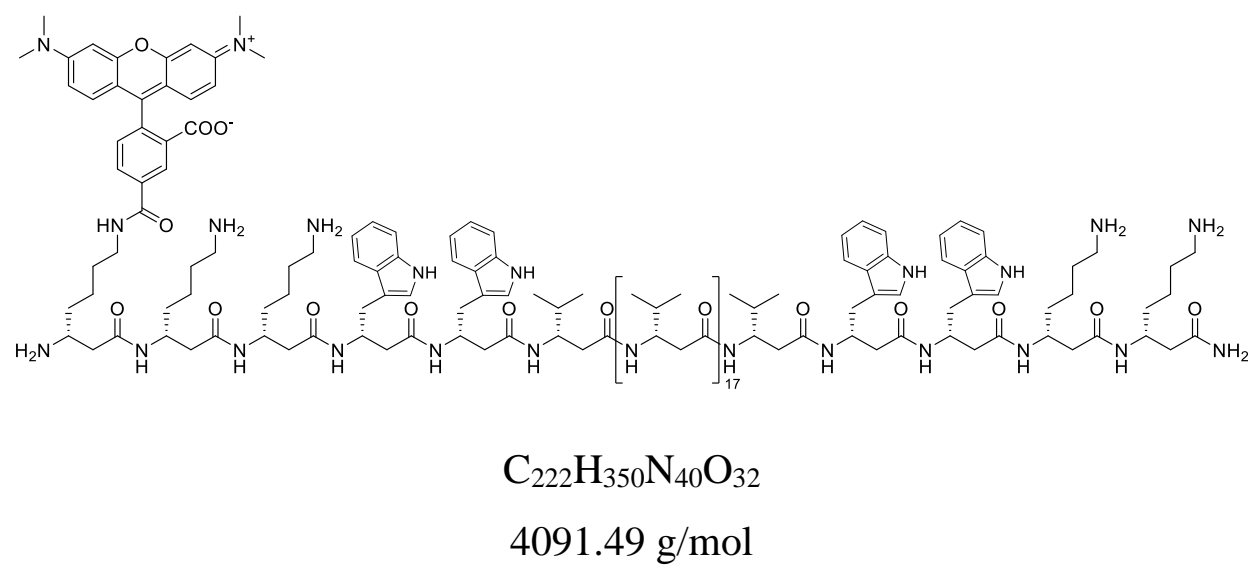

22

NovaPEG rink amide resin LL (50.0 mg, $8.50 \mu \mathrm{mol}, 170 \mu \mathrm{mol} / \mathrm{g}, 1.00 \mathrm{eq})$ was modified according to SOP7 with Fmoc- $\beta^{3}$-D-Lys(Boc)-OH (20.5 mg, $42.5 \mu$ mol, 5.00 eq), Fmoc- $\beta^{3}$-D$\operatorname{Trp}$ (Boc)-OH (23.0 mg, $42.5 \mu \mathrm{mol}, 5.00 \mathrm{eq})$, Fmoc- $\beta^{3}$-D-Val-OH (15.0 mg, $42.5 \mu \mathrm{mol}$, $5.00 \mathrm{eq})$ and Boc- $\beta^{3}$-D-Lys(Fmoc)-OH (20.5 mg, $\left.42.5 \mu \mathrm{mol}, 5.00 \mathrm{eq}\right)$, followed by Fmoc deprotection and TAMRA labeling. Therefore, TAMRA (18.3 mg, $42.5 \mu \mathrm{mol}, 5.00 \mathrm{eq}$ ), was activated with a mixture of $0.5 \mathrm{M}$ HOAt and $0.5 \mathrm{M}$ HATU in DMF $(85.0 \mu \mathrm{L}, 42.5 \mu \mathrm{mol}$, $5.00 \mathrm{eq})$ and $2.0 \mathrm{M}$ DIPEA in NMP $(42.5 \mu \mathrm{L}, 85.0 \mu \mathrm{mol}, 10.0 \mathrm{eq})$. The activated dye was then added to the resin and treated with microwave irradiation $(15 \mathrm{~W})$ for $2 \mathrm{~h}$ at $65^{\circ} \mathrm{C}$. Afterwards, the resin was washed with DMF $(15 \times 5 \mathrm{~mL})$ and $\mathrm{MeOH}(15 \times 5 \mathrm{~mL})$ and the peptide was cleaved according to SOP10. The crude peptide was purified via semi-preparative HPLC to obtain compound $\mathbf{2 2}$ as a pink solid.

HPLC (semi-preparative, 80-100 \% B in $30 \mathrm{~min}, \lambda / \mathrm{nm}: 215,280,565$ ): $t_{\mathrm{R}}=20.10 \mathrm{~min}$. ESI-MS $(m / z): 682.8[\mathrm{M}+6 \mathrm{H}]^{6+}, 819.1[\mathrm{M}+5 \mathrm{H}]^{5+}, 1023.7[\mathrm{M}+4 \mathrm{H}]^{4+}, 1364.6[\mathrm{M}+3 \mathrm{H}]^{3+}$.

HR-MS (ESI): calc. for $\left[\mathrm{C}_{222} \mathrm{H}_{356} \mathrm{~N}_{40} \mathrm{O}_{32}\right]^{6+}\left([\mathrm{M}+6 \mathrm{H}]^{6+}\right)$ : 682.4571 , found: 682.4577 , calc. for $\left[\mathrm{C}_{222} \mathrm{H}_{355} \mathrm{~N}_{40} \mathrm{O}_{32}\right]^{5+}\left([\mathrm{M}+5 \mathrm{H}]^{5+}\right): 818.7471$, found: 818.7469 , calc. for $\left[\mathrm{C}_{222} \mathrm{H}_{354} \mathrm{~N}_{40} \mathrm{O}_{32}\right]^{4+}$ $\left([\mathrm{M}+4 \mathrm{H}]^{4+}\right)$ : 1023.1820, found: 1023.1823. 
H- ${ }^{\mathrm{h}}$ Lys(acetyl)- ${ }^{\mathrm{h}} \mathrm{Lys}_{2}{ }^{\mathrm{h}}{ }^{\mathrm{h}} \operatorname{Trp}_{2}{ }^{\mathrm{h}}{ }^{\mathrm{h}} \mathrm{Val}_{19-}{ }^{\mathrm{h}}{ }^{\mathrm{Tr}} \mathrm{Tr}_{2-}{ }^{\mathrm{h}} \mathrm{Lys}_{2}-\mathrm{CONH}_{2}$ (24)

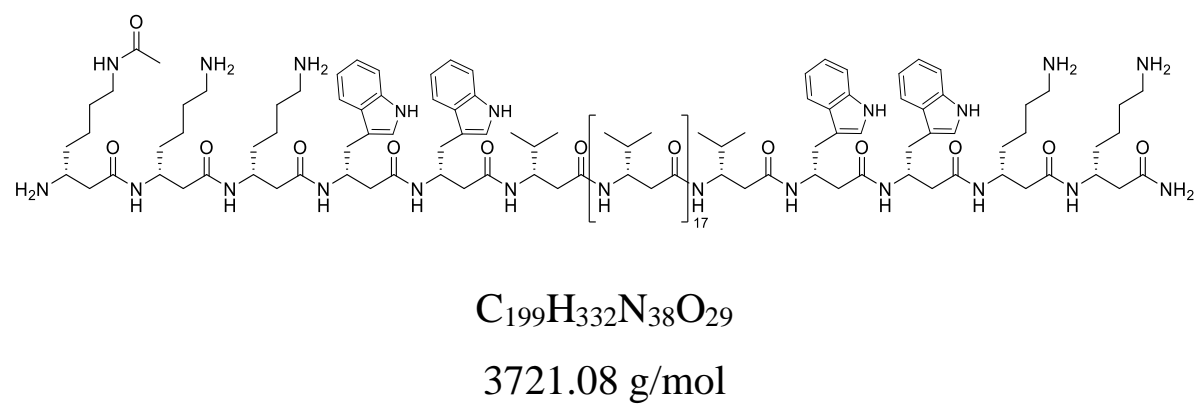

24

NovaPEG rink amide resin LL (200 mg, $40.0 \mu \mathrm{mol}, 200 \mu \mathrm{mol} / \mathrm{g}, 1.00 \mathrm{eq}$ ) was modified according to SOP5 with Fmoc- $\beta^{3}$-D-Lys(Boc)-OH (96.5 mg, $\left.200 \mu \mathrm{mol}, 5.00 \mathrm{eq}\right)$, Fmoc- $\beta^{3}$-DTrp(Boc)-OH (108 mg, $200 \mu \mathrm{mol}, 5.00$ eq), Fmoc- $\beta^{3}$-D-Val-OH (70.7 mg, $200 \mu \mathrm{mol}$, $5.00 \mathrm{eq})$ and Boc- $\beta^{3}$-D-Lys(Fmoc)-OH (96.5 mg, $\left.200 \mu \mathrm{mol}, 5.00 \mathrm{eq}\right)$, followed by Fmoc deprotection and acetylation with a mixture of acetic anhydride and DMF (1:4, $v / v, 5 \mathrm{~mL})$ for $3 \mathrm{~min}$ at $65^{\circ} \mathrm{C}$ under microwave irradiation $(25 \mathrm{~W})$. Afterwards, the resin was washed with $\mathrm{DMF}(3 \times 5 \mathrm{~mL})$ and $\mathrm{MeOH}(3 \times 5 \mathrm{~mL})$ and the peptide was cleaved according to SOP10. The crude peptide was purified via semi-preparative HPLC to obtain compound 24 as a colorless solid.

HPLC (semi-preparative, $80-100 \% \mathrm{~B}$ in $30 \mathrm{~min}$ at $50{ }^{\circ} \mathrm{C}, \lambda / \mathrm{nm}: 215,254,280$ ): $t_{\mathrm{R}}=$ $21.10 \mathrm{~min}$.

ESI-MS $(m / z): 745.1[\mathrm{M}+5 \mathrm{H}]^{5+}, 931.2[\mathrm{M}+4 \mathrm{H}]^{4+}, 1241.2[\mathrm{M}+3 \mathrm{H}]^{3+}, 1861.3[\mathrm{M}+2 \mathrm{H}]^{2+}$.

HR-MS (ESI): calc. for $\left[\mathrm{C}_{199} \mathrm{H}_{337} \mathrm{~N}_{38} \mathrm{O}_{29}\right]^{5+}\left([\mathrm{M}+5 \mathrm{H}]^{5+}\right)$ : 744.7207, found: 744.7207 , calc. for $\left[\mathrm{C}_{199} \mathrm{H}_{336} \mathrm{~N}_{38} \mathrm{O}_{29}\right]^{4+}\left([\mathrm{M}+4 \mathrm{H}]^{4+}\right)$ : 930.6491 , found: 930.6486 , calc. for $\left[\mathrm{C}_{199} \mathrm{H}_{335} \mathrm{~N}_{38} \mathrm{O}_{29}\right]^{3+}$ $\left([\mathrm{M}+3 \mathrm{H}]^{3+}\right): 1240.5297$, found: 1240.5293 . 
TAMRA- $\beta$ Ala- ${ }^{\mathrm{h}} \mathrm{Lys}_{2}{ }^{-}{ }^{\mathrm{h}} \mathrm{Trp}_{2}-{ }^{\mathrm{h}} \mathrm{Val}_{19-}{ }^{\mathrm{h}} \mathrm{Trp}_{2}-{ }^{\mathrm{h}} \mathrm{Lys}_{2}-\mathrm{CONH}_{2}(\mathbf{3 1})$

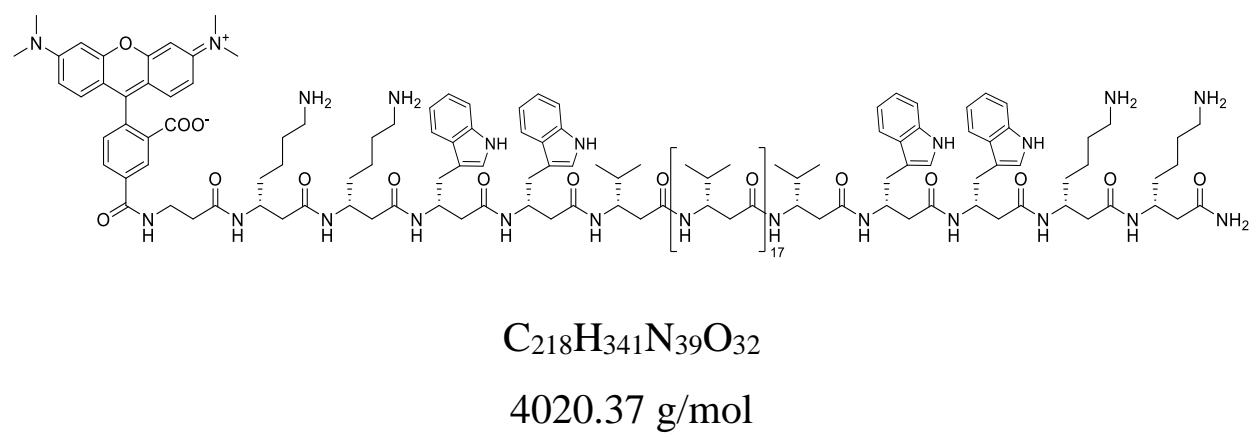

31

NovaPEG rink amide resin LL (100 mg, $17.0 \mu \mathrm{mol}, 170 \mu \mathrm{mol} / \mathrm{g}, 1.00 \mathrm{eq})$ was modified according to SOP5 with Fmoc- $\beta^{3}$-D-Lys(Boc)-OH (41.0 mg, $\left.85.0 \mu \mathrm{mol}, 5.00 \mathrm{eq}\right)$, Fmoc- $\beta^{3}$-D$\operatorname{Trp}($ Boc)-OH (45.9 mg, $85.0 \mu \mathrm{mol}, 5.00 \mathrm{eq})$, Fmoc- $\beta^{3}$-D-Val-OH $(30.0 \mathrm{mg}, 85.0 \mu \mathrm{mol}$, $5.00 \mathrm{eq})$ and Fmoc- $\beta$-Ala-OH (26.5 mg, $42.5 \mu \mathrm{mol}, 5.00 \mathrm{eq})$, followed by Fmoc deprotection and TAMRA labeling. Therefore, TAMRA (36.6 mg, $85.0 \mu \mathrm{mol}, 5.00 \mathrm{eq})$, was activated with DIC ( $26.3 \mu \mathrm{L}, 21.4 \mathrm{mg}, 170 \mu \mathrm{mol}, 10.0 \mathrm{eq})$ and Oxyma (12.1 mg, $85.0 \mu \mathrm{mol}$, $5.00 \mathrm{eq})$ in DMF $(250 \mu \mathrm{L})$. The activated dye was then added to the resin and treated with microwave irradiation $(15 \mathrm{~W})$ for $2 \mathrm{~h}$ at $65^{\circ} \mathrm{C}$. Afterwards, the resin was washed with DMF $(15 \times 5 \mathrm{~mL})$ and $\mathrm{MeOH}(15 \times 5 \mathrm{~mL})$ and the peptide was cleaved according to SOP10. The crude peptide was purified via semi-preparative HPLC to obtain compound $\mathbf{3 1}$ as a pink solid.

HPLC (semi-preparative, 80-100 \% B in $30 \mathrm{~min}, \lambda / \mathrm{nm}: 215,280,565$ ): $t_{\mathrm{R}}=21.24 \mathrm{~min}$. ESI-MS $(\mathrm{m} / \mathrm{z}): 804.9[\mathrm{M}+5 \mathrm{H}]^{5+}, 1005.9[\mathrm{M}+4 \mathrm{H}]^{4+}, 1340.9[\mathrm{M}+3 \mathrm{H}]^{3+}$.

HR-MS (ESI): calc. for $\left[\mathrm{C}_{218} \mathrm{H}_{346} \mathrm{~N}_{39} \mathrm{O}_{32}\right]^{5+}\left([\mathrm{M}+5 \mathrm{H}]^{5+}\right)$ : 804.5324, found: 804.5323, calc. for $\left[\mathrm{C}_{218} \mathrm{H}_{345} \mathrm{~N}_{39} \mathrm{O}_{32}\right]^{4+}\left([\mathrm{M}+4 \mathrm{H}]^{4+}\right):$ 1005.4136, found: 1005.4126, calc. for $\left[\mathrm{C}_{218} \mathrm{H}_{344} \mathrm{~N}_{39} \mathrm{O}_{32}\right]^{3+}\left([\mathrm{M}+3 \mathrm{H}]^{3+}\right): 1340.2158$, found: 1340.2141 . 


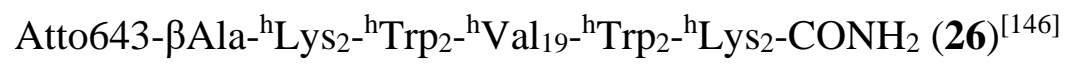

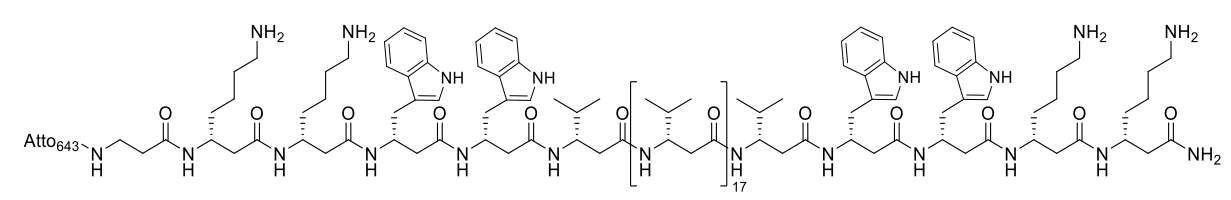

$4427 \mathrm{~g} / \mathrm{mol}$

26

NovaPEG rink amide resin LL (16.0 mg, $3.20 \mu \mathrm{mol}, 200 \mu \mathrm{mol} / \mathrm{g}, 1.00 \mathrm{eq})$ was modified according to SOP5 with Fmoc- $\beta^{3}$-D-Lys(Boc)-OH (7.70 mg, $16.0 \mu \mathrm{mol}, 5.00$ eq), Fmoc- $\beta^{3}$-DTrp(Boc)-OH (8.60 mg, $16.0 \mu \mathrm{mol}, 5.00 \mathrm{eq})$, Fmoc- $\beta^{3}$-D-Val-OH $(5.70 \mathrm{mg}, 16.0 \mu \mathrm{mol}$, $5.00 \mathrm{eq})$ and Fmoc- $\beta$-Ala-OH (5.00 mg, $16.0 \mu \mathrm{mol}, 5.00 \mathrm{eq})$, followed by Fmoc deprotection and Atto643 labeling. Therefore, Atto643-NHS ester (2.50 mg, $2.60 \mu \mathrm{mol}, 0.81 \mathrm{eq})$ was dissolved in dry DMSO $(400 \mu \mathrm{L})$ and DIPEA $(2.18 \mu \mathrm{L}, 1.65 \mathrm{mg}, 12.8 \mu \mathrm{mol}, 4.00 \mathrm{eq})$ was added. The mixture was added to the resin and treated with microwave irradiation $(10 \mathrm{~W})$ for $2 \mathrm{~h}$ at $37^{\circ} \mathrm{C}$, followed by shaking overnight at $37^{\circ} \mathrm{C}$. The resin was washed with DMF $(15 \times 5 \mathrm{~mL}), \mathrm{MeOH}(15 \times 5 \mathrm{~mL})$ and cleaved according to SOP10. The crude peptide was purified via semi-preparative HPLC to obtain compound $\mathbf{2 6}$ as a blue solid.

HPLC (semi-preparative, $80-100 \% \mathrm{~B}$ in $30 \mathrm{~min}$, at $40{ }^{\circ} \mathrm{C}, \lambda / \mathrm{nm}: 215,280,643$ ): $t_{\mathrm{R}}=$ $34.50 \mathrm{~min}$.

ESI-MS $(m / z): 1476.6[\mathrm{M}+3 \mathrm{H}]^{3+}, 1491.3\left[\mathrm{M}+3 \mathrm{H}+\mathrm{CO}_{2}\right]^{3+}, 1506.2\left[\mathrm{M}+3 \mathrm{H}+2 \mathrm{CO}_{2}\right]^{3+}$. 
Atto643- $\beta$ Ala- ${ }^{\mathrm{h}}$ Val- ${ }^{\mathrm{h}}$ Lys- ${ }^{\mathrm{h}}$ Val- ${ }^{\mathrm{h}}$ Lys- ${ }^{\mathrm{h}}$ Val- ${ }^{\mathrm{h}}$ Lys- ${ }^{\mathrm{h}} \mathrm{Lys}_{2}-{ }^{\mathrm{h}} \mathrm{Trp}_{2}{ }^{-}{ }^{\mathrm{h}} \mathrm{Val}_{19}{ }^{\mathrm{h}}{ }^{\mathrm{T}} \mathrm{Trp}_{2}{ }^{-}{ }^{\mathrm{h}} \mathrm{Lys}_{2}-\mathrm{CONH}_{2}$ $(27)^{[146]}$

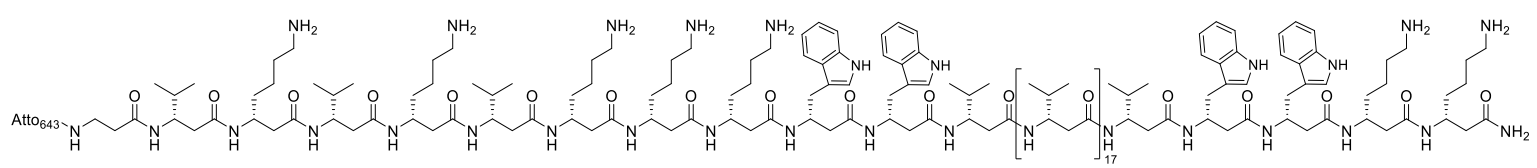

$5193 \mathrm{~g} / \mathrm{mol}$

27

NovaPEG rink amide resin LL (16.0 mg, $3.20 \mu \mathrm{mol}, 200 \mu \mathrm{mol} / \mathrm{g}, 1.00 \mathrm{eq})$ was modified according to SOP5 with Fmoc- $\beta^{3}$-D-Lys(Boc)-OH (7.70 mg, $16.0 \mu$ mol, 5.00 eq), Fmoc- $\beta^{3}$-D$\operatorname{Trp}$ (Boc)-OH (8.60 mg, $16.0 \mu \mathrm{mol}, 5.00 \mathrm{eq})$, Fmoc- $\beta^{3}$-D-Val-OH (5.70 mg, $16.0 \mu \mathrm{mol}$, $5.00 \mathrm{eq})$ and Fmoc- $\beta$-Ala-OH $(5.00 \mathrm{mg}, 16.0 \mu \mathrm{mol}, 5.00 \mathrm{eq})$, followed by Fmoc deprotection and Atto643 labeling. Therefore, Atto643-NHS ester (2.50 mg, $2.60 \mu \mathrm{mol}, 0.81 \mathrm{eq})$ was dissolved in dry DMSO $(400 \mu \mathrm{L})$ and DIPEA $(2.18 \mu \mathrm{L}, 1.65 \mathrm{mg}, 12.8 \mu \mathrm{mol}, 4.00 \mathrm{eq})$ was added. The mixture was added to the resin and treated with microwave irradiation $(10 \mathrm{~W})$ for $2 \mathrm{~h}$ at $37^{\circ} \mathrm{C}$, followed by shaking overnight at $37^{\circ} \mathrm{C}$. The resin was washed with DMF $(15 \times 5 \mathrm{~mL}), \mathrm{MeOH}(15 \times 5 \mathrm{~mL})$ and cleaved according to SOP10. The crude peptide was purified via semi-preparative HPLC to obtain compound 27 as a blue solid.

HPLC (semi-preparative, 80-100 \% B in $30 \mathrm{~min}, \lambda / \mathrm{nm}: 215,280,643$ ): $t_{\mathrm{R}}=33.00 \mathrm{~min}$. ESI-MS $(\mathrm{m} / \mathrm{z}): 866.5[\mathrm{M}+6 \mathrm{H}]^{6+}, 1039.5[\mathrm{M}+5 \mathrm{H}]^{5+}, 1299.3[\mathrm{M}+4 \mathrm{H}]^{4+}, 1731.7[\mathrm{M}+3 \mathrm{H}]^{3+}$. 



\section{Appendix}

a)

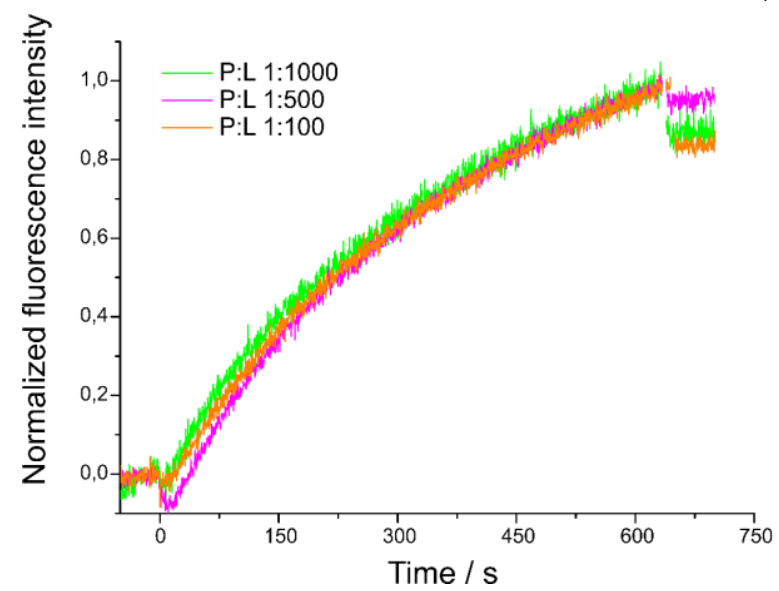

b)

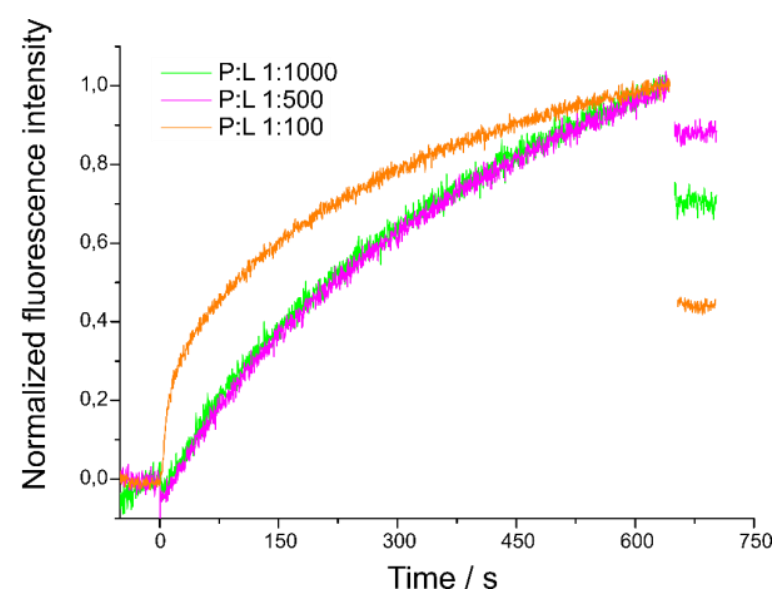

Figure 46: DPX addition for $\mathrm{P} / \mathrm{L}$ ratios of 1:1000 to 1:100 with an outer $\mathrm{pH}$ of 8.4 for $\mathrm{CA} \cdot \mathrm{M}$ modified peptides $\mathbf{1}$ and 2 (a) and the transmembrane domain 21 (b).

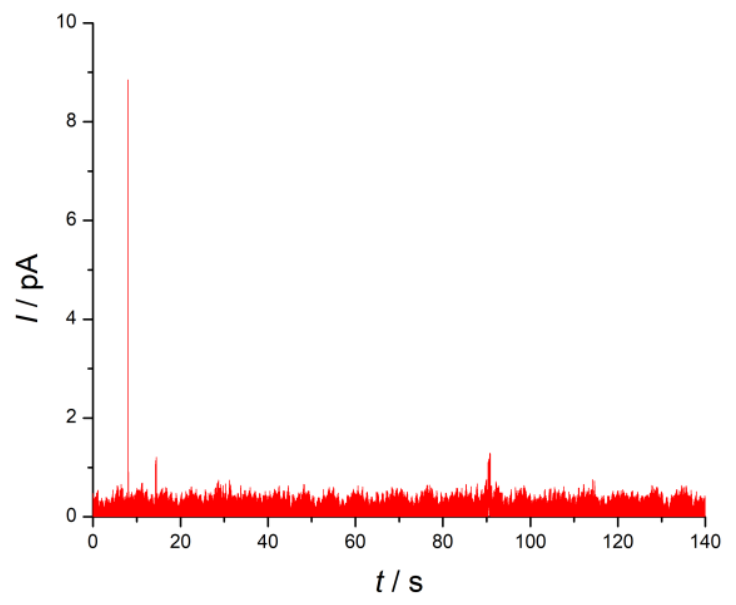

Figure 47: Time-resolved currents after applying a constant voltage of $150 \mathrm{mV}$ to both sides of the membrane with the incorporated transmembrane domain $21(100 \mathrm{nM})$ at $\mathrm{pH} 1.3$. 

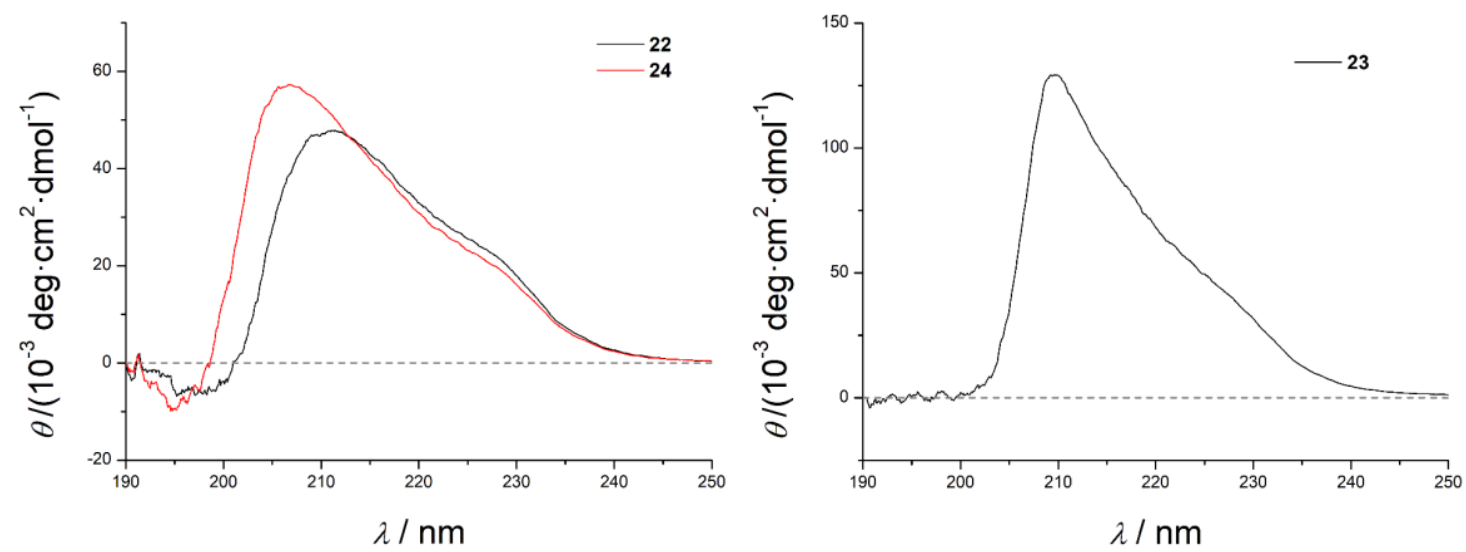

Figure 48: CD spectra of 22 and $24(50 \mu \mathrm{M})$ and $23(50 \mu \mathrm{M})$ in $\mathrm{MeOH}$ at $25^{\circ} \mathrm{C}$. 


\section{Abbreviations}

\begin{tabular}{|c|c|}
\hline $\mathrm{Ac}_{2} \mathrm{O}$ & acetic anhydride \\
\hline $\mathrm{ACHC}$ & trans-2-aminocyclohexanecarboxylic acid \\
\hline $\mathrm{AcOH}$ & acetic acid \\
\hline $\mathrm{ACPC}$ & trans-2-aminocyclopentanecarboxylic acid \\
\hline ATP & adenosine triphosphate \\
\hline ATR & attenuated total reflectance \\
\hline $\mathrm{BFP}$ & blue fluorescent protein \\
\hline Boc & tert-butoxycarbonyl \\
\hline $\mathrm{CA}$ & cyanuric acid \\
\hline Calmodulin & calcium-modulated protein \\
\hline $\mathrm{Cbz}$ & benzyloxycarbonyl \\
\hline $\mathrm{CD}$ & circular dichroismn \\
\hline CFP & cyan fluorescent protein \\
\hline CLSM & confocal laser scanning microscopy \\
\hline DBU & 1,8-diazabicyclo[5.4.0]undec-7-en \\
\hline DCM & dichloromethane \\
\hline DIC & $N, N$ '-diisopropylcarbodiimide \\
\hline DIPEA & $N, N$-diisopropylethylamine \\
\hline
\end{tabular}


DLPC 1,2-dilauroyl-sn-glycero-3-phosphocholine

DLS dynamic light scattering

DMF $\quad N, N$-dimethylformamide

DMSO dimethyl sulfoxide

DOPC 1,2-dioleoyl-sn-glycero-3-phosphocholine

DPX $\quad p$-xylene-bis $(N$-pyridinium bromide $)$

EPR electron paramagnetic resonance

eq equivalents

ESI electrospray ionization

Fmoc fluorenylmethoxycarbonyl

FRET FÖRSTER resonance energy transfer

GFP green fluorescent protein

GUV giant unilamellar vesicle

HATU O-(7-azabenzotriazol-1-yl)- $N, N, N^{\prime}, N^{\prime}$-tetramethyluronium hexafluorophosphate

HEPES 4-(2-hydroxyethyl)-1-piperazineethanesulfonic acid

HOAt 1-hydroxy-7-azabenzotriazole

HPLC high performance liquid chromatography

HR-MS high resolution mass spectrometry

IR infrared

KALP peptide model system with a sequence of GKK(LA) ${ }_{n} L K K A$

LUV large unilamellar vesicle

Lys lysine

MES 2-(N-morpholino)ethanesulfonic acid

MIET metal-induced energy transfer 
MLCK myosin light-chain kinase

Mtt 4-methyltrityl

NBD 7-nitrobenzofurazan

NHS N-hydroxysuccinimide

NMP N-methyl-2-pyrrolidone

NMR nuclear magnetic resonance

NSET nanoparticle-based surface energy transfer

o.n. overnight

$\mathrm{OSu} \quad$ succinimide

P/L peptide-to-lipid

PALM photoactivated localization microscopy

PG protecting group

pH pondus hydrogenii

Ph phenyl

pNZ $\quad$-nitrobenzyloxycarbonyl

POPC 1-palmitoyl-2-oleoyl-glycero-3-phosphocholine

ppm parts per million

PyAOP 7-azabenzotriazole-1-yl-oxy-tris-pyrrolodino-phosphonium hexafluorophosphate

PyBOP benzotriazole-1-yl-oxy-tris-pyrrolodino-phosphonium hexafluorophosphate

rt room temperature

SLB supported lipid bilayer

SNARE soluble $N$-ethylmaleimide-sensitive factor attachment protein receptor

SPPS solid-phase peptide synthesis

STORM stochastic optical reconstruction microscopy 
TAMRA 5(6)-carboxytetramethylrhodamine

TCSPC time-correlated single photon counting

TFA trifluoroacetic acid

THF tetrahydrofuran

TIS triisopropylsilan

TLC thin layer chromatography

TMD transmembrane domain

TMS trimethylsilan

Trp tryptophan

UV ultraviolet

Val valine

Vis visual

$v / v \quad$ volume-to-volume

WALP peptide model system with a sequence of GWW(LA) ${ }_{n} L W W A$

YFP yellow fluorescent protein 


\section{References}

[1] A. Krogh, B. Larsson, G. von Heijne, E. L. L. Sonnhammer, J. Mol. Biol. 2001, 305, $567-580$.

[2] Z. Cournia, T. W. Allen, I. Andricioaei, B. Antonny, D. Baum, G. Brannigan, N.-V. Buchete, J. T. Deckman, L. Delemotte, C. Del Val, R. Friedman, P. Gkeka, H.-C. Hege, J. Hénin, M. A. Kasimova, A. Kolocouris, M. L. Klein, S. Khalid, M. J. Lemieux, N. Lindow, M. Roy, J. Selent, M. Tarek, F. Tofoleanu, S. Vanni, S. Urban, D. J. Wales, J. C. Smith, A.-N. Bondar, J. Membr. Biol. 2015, 248, 611-640.

[3] Y. Guo, S. Pogodin, V. A. Baulin, J. Chem. Phys. 2014, 140, 174903.

[4] N. A. Wong, M. H. Saier, Int. J. Mol. Sci. 2021, 22, 1308.

[5] C. Altenbach, T. Marti, H. Khorana, W. Hubbell, Science 1990, 248, 1088-1092.

[6] I. Ahmad, N. Nawaz, N. M. Darwesh, S. ur Rahman, M. Z. Mustafa, S. B. Khan, S. G. Patching, Protein Expr. Purif. 2018, 144, 12-18.

[7] Y.-D. Wu, W. Han, D.-P. Wang, Y. Gao, Y.-L. Zhao, Acc. Chem. Res. 2008, 41, $1418-1427$.

[8] J. J. Barchi, X. Huang, D. H. Appella, L. A. Christianson, S. R. Durell, S. H. Gellman, J. Am. Chem. Soc. 2000, 122, 2711-2718.

[9] D. M. Pahlke, U. Diederichsen, J. Pept. Sci. 2016, 22, 636-641.

[10] U. Rost, Y. Xu, T. Salditt, U. Diederichsen, ChemPhysChem 2016, 17, 2525-2534.

[11] U. Rost, C. Steinem, U. Diederichsen, Chem. Sci. 2016, 7, 5900-5907.

[12] U. Rost, Organisation and Recognition of Artificial Transmembrane Peptides, University of Göttingen, 2016.

[13] S. Kabatas Glowacki, K. Koszinowski, D. Hübner, H. Frauendorf, P. Vana, U. Diederichsen, Chem. - Eur. J. 2020, 26, 12145-12149.

[14] A. Ranganathan, V. R. Pedireddi, C. N. R. Rao, J. Am. Chem. Soc. 1999, 121, 17521753. 
[15] P. E. Schneggenburger, S. Müllar, B. Worbs, C. Steinem, U. Diederichsen, J. Am. Chem. Soc. 2010, 132, 8020-8028.

[16] H. Eberhard, F. Diezmann, O. Seitz, Angew. Chem. 2011, 123, 4232-4236.

[17] T. Zettl, R. S. Mathew, S. Seifert, S. Doniach, P. A. B. Harbury, J. Lipfert, Nano Lett. 2016, 16, 5353-5357.

[18] M. Afri, C. Alexenberg, P. Aped, E. Bodner, S. Cohen, M. Ejgenburg, S. Eliyahu, P. Gilinsky-Sharon, Y. Harel, M. E. Naqqash, H. Porat, A. Ranz, A. A. Frimer, Chem. Phys. Lipids 2014, 184, 105-118.

[19] J. R. Burns, J. W. Wood, E. Stulz, Front. Chem. 2020, 8, 113.

[20] J. T. Littleton, J. Bai, B. Vyas, R. Desai, A. E. Baltus, M. B. Garment, S. D. Carlson, B. Ganetzky, E. R. Chapman, J. Neurosci. 2001, 21, 1421-1433.

[21] E. Orduna-Malea, E. Delgado López-Cózar, J. Altmetrics 2019, 2, 3.

[22] N. Fraser, B. Kramer, Covid19_preprints, Figshare, 2021.

[23] D. Niether, H. Kriegs, J. K. G. Dhont, S. Wiegand, J. Chem. Phys. 2018, 149, 044506.

[24] C. Hackenberger, Chem. Unserer Zeit 2006, 40, 174-183.

[25] A. Esteras-Chopo, M. T. Pastor, M. López de la Paz, in Protein Des., Humana Press, New Jersey, 2006, pp. 253-276.

[26] E. A. Porter, B. Weisblum, S. H. Gellman, J. Am. Chem. Soc. 2002, 124, 7324-7330.

[27] R. P. Cheng, S. H. Gellman, W. F. DeGrado, Chem. Rev. 2001, 101, 3219-3232.

[28] S. H. Gellman, Acc. Chem. Res. 1998, 31, 173-180.

[29] B. L. Iverson, Nature 1997, 385, 113-115.

[30] D. Seebach, J. L. Matthews, Chem. Commun. 1997, 2015-2022.

[31] W. F. DeGrado, J. P. Schneider, Y. Hamuro, J. Pept. Res. 2008, 54, 206-217.

[32] J. Frackenpohl, P. I. Arvidsson, J. V. Schreiber, D. Seebach, Chembiochem Eur. J. Chem. Biol. 2001, 2, 445-455.

[33] D. Seebach, P. E. Ciceri, M. Overhand, B. Jaun, D. Rigo, L. Oberer, U. Hommel, R. Amstutz, H. Widmer, Helv. Chim. Acta 1996, 79, 2043-2066.

[34] L. M. Johnson, S. H. Gellman, in Methods Enzymol., Elsevier, 2013, pp. 407-429.

[35] J. M. Berg, J. L. Tymoczko, L. Stryer, G. J. Gatto, Biochemie, Springer Spektrum, Berlin Heidelberg, 2013.

[36] F. von Nussbaum, P. Spiteller, in Highlights Bioorganic Chem. (Eds.: C. Schmuck, H. Wennemers), Wiley, 2004, pp. 63-89.

[37] E. Juaristi, V. A. Soloshonok, Enantioselective Synthesis of Beta-Amino Acids, 2005.

[38] T. Ye, M. A. McKervey, Chem. Rev. 1994, 94, 1091-1160. 
[39] F. Arndt, B. Eistert, Berichte Dtsch. Chem. Ges. B Ser. 1935, 68, 200-208.

[40] H. Meier, K.-P. Zeller, Angew. Chem. Int. Ed. Engl. 1975, 14, 32-43.

[41] R. Caputo, E. Cassano, L. Longobardo, G. Palumbo, Tetrahedron 1995, 51, 12337 12350.

[42] E. Juaristi, D. Quintana, M. Balderas, E. García-Pérez, Tetrahedron Asymmetry 1996, 7, 2233-2246.

[43] J. Podlech, D. Seebach, Angew. Chem. Int. Ed. Engl. 1995, 34, 471-472.

[44] S. Liu, S. H. Gellman, J. Org. Chem. 2020, 85, 1718-1724.

[45] D. Seebach, L. Schaeffer, F. Gessier, P. Bindschädler, C. Jäger, D. Josien, S. Kopp, G. Lelais, Y. R. Mahajan, P. Micuch, R. Sebesta, B. W. Schweizer, Helv. Chim. Acta 2003, 86, 1852-1861.

[46] A. Banerjee, P. Balaram, Curr. Sci. 1997, 73, 1067-1077.

[47] S. Krauthäuser, L. A. Christianson, D. R. Powell, S. H. Gellman, J. Am. Chem. Soc. 1997, 119, 11719-11720.

[48] D. Seebach, S. Abele, K. Gademann, B. Jaun, Angew. Chem. Int. Ed. 1999, 38, 15951597.

[49] B. W. Gung, Z. Zhu, J. Org. Chem. 1997, 62, 6100-6101.

[50] D. Seebach, K. Gademann, J. V. Schreiber, J. L. Matthews, T. Hintermann, B. Jaun,

L. Oberer, U. Hommel, H. Widmer, Helv. Chim. Acta 1997, 80, 2033-2038.

[51] Y.-D. Wu, D.-P. Wang, J. Am. Chem. Soc. 1998, 120, 13485-13493.

[52] D. Seebach, J. V. Schreiber, S. Abele, X. Daura, W. F. van Gunsteren, Helv. Chim. Acta 2000, 83, 34-57.

[53] L. A. Christianson, M. J. Lucero, D. H. Appella, D. A. Klein, S. H. Gellman, J. Comput. Chem. 2000, 21, 763-773.

[54] D. Seebach, S. Abele, K. Gademann, G. Guichard, T. Hintermann, B. Jaun, J. L. Matthews, J. V. Schreiber, L. Oberer, U. Hommel, H. Widmer, Helv. Chim. Acta 1998, 81, 932-982.

[55] D. H. Appella, L. A. Christianson, I. L. Karle, D. R. Powell, S. H. Gellman, J. Am. Chem. Soc. 1996, 118, 13071-13072.

[56] D. H. Appella, L. A. Christianson, I. L. Karle, D. R. Powell, S. H. Gellman, J. Am. Chem. Soc. 1999, 121, 6206-6212.

[57] J. Applequist, K. A. Bode, D. H. Appella, L. A. Christianson, S. H. Gellman, J. Am. Chem. Soc. 1998, 120, 4891-4892. 
[58] J. Bella, C. Aleman, J. M. Fernandez-Santin, C. Alegre, J. A. Subirana, Macromolecules 1992, 25, 5225-5230.

[59] J. M. Fernández-Santín, J. Aymamí, A. Rodríguez-Galán, S. Muñoz-Guerra, J. A. Subirana, Nature 1984, 311, 53-54.

[60] J. M. Fernandez-Santin, S. Munoz-Guerra, A. Rodriguez-Galan, J. Aymami, J. Lloveras, J. A. Subirana, E. Giralt, M. Ptak, Macromolecules 1987, 20, 62-68.

[61] D. H. Appella, J. J. Barchi, S. R. Durell, S. H. Gellman, J. Am. Chem. Soc. 1999, 121, 2309-2310.

[62] N. Rathore, S. H. Gellman, J. J. de Pablo, Biophys. J. 2006, 91, 3425-3435.

[63] D. Seebach, M. Overhand, F. N. M. Kühnle, B. Martinoni, L. Oberer, U. Hommel, H. Widmer, Helv. Chim. Acta 1996, 79, 913-941.

[64] D. Seebach, D. F. Hook, A. Glättli, Biopolymers 2006, 84, 23-37.

[65] T. E. Creighton, Proteins: Structures and Molecular Properties, W.H. Freeman, New York, 1993.

[66] K. A. Bode, J. Applequist, Macromolecules 1997, 30, 2144-2150.

[67] P. Armand, K. Kirshenbaum, R. A. Goldsmith, S. Farr-Jones, A. E. Barron, K. T. V. Truong, K. A. Dill, D. F. Mierke, F. E. Cohen, R. N. Zuckermann, E. K. Bradley, Proc. Natl. Acad. Sci. 1998, 95, 4309-4314.

[68] K. Kirshenbaum, A. E. Barron, R. A. Goldsmith, P. Armand, E. K. Bradley, K. T. V. Truong, K. A. Dill, F. E. Cohen, R. N. Zuckermann, Proc. Natl. Acad. Sci. 1998, 95 , 4303-4308.

[69] S. H. Gellman, Curr. Opin. Chem. Biol. 1998, 2, 717-725.

[70] M. A. Wouters, P. M. G. Curmi, Proteins Struct. Funct. Genet. 1995, 22, 119-131.

[71] C. K. Smith, L. Regan, Acc. Chem. Res. 1997, 30, 153-161.

[72] P. I. Arvidsson, M. Rueping, D. Seebach, Chem. Commun. 2001, 649-650.

[73] R. P. Cheng, W. F. DeGrado, J. Am. Chem. Soc. 2001, 123, 5162-5163.

[74] D. M. Pahlke, Synthesis, Characterisation and Sensor-Functionalisation of Transmembrane $\beta$-Peptides, University of Göttingen, 2018.

[75] S. Tan, H. T. Tan, M. C. M. Chung, Proteomics 2008, 8, 3924-3932.

[76] P. J. Robinson, in ADP-Ribosylation Anim. Tissues (Eds.: F. Haag, F. Koch-Nolte), Springer US, Boston, MA, 1997, pp. 365-370.

[77] J. T. Groves, J. Kuriyan, Nat. Struct. Mol. Biol. 2010, 17, 659-665.

[78] H. Kimizuka, K. Koketsu, J. Theor. Biol. 1964, 6, 290-305. 
[79] B. M. Gorzelle, A. K. Hoffman, M. H. Keyes, D. N. Gray, D. G. Ray, C. R. Sanders, J. Am. Chem. Soc. 2002, 124, 11594-11595.

[80] J. A. Killian, FEBS Lett. 2003, 555, 134-138.

[81] M. R. R. de Planque, B. B. Bonev, J. A. A. Demmers, D. V. Greathouse, R. E. Koeppe, F. Separovic, A. Watts, J. A. Killian, Biochemistry 2003, 42, 5341-5348.

[82] J. A. Killian, I. Salemink, M. R. R. de Planque, G. Lindblom, R. E. Koeppe, D. V. Greathouse, Biochemistry 1996, 35, 1037-1045.

[83] M. R. R. de Planque, J. A. Killian*, Mol. Membr. Biol. 2003, 20, 271-284.

[84] S. K. Kandasamy, R. G. Larson, Biophys. J. 2006, 90, 2326-2343.

[85] D. P. Siegel, V. Cherezov, D. V. Greathouse, R. E. Koeppe, J. A. Killian, M. Caffrey, Biophys. J. 2006, 90, 200-211.

[86] T. M. Weiss, P. C. A. van der Wel, J. A. Killian, R. E. Koeppe, H. W. Huang, Biophys. J. 2003, 84, 379-385.

[87] T. Kim, W. Im, Biophys. J. 2010, 99, 175-183.

[88] B. D. Rao, S. Shrivastava, A. Chattopadhyay, in Membr. Organ. Dyn. (Ed.: A. Chattopadhyay), Springer International Publishing, Cham, 2017, pp. 375-387.

[89] D. Petersen, Konformation Und Orientierung von Synthetisierten $\beta$-Peptiden in Membransystemen, University of Göttingen, 2015.

[90] J. Wegner, Synthesis of Rigid Spin Labels for the Investigation of Transmembrane Peptides by EPR Spectroscopy, University of Göttingen, 2018.

[91] J. T. Vivian, P. R. Callis, Biophys. J. 2001, 80, 2093-2109.

[92] S. Lew, J. Ren, E. London, Biochemistry 2000, 39, 9632-9640.

[93] J. Ren, S. Lew, J. Wang, E. London, Biochemistry 1999, 38, 5905-5912.

[94] J. Ren, S. Lew, Z. Wang, E. London, Biochemistry 1997, 36, 10213-10220.

[95] R. M. Murphy, A. M. Tsai, in Misbehaving Proteins, Springer New York, New York, NY, 2006, pp. 3-13.

[96] G. Invernizzi, E. Papaleo, R. Sabate, S. Ventura, Int. J. Biochem. Cell Biol. 2012, 44, $1541-1554$.

[97] J. M. Yon, J.-M. Betton, Biol. Cell 1991, 71, 17-23.

[98] M. Gadzała, D. Dułak, B. Kalinowska, Z. Baster, M. Bryliński, L. Konieczny, M. Banach, I. Roterman, J. Mol. Graph. Model. 2019, 87, 227-239.

[99] P. Timmerman, L. J. Prins, Eur. J. Org. Chem. 2001, 2001, 3191-3205.

[100] N. Grinberg, P. W. Carr, Advances in Chromatography, 2018. 
[101] T. L. Cottrell, The Strengths of Chemical Bonds, Butterworths Scientific Publications, 1958.

[102] J. D. Watson, F. H. C. Crick, Nature 1953, 171, 737-738.

[103] N. V. Di Russo, D. A. Estrin, M. A. Martí, A. E. Roitberg, PLoS Comput. Biol. 2012, $8, \mathrm{e} 1002761$.

[104] T. Gelbrich, D. Rossi, C. A. Häfele, U. J. Griesser, CrystEngComm 2011, 13, 5502.

[105] Y. Molard, D. M. Bassani, J. Desvergne, P. N. Horton, M. B. Hursthouse, J. H. R. Tucker, Angew. Chem. Int. Ed. 2005, 44, 1072-1075.

[106] G. M. Whitesides, E. E. Simanek, J. P. Mathias, C. T. Seto, D. Chin, M. Mammen, D. M. Gordon, Acc. Chem. Res. 1995, 28, 37-44.

[107] J. P. Mathias, E. E. Simanek, J. A. Zerkowski, C. T. Seto, G. M. Whitesides, J. Am. Chem. Soc. 1994, 116, 4316-4325.

[108] A. Mühleip, R. Kock Flygaard, J. Ovciarikova, A. Lacombe, P. Fernandes, L. Sheiner, A. Amunts, Nat. Commun. 2021, 12, 120.

[109] M. Wolff, B. Zhang-Haagen, C. Decker, B. Barz, M. Schneider, R. Biehl, A. Radulescu, B. Strodel, D. Willbold, L. Nagel-Steger, Sci. Rep. 2017, 7, 2493.

[110] C. T. Seto, G. M. Whitesides, J. Am. Chem. Soc. 1990, 112, 6409-6411.

[111] J. A. Zerkowski, C. T. Seto, G. M. Whitesides, J. Am. Chem. Soc. 1992, 114, 54735475 .

[112] J. P. Mathias, E. E. Simanek, G. M. Whitesides, J. Am. Chem. Soc. 1994, 116, 43264340.

[113] J. A. Zerkowski, C. T. Seto, D. A. Wierda, G. M. Whitesides, J. Am. Chem. Soc. 1990, 112, 9025-9026.

[114] P. Motloch, C. A. Hunter, Chem. - Eur. J. 2021, 27, 3302-3305.

[115] A. Glättli, D. Seebach, W. F. van Gunsteren, Helv. Chim. Acta 2004, 87, 2487-2506.

[116] J. A. Kritzer, J. Tirado-Rives, S. A. Hart, J. D. Lear, W. L. Jorgensen, A. Schepartz, J. Am. Chem. Soc. 2005, 127, 167-178.

[117] A. J. de Jesus, T. W. Allen, Biochim. Biophys. Acta BBA - Biomembr. 2013, 1828, 864-876.

[118] J. A. Killian, G. von Heijne, Trends Biochem. Sci. 2000, 25, 429-434.

[119] D. Milardi, M. F. M. Sciacca, M. Pappalardo, D. M. Grasso, C. La Rosa, Eur. Biophys. J. 2011, 40, 1-12.

[120] R. B. Merrifield, J. Am. Chem. Soc. 1963, 85, 2149-2154.

[121] B. Marglin, R. B. Merrifield, J. Am. Chem. Soc. 1966, 88, 5051-5052. 
[122] J. D. Young, A. S. Huang, N. Ariel, J. B. Bruins, D. Ng, R. L. Stevens, Pept. Res. 1990, 3, 194-200.

[123] J. Farrera-Sinfreu, M. Royo, F. Albericio, Tetrahedron Lett. 2002, 43, 7813-7815.

[124] A. Isidro-Llobet, J. Guasch-Camell, M. Álvarez, F. Albericio, Eur. J. Org. Chem. 2005, 2005, 3031-3039.

[125] S. Mahesh, K.-C. Tang, M. Raj, Molecules 2018, 23, 2615.

[126] X. Daura, D. Bakowies, D. Seebach, J. Fleischhauer, W. F. van Gunsteren, P. Krüger, Eur. Biophys. J. 2003, 32, 661-670.

[127] B. A. Wallace, Protein Sci. 2003, 12, 875-884.

[128] N. J. Greenfield, Nat. Protoc. 2006, 1, 2876-2890.

[129] S. M. Saparov, K. Erlandson, K. Cannon, J. Schaletzky, S. Schulman, T. A. Rapoport, P. Pohl, Mol. Cell 2007, 26, 501-509.

[130] B. Ponsioen, L. van Zeijl, W. H. Moolenaar, K. Jalink, Exp. Cell Res. 2007, 313, 415-423.

[131] N. A. Schilling, A. Berscheid, J. Schumacher, J. S. Saur, M. C. Konnerth, S. N. Wirtz, J. M. Beltrán-Beleña, A. Zipperer, B. Krismer, A. Peschel, H. Kalbacher, H. BrötzOesterhelt, C. Steinem, S. Grond, Angew. Chem. Int. Ed. 2019, 58, 9234-9238.

[132] K. Kano, J. H. Fendler, Biochim. Biophys. Acta BBA - Biomembr. 1978, 509, 289299.

[133] Z.-Y. Liu, R. Solow, V. W. Hu, Biochim. Biophys. Acta BBA - Biomembr. 1988, 945, 253-262.

[134] B. de Campos Vidal, M. L. S. Mello, Micron 2011, 42, 283-289.

[135] J. A. Kozuch, Structure-Function Relationships of Membrane Proteins - Spectroelectrochemical Investigation of Artificial Membranes, Technische Universität Berlin, 2012.

[136] A. M. Brückner, P. Chakraborty, S. H. Gellman, U. Diederichsen, Angew. Chem. Int. Ed. 2003, 42, 4395-4399.

[137] P. Chakraborty, U. Diederichsen, Chem. - Eur. J. 2005, 11, 3207-3216.

[138] P. K. Wolber, B. S. Hudson, Biophys. J. 1979, 28, 197-210.

[139] X. Zhang, W. Fu, C. G. Palivan, W. Meier, Sci. Rep. 2013, 3, 2196.

[140] R. E. W. Hancock, K. Poole, M. Gimple, R. Benz, Biochim. Biophys. Acta BBA Biomembr. 1983, 735, 137-144.

[141] D. Boytsov, C. Hannesschlaeger, A. Horner, C. Siligan, P. Pohl, Biotechnol. J. 2020, 15, 1900450. 
[142] M. Rossi, F. Thei, M. Tartagni, Sens. Transducers J. 1726-5479 2012, 14.

[143] M. Montal, P. Mueller, Proc. Natl. Acad. Sci. U. S. A. 1972, 69, 3561-3566.

[144] P. Johns, in Clin. Neurosci., Elsevier, 2014, pp. 71-80.

[145] Q. Kuang, P. Purhonen, H. Hebert, Cell. Mol. Life Sci. 2015, 72, 3677-3693.

[146] M. Kloos, A. Sharma, J. Enderlein, U. Diederichsen, J. Pept. Sci. 2021, DOI $10.1002 /$ psc. 3355 .

[147] L. Stryer, R. P. Haugland, Proc. Natl. Acad. Sci. 1967, 58, 719-726.

[148] T. Ha, T. Enderle, D. F. Ogletree, D. S. Chemla, P. R. Selvin, S. Weiss, Proc. Natl. Acad. Sci. 1996, 93, 6264-6268.

[149] S. Hohng, S. Lee, J. Lee, M. H. Jo, Chem Soc Rev 2014, 43, 1007-1013.

[150] I. Rasnik, S. A. McKinney, T. Ha, Nat. Methods 2006, 3, 891-893.

[151] C. Bustamante, Z. Bryant, S. B. Smith, Nature 2003, 421, 423-427.

[152] Y. N. Teo, E. T. Kool, Chem. Rev. 2012, 112, 4221-4245.

[153] J. Hohlbein, T. D. Craggs, T. Cordes, Chem Soc Rev 2014, 43, 1156-1171.

[154] R. Y. Tsien, Annu. Rev. Biochem. 1998, 67, 509-544.

[155] B. Pollok, Trends Cell Biol. 1999, 9, 57-60.

[156] A. Miyawaki, J. Llopis, R. Heim, J. M. McCaffery, J. A. Adams, M. Ikura, R. Y. Tsien, Nature 1997, 388, 882-887.

[157] A. Crivici, M. Ikura, Annu. Rev. Biophys. Biomol. Struct. 1995, 24, 85-116.

[158] M. Ikura, G. Clore, A. Gronenborn, G. Zhu, C. Klee, A. Bax, Science 1992, 256, 632-638.

[159] Y. S. Babu, C. E. Bugg, W. J. Cook, J. Mol. Biol. 1988, 204, 191-204.

[160] X. Zhuang, Science 2000, 288, 2048-2051.

[161] E. T. Mollova, Curr. Opin. Chem. Biol. 2002, 6, 823-828.

[162] P. C. Ray, Z. Fan, R. A. Crouch, S. S. Sinha, A. Pramanik, Chem Soc Rev 2014, 43, 6370-6404.

[163] C. Sönnichsen, B. M. Reinhard, J. Liphardt, A. P. Alivisatos, Nat. Biotechnol. 2005, $23,741-745$.

[164] J. Wegner, G. Valora, K. Halbmair, A. Kehl, B. Worbs, M. Bennati, U. Diederichsen, Chem. - Eur. J. 2019, 25, 2203-2207.

[165] I. Gregor, A. Chizhik, N. Karedla, J. Enderlein, Nanophotonics 2019, 8, 1689-1699.

[166] A. Ghosh, A. Sharma, A. I. Chizhik, S. Isbaner, D. Ruhlandt, R. Tsukanov, I. Gregor, N. Karedla, J. Enderlein, Nat. Photonics 2019, 13, 860-865.

[167] Th. Förster, Ann. Phys. 1948, 437, 55-75. 
[168] D. M. Lilley, T. J. Wilson, Curr. Opin. Chem. Biol. 2000, 4, 507-517.

[169] R. M. Clegg, Curr. Opin. Biotechnol. 1995, 6, 103-110.

[170] I. Medintz, N. Hildebrandt, Eds. , FRET - Förster Resonance Energy Transfer: From Theory to Applications, Wiley-VCH, Weinheim, 2013.

[171] L. Stryer, Annu. Rev. Biochem. 1978, 47, 819-846.

[172] J. W. Lichtman, J.-A. Conchello, Nat. Methods 2005, 2, 910-919.

[173] G. S. Kaminski Schierle, C. W. Bertoncini, F. T. S. Chan, A. T. van der Goot, S. Schwedler, J. Skepper, S. Schlachter, T. van Ham, A. Esposito, J. R. Kumita, E. A. A. Nollen, C. M. Dobson, C. F. Kaminski, ChemPhysChem 2011, 12, 673-680.

[174] A. Kitamura, K. Nagata, M. Kinjo, Int. J. Mol. Sci. 2015, 16, 6076-6092.

[175] H. Murakoshi, A. C. E. Shibata, Y. Nakahata, J. Nabekura, Sci. Rep. 2015, 5, 15334.

[176] A. Nagarajan, R. Bodhicharla, J. Winter, C. Anbalagan, K. Morgan, M. Searle, A. Nazir, A. Adenle, A. Fineberg, D. Brady, K. Vere, J. Richens, P. O’Shea, D. Bell, D. de-Pomerai, CNS Neurol. Disord. - Drug Targets 2015, 14, 1054-1068.

[177] T. J. van Ham, A. Esposito, J. R. Kumita, S.-T. D. Hsu, G. S. Kaminski Schierle, C. F. Kaminski, C. M. Dobson, E. A. A. Nollen, C. W. Bertoncini, J. Mol. Biol. 2010, $395,627-642$.

[178] E. Abbe, Arch. Für Mikrosk. Anat. 1873, 9, 413-468.

[179] G. Shtengel, J. A. Galbraith, C. G. Galbraith, J. Lippincott-Schwartz, J. M. Gillette, S. Manley, R. Sougrat, C. M. Waterman, P. Kanchanawong, M. W. Davidson, R. D. Fetter, H. F. Hess, Proc. Natl. Acad. Sci. 2009, 106, 3125.

[180] D. Aquino, A. Schönle, C. Geisler, C. v Middendorff, C. A. Wurm, Y. Okamura, T. Lang, S. W. Hell, A. Egner, Nat. Methods 2011, 8, 353-359.

[181] A. M. Szalai, B. Siarry, J. Lukin, D. J. Williamson, N. Unsain, D. Refojo, A. Cáceres, M. Pilo-Pais, G. Acuna, D. M. Owen, S. Simoncelli, F. D. Stefani, bioRxiv 2020, 693994.

[182] B. Hochreiter, A. Pardo-Garcia, J. Schmid, Sensors 2015, 15, 26281-26314.

[183] G. Yang, L. Li, W. B. Lee, M. C. Ng, Sci. Technol. Adv. Mater. 2018, 19, 613-648.

[184] I. A. Popov, K. V. Bozhenko, A. I. Boldyrev, Nano Res. 2012, 5, 117-123.

[185] J. W. Weber, V. E. Calado, M. C. M. van de Sanden, Appl. Phys. Lett. 2010, 97, 091904.

[186] P. R. Wallace, Phys. Rev. 1947, 71, 622-634.

[187] K. S. Novoselov, Science 2004, 306, 666-669. 
[188] A. I. Chizhik, J. Rother, I. Gregor, A. Janshoff, J. Enderlein, Nat. Photonics 2014, 8, $124-127$.

[189] N. Karedla, A. I. Chizhik, I. Gregor, A. M. Chizhik, O. Schulz, J. Enderlein, ChemPhysChem 2014, 15, 705-711.

[190] B. Joseph, A. Sikora, E. Bordignon, G. Jeschke, D. S. Cafiso, T. F. Prisner, Angew. Chem. Int. Ed. 2015, 54, 6196-6199.

[191] K. T. Lewis, A. R. Naik, S. S. Laha, S. Wang, G. Mao, E. Kuhn, B. P. Jena, Semin. Cell Dev. Biol. 2018, 73, 57-63.

[192] L. G. L. Richardson, Plant Physiol. 2019, 180, 703-705.

[193] J. H. Schwartz, G. Li, Q. Yang, V. Suri, J. J. Ross, E. A. Alexander, Kidney Int. 2007, $72,1310-1315$.

[194] M. Anderson, A. Moshnikova, D. M. Engelman, Y. K. Reshetnyak, O. A. Andreev, Proc. Natl. Acad. Sci. 2016, 113, 8177-8181.

[195] S. Pöyry, I. Vattulainen, Biochim. Biophys. Acta BBA - Biomembr. 2016, 1858, 23222333.

[196] R. C. MacDonald, A. D. Bangham, J. Membr. Biol. 1972, 7, $29-53$.

[197] C. T. Everitt, D. A. Haydon, J. Theor. Biol. 1968, 18, 371-379.

[198] M. Eisenberg, T. Gresalfi, T. Riccio, S. McLaughlin, Biochemistry 1979, 18, 52135223.

[199] N. Agmon, H. J. Bakker, R. K. Campen, R. H. Henchman, P. Pohl, S. Roke, M. Thämer, A. Hassanali, Chem. Rev. 2016, 116, 7642-7672.

[200] A. Gandhi, D. Lakshminarasimhan, Y. Sun, H.-C. Guo, Sci. Rep. 2011, 1, 186.

[201] J. D. Bruton, A. Katz, H. Westerblad, Proc. Natl. Acad. Sci. 1999, 96, 3281-3286.

[202] C. K. Go, R. Hooper, M. R. Aronson, B. Schultz, T. Cangoz, N. Nemani, Y. Zhang, M. Madesh, J. Soboloff, Sci. Signal. 2019, 12, eaaw2627.

[203] T. Arnesen, PLoS Biol. 2011, 9, e1001074.

[204] A. C. Obermeyer, J. B. Jarman, M. B. Francis, J. Am. Chem. Soc. 2014, 136, 95729579.

[205] I. Sélo, L. Négroni, C. Créminon, J. Grassi, J. M. Wal, J. Immunol. Methods 1996, 199, 127-138.

[206] R. A. Farley, C. M. Tran, C. T. Carilli, D. Hawke, J. E. Shively, J. Biol. Chem. 1984, 259, 9532-9535.

[207] M. Schweikle, S. H. Bjørnøy, A. T. J. van Helvoort, H. J. Haugen, P. Sikorski, H. Tiainen, Acta Biomater. 2019, 90, 132-145. 
[208] F. Schueder, J. Stein, F. Stehr, A. Auer, B. Sperl, M. T. Strauss, P. Schwille, R. Jungmann, Nat. Methods 2019, 16, 1101-1104.

[209] S. Derakhshani, A. Kurz, L. Japtok, F. Schumacher, L. Pilgram, M. Steinke, B. Kleuser, M. Sauer, S. Schneider-Schaulies, E. Avota, Front. Immunol. 2019, 10, 1294.

[210] Atto-Tec GmbH, 2021, https://www.atto-tec.com/images/ATTO/Procedures/NHS.pdf.

[211] D. F. Waugh, in Adv. Protein Chem., Elsevier, 1954, pp. 325-437.

[212] S. Jones, J. M. Thornton, Proc. Natl. Acad. Sci. 1996, 93, 13-20.

[213] I. M. A. Nooren, EMBO J. 2003, 22, 3486-3492.

[214] J. F. Danielli, J. Exp. Biol. 1944, 20, 167-176.

[215] B. Bilgicer, K. Kumar, Proc. Natl. Acad. Sci. 2004, 101, 15324-15329.

[216] A. Pingoud, C. Urbanke, Arbeitsmethoden der Biochemie: enthält 50 Tabellen, De Gruyter, Berlin, 1997.

[217] T. Sammakia, in Encycl. Reag. Org. Synth. (Ed.: John Wiley \& Sons, Ltd), John Wiley \& Sons, Ltd, Chichester, UK, 2001, p. rd017.

[218] F. Arndt, Org. Synth. 1935, 15, 3.

[219] G. Guichard, S. Abele, D. Seebach, Helv. Chim. Acta 1998, 81, 187-206.

[220] P. I. Arvidsson, J. Frackenpohl, D. Seebach, Helv. Chim. Acta 2003, 86, 1522-1553.

[221] B. S. Patil, G.-R. Vasanthakumar, V. V. Suresh Babu, Lett. Pept. Sci. 2002, 9, 231233.

[222] M. Gude, J. Ryf, P. D. White, Lett. Pept. Sci. 2002, 9, 203-206.

[223] Novabiochem ${ }^{\circledR}$, Peptide Synthesis, Merck, 2015.

[224] R. C. MacDonald, R. I. MacDonald, B. Ph. M. Menco, K. Takeshita, N. K. Subbarao, L. Hu, Biochim. Biophys. Acta BBA - Biomembr. 1991, 1061, 297-303.

[225] M. J. Hope, M. B. Bally, G. Webb, P. R. Cullis, Biochim. Biophys. Acta BBA Biomembr. 1985, 812, 55-65.

[226] M. C. Groth, Investigation of the Linker Region of Coiled Coiled SNARE-Analoga and Membrane Composition on Vesicle Fusion, University of Göttingen, 2020.

[227] H. Sajiki, Tetrahedron Lett. 1995, 36, 3465-3468.

[228] Y. Zeng, Y. Pratumyot, X. Piao, D. Bong, J. Am. Chem. Soc. 2012, 134, 832-835.

[229] R. Wodtke, G. Ruiz-Gómez, M. Kuchar, M. T. Pisabarro, P. Novotná, M. Urbanová, J. Steinbach, J. Pietzsch, R. Löser, Org. Biomol. Chem. 2015, 13, 1878-1896. 
[230] R. Srivastava, Design, Synthesis, and Molecular Self-Assembly of $\beta$-Peptides, University of Göttingen, 2009.

[231] Z. Moussa, Z. M. A. Judeh, S. A. Ahmed, RSC Adv. 2019, 9, 35217-35272.

[232] R. Wakabayashi, H. Obayashi, R. Hashimoto, N. Kamiya, M. Goto, Chem. Commun. 2019, 55, 6997-7000. 


\section{Acknowledgements}

Zunächst möchte ich PROF. Dr. Ulf DiEDERICHSEN für die Möglichkeit danken, meine Dissertation in seiner Arbeitsgruppe anfertigen zu dürfen. Vielen Dank für die interessante Themenstellung, die wissenschaftliche Freiheit und die Unterstützung in den letzten Jahren. Auch möchte ich mich für die entgegengebrachte Freundlichkeit, den Respekt und vor allem die Menschlichkeit bedanken, mit der Sie mir zu jedem Zeitpunkt begegnet sind.

Weiterer Dank gilt Prof. Dr. ClaUdia STEINEM für das spontane und selbstlose Einspringen als Erstprüferin, die produktiven Diskussionen und stetige Hilfsbereitschaft, sowohl fachlich als auch organisatorisch. Zudem möchte ich Prof. DR. KAI TITTMANN danken, der im gleichen Zuge mit Selbstverständlichkeit das Korreferat übernommen hat.

Prof. DR. JÖRg ENDERLEIN, DR. Michael JOHN und DR. HOLM FraUENDORF danke ich für die Teilnahme an meiner Prüfungskommission.

Meinen Kooperationspartnern DominiK RupPelt, AnNA MAZnichenKo, AKSHITA Sharma sowie Prof. Dr. Claudia Steinem, Prof. Dr. Peter Pohl und Prof. Dr. Jörg Enderlein möchte ich für die gute Zusammenarbeit und das Engagement danken.

DR. Holm FraUENDORF, DR. MichaEl JOHN und allen Mitarbeitern der Massen- und NMRAbteilung danke ich zusätzlich für die Bearbeitung zahlreicher Proben und Aufnahme der Massen- bzw. NMR-Spektren.

ANGELA HEINEMANN danke ich für die organisatorische und stets hilfsbereite Unterstützung. DANIEL FRANK danke ich für technische Unterstützung und für die Synthese der zahlreichen Liter an Diazomethan, die ich während der letzten Jahre verbraucht habe. BRIGITTE WORBS danke ich sehr für die Synthesen meiner CA·M Bausteine. 
Auch ein Dank an alle Mitarbeiter*innen des Instituts, darunter RALF GERKE, SASCHA Herwig, Wolfram Mathis und RenAte für ihre Hilfsbereitschaft und gewissenhafte Arbeit.

DR. INGO MEY gilt besonderer Dank für die fachliche Hilfe, die zahlreichen Tipps und das Einschieben kurzfristiger Meetings, auch wenn er selbst kaum Zeit hat. Danke zudem für die außergewöhnlich gute Organisation der Lehre.

Für das Korrekturlesen von Teilen dieser Arbeit möchte ich mich bei NILS GEHRMANN, DR. Mike Groth, Nils Hesselbarth, Anna Maznichenko, Fehmke Reichardt und Dominik RUPPElt bedanken. Besonderer Dank gilt TOBIAS SCHMIDT, PIRAJEEV SELVACHANDRAN und DR. ULRIKE STOLLBERG.

Zudem danke ich allen Mitgliedern, aktiv und ehemalig, für die gute Zusammenarbeit in der Arbeitsgruppe, die entspannte Arbeitsatmosphäre und die stetige Hilfsbereitschaft. Vor allem danke ich dabei allen Mitarbeiter*innen aus Labor 108.

Außerdem danke ich VAnessa Reusche, Tobias Schmidt, PirajeEv Selvachandran, DR. UlRIKE STOLlBERG und MARKUS WIEGAND für den entspannten und ehrlichen Umgang miteinander und die entstandenen Freundschaften.

DR. UlRIKE STOLLBERG danke ich zusätzlich für die selbstlose Hilfe und das Beantworten zahlreicher Fragen, selbst Jahre nach der eigenen Promotion. Vielen Dank für die investierte Zeit, Mühe und Motivation sowie natürlich die schönen Wakeboard-Ausflüge.

Für die letzten neun Jahre möchte ich mich zusätzlich bei allen bedanken, die mich auch privat während der Zeit in Göttingen begleitet haben. Vor allem Danke an ANDREJ DERKSEN, Lise Don, MARIUs Torben RudolPH und UGUR YüZGÜLen. Für morgendliche, schweißtreibende Gymsessions geht Dank an Dr. Peter Stollberg und MARKUS WiEGAND. Besonderer Dank, gerade im letzten Promotionsjahr, gilt NiLs GeHRMAnN, Olga Kuhn, FEHMKE REICHARDT und NiKOLAS WOLTER.

Letztendlich danke ich meiner Familie für die Unterstützung während des Studiums. 